\section{Use of MRI and audiological tests in presymptomatic diagnosis of type 2 neurofibromatosis (NF2)}

EDITOR-We have previously reported on a large clinical study of patients with neurofibromatosis $2(\mathrm{NF} 2)^{1}$ and described the usefulness of audiological screening in early detection of VS in NF2. ${ }^{2}$ Although DNA diagnosis is possible by linkage analysis and by detecting the NF2 family specific mutation, this is not possible in all cases. Only $40 \%$ of sporadic patients (new mutations) have an identifiable NF2 mutation $^{3}$ and as $50 \%$ of NF2 patients have no family history, ${ }^{4}$ up to $30 \%$ of those at risk of NF2 will not be able to have a DNA presymptomatic test. While it is possible to calculate residual risks of NF2 from age at onset of symptoms curves, ${ }^{5}$ a more useful measure would be the level of risk reduction from a normal cranial MRI scan. A database recording information on affected subjects with NF2 was set up in Manchester in 1989. Patients were actively sought across the UK from paediatricians, neurosurgeons, ENT surgeons, geneticists, and dermatologists. We have used this database to determine the age at which MRI detects asymptomatic tumours in subjects with NF2 and the value of audiological screening. We have also created life curves for risk reduction in subjects at $50 \%$ risk of NF2.

Patient details from hospital notes and proformas have been entered into a database at St Mary's Hospital Manchester since 1989. A total of 344 patients fulfilling our published criteria for NF2 are recorded (table 1). ${ }^{135}$ Information on all known tumours, age at presentation and diagnosis, and many different symptoms are included. We have analysed details of patients who have been detected as having VS on a screening MRI scan without any known central nervous system pathology, signs, or symptoms. It has been our practice to carry out a baseline MRI scan between 12 and 16 years of age, although some centres have screened earlier. A review was also made of subjects diagnosed on the basis of presymptomatic DNA tests. A separate analysis was undertaken on those cases who had sequential audiological screening with pure tone audiogram and ABR before MRI scanning. Standard MRI screening usually involved $\mathrm{T} 1$ and $\mathrm{T} 2$ weighted images before, and $\mathrm{T} 1$ weighted images after gadolinium enhancement with $3 \mathrm{~mm}$ cuts through the internal auditory meati.

A cumulative age at onset curve was derived from the age at presymptomatic diagnosis on MRI scan (fig 1) and for residual risk of NF2 (fig 2). An adjustment was made for large tumours detected on initial prevalence scan. This

Table 1 Diagnostic criteria for NF2

Bilateral vestibular schwannomas OR family history of NF2 PLUS

(1) Unilateral VS OR

(2) Any two of: meningioma, glioma, neurofibroma, schwannoma, posterior subcapsular lenticular opacities

Additional criteria

Unilateral VS + any two of: meningioma, glioma, neurofibroma, schwannoma, and posterior subcapsular opacities

OR

Multiple meningioma ( 2 or more) + unilateral VS or any 2 of: glioma, neurofibroma, schwannoma, and cataract allowed for an annual growth rate of $2 \mathrm{~mm}$ (derived from our unpublished data and those of $\mathrm{M}$ Baser/V Mautner) with a minimum detection size of $2-3 \mathrm{~mm}$. Thus, a $20 \mathrm{~mm}$ tumour could have been detected up to an average of eight or nine years earlier. Age of onset curves were also derived from offspring in NF2 families to determine the proportion who had developed symptoms by each five year age group. Residual risks of NF2 were based on Bayesian calculations, ${ }^{3}$ so when $67 \%$ of subjects would be expected to be symptomatic or detected on MRI the residual risk of NF2 would be $25 \%$.

MRI screening is useful for reducing the residual risk of someone at initial $50 \%$ risk of inheriting NF2. ABR screening still has a place in early detection of vestibular schwannoma, although MRI screening is the method of choice.

Forty three first degree relatives of NF2 patients have been diagnosed with NF2 presymptomatically. Twenty one patients were diagnosed initially with a presymptomatic DNA test using linkage or mutation analysis. Fourteen of these have subsequently been found to have VS on MRI scan. The remaining seven children have not had an initial MRI scan. Twenty one further patients were diagnosed on the basis of an MRI scan before having symptoms. These scans were carried out on initial assessment when the patient was first known to be at risk. Thus, some scans were only performed when the patients were in their twenties to forties and the tumour size at initial diagnosis therefore varied from 1-20 $\mathrm{mm}$ in diameter. Mean age at initial positive scan was 20.5 years (range 8-45 years, median 18

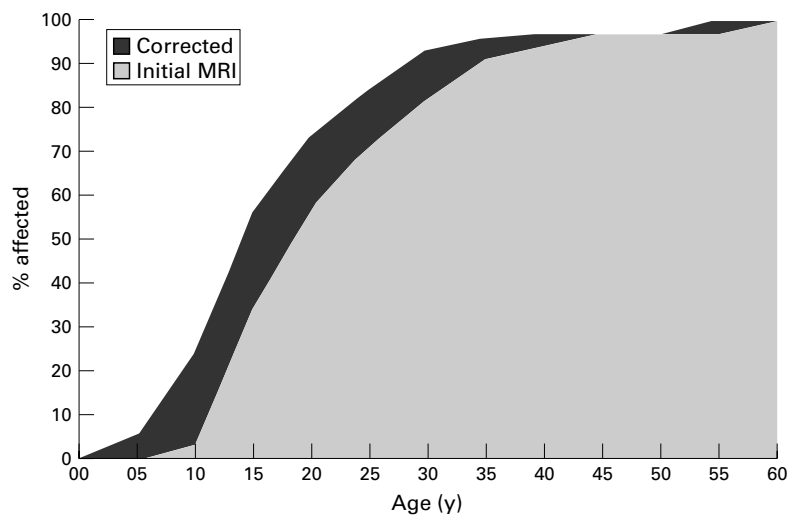

Figure 1 Cumulative chance of detecting NF2 using MRI based on prospective screening in 35 at risk subjects.

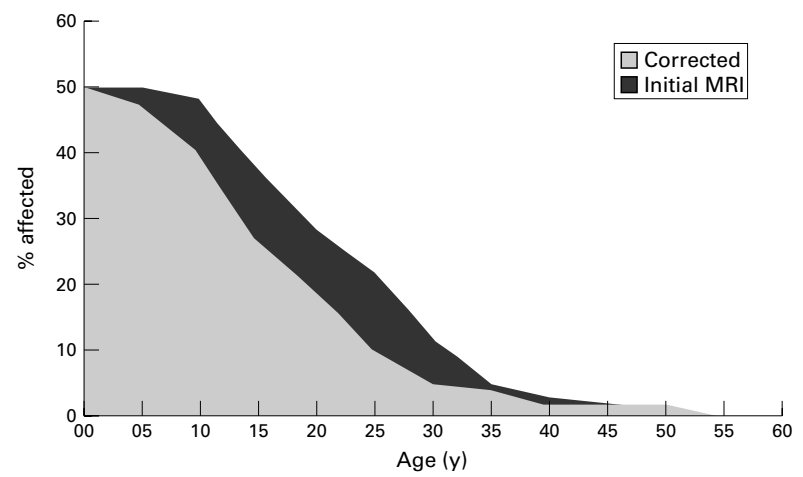

Figure 2 Residual risk of NF2 if MRI negative based on screening 35 at risk subjects. 


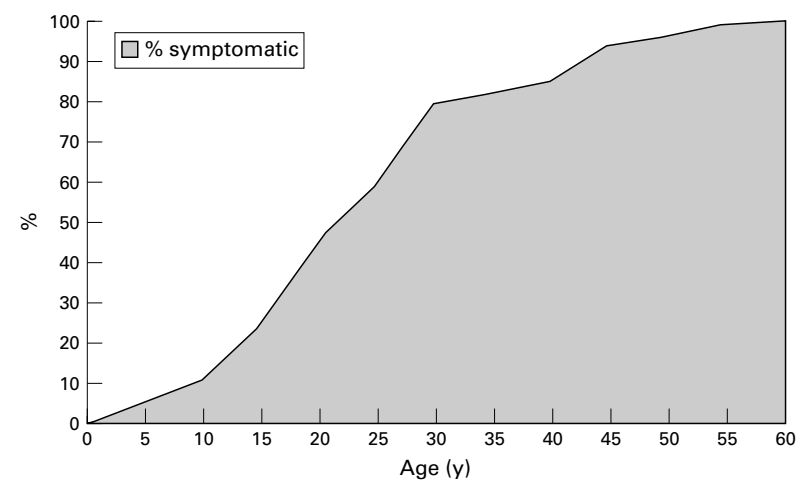

Figure 3 Age at onset of symptoms in 110 offspring of NF2 patients.

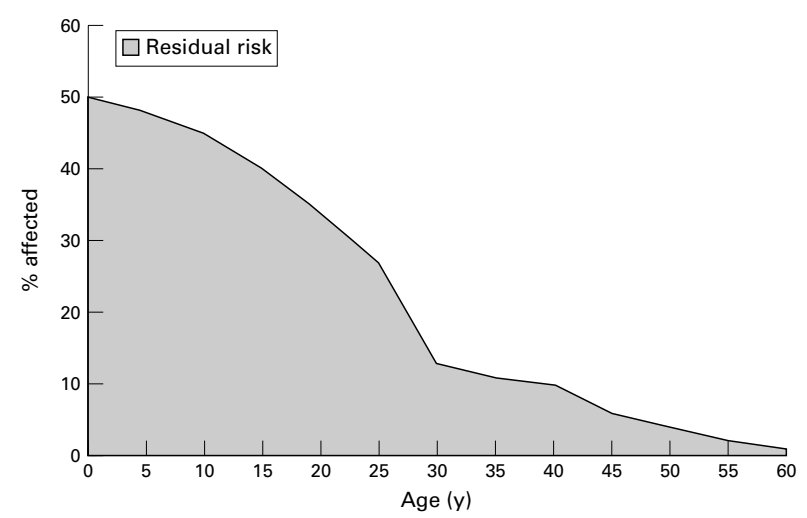

Figure 4 Residual risk of NF2 based on age at onset of symptoms in 110 offspring of NF2 patients.

years). All but two patients were the offspring of a known NF2 patient. One father of a severely affected NF2 patient who claimed not to have symptoms had bilateral 15 and 10 mm VS on initial MRI scan aged 45 years. A further 53 year old male with an affected brother has had a normal MRI scan, but his son aged 19 years had a unilateral VS on scan aged 19 years. The family have a deletion in the NF2 gene removing one exonic cosmid (J Dumanski, personal communication). Only three patients had an initial normal MRI scan. The 45 year old father noted above was excluded from analysis as he may represent a mosaic and was not at a priori $50 \%$ risk. Of the 34 patients detected presymptomatically, DNA presymptomatic testing would be possible in 24 owing to the presence of a known mutation or a pedigree structure suitable for linkage analysis at time of diagnosis. However, in 10 cases $(30 \%)$ no testing would have been possible if the patient presented at the time of writing. Age of onset of symptoms in 110 offspring of NF2 patients is presented in fig 3, while the residual risk for NF2 in someone asymptomatic at $50 \%$ initial risk is presented in fig 4.

Fourteen patients had records of both pure tone audiograms and ABR testing within three months of the initial positive MRI scan (11 from Manchester). Twelve pure tone audiograms were within normal limits with no threshold above $20 \mathrm{~dB}$. Two audiograms showed a unilateral high frequency hearing loss. Five patients with bilateral intracanalicular VS (1-8 $\mathrm{mm}$ diameter) and a further patient with a $1 \mathrm{~mm}$ unilateral VS showed no abnormality on audiogram or ABR testing. ABR tests carried out one year later on four bilateral cases showed delayed latencies on both sides in 3/4 while intracanalicular diameter remained $<9 \mathrm{~mm}$. In three further patients with bilateral VS on scan, the smaller tumour did not cause an abnormality to the ABR, although intracanalicular diameter did not exceed $5 \mathrm{~mm}$. In one of these tumours, six years after initial scan the tumour still showed no delay in latencies or wave morphology although the tumour was impinging on the $\mathrm{CP}$ angle. In all the remaining five patients there was abnormal wave morphology or delay of latencies bilaterally consistent with MRI findings. Of the 27 tumours from 14 patients, 19 have shown abnormal ABR (six one year after MRI detection of VS) with a range of $2 \mathrm{~mm}$ intracanalicular diameter to 15 $\mathrm{mm}$ intracranial diameter. Median diameter at initial ABR abnormality was $6 \mathrm{~mm}$, with only one VS extending into the cerebellopontine angle not being detected.

The UK NF2 database is to our knowledge the largest clinical database of NF2 in the world. While ascertainment for the whole UK is not complete, the living diagnostic prevalence of 1 in 270000 comes close to the 1 in 200000 we previously calculated from our own population in the north west. ${ }^{4}$ Therefore, this patient series approximates to a population based series of patients presenting with NF2. We have detected VS on MRI scans in 35 patients without NF2 symptoms or signs. The age curves derived from this group of patients (figs 1 and 2) will be useful in counselling subjects at $50 \%$ risk of the disease, particularly if no DNA test is available in their family. As mutation detection can take up to six months, some degree of risk reduction will already be possible before a test becomes available in a family. These curves will, if anything, underestimate the degree of risk reduction. This is because scans are not undertaken until 10 years of age and, as can be seen from fig 3, 10\% of NF2 offspring present symptomatically before 10 years of age. Our corrected curves assume an arbitrary rate of growth of $2 \mathrm{~mm}$ per year. Many of the families in which presymptomatic diagnosis was made are at the extreme mild end of the scale with missense or splice site mutations and large deletions. ${ }^{6-9}$ All the patients in table 2 in which a mutation had been found had these types of mutation. Nonetheless, faced with a patient without obvious features of NF2 in which the family history of NF2 is mild, the curves are very useful. Most patients with severe NF2 do not have children ${ }^{3}$ and therefore most offspring are at risk of the milder forms of the disease. Indeed, many children of sporadic patients with NF2 may be at less than $50 \%$ initial risk owing to gonosomal mosaicism in their parent. ${ }^{3}$

The value of early detection of VS is still open to some debate. However, the only realistic chance of hearing preservation surgery is when the tumour is small ${ }^{10}{ }^{11}$ and tumours may not present symptomatically until $20 \mathrm{~mm}$ in diameter. ABR testing, while not detecting some of the very small intracanalicular tumours, still detected the great majority of tumours at a size when hearing preservation surgery would not have been compromised. However, the larger size at detection would leave less leeway for observation of the growth rate of the tumour. Where MRI scans are less accessible, ABR testing has more of a role than CT scanning (see case 11) and could serve as a back up to MRI in the interval years after normal scans.

It is clear that NF2 patients fare better if they are managed in specialist centres where surgery and occasionally other measures such as radiosurgery can be offered at the appropriate time. ${ }^{12}$ In experienced hands, hearing can be preserved with removal of VS and rehabilitation is now possible with auditory brain stem implants and on occasion with cochlear implants. ${ }^{10} 11$

There is still clearly a place for MRI and audiological screening in at risk relatives as $30 \%$ of the patients in this study would not have been able to have predictive DNA tests. While the proportion of families with mutations can be boosted by a comprehensive deletion finding strategy, ${ }^{13}$ these are not widely available for NF2 or many other diseases $(B R C A 1 / 2)$ and still fail to detect mosaic 
Table 2 Audiological features in 14 NF2 patients presenting with presymptomatic VS on MRI scan

\begin{tabular}{|c|c|c|c|c|c|c|c|c|c|}
\hline Case & Sex & Side & $\begin{array}{l}\text { Age at } M R I \\
\text { diagnosis }(y)\end{array}$ & Pure tone audio & $\begin{array}{l}\text { ABR at MRI } \\
\text { diagnosis }\end{array}$ & $\begin{array}{l}\text { ABR } 12 \text { months } \\
\text { later }\end{array}$ & $\begin{array}{l}\text { Previous normal MRI } \\
\text { (y) }\end{array}$ & $\begin{array}{l}\text { Size of VS on } \\
M R I(\mathrm{~mm})\end{array}$ & Mutation \\
\hline \multirow[t]{2}{*}{1} & M & Left & 16.9 & Normal & Normal & Abnormal & No & $4 \mathrm{~mm}$ & Yes \\
\hline & & Right & & Normal & Normal & Abnormal & No & $1 \mathrm{~mm}$ & \\
\hline \multirow[t]{2}{*}{2} & $\mathrm{~F}$ & Left & 18.2 & Normal & Normal & Abnormal & Yes (16) & $3 \mathrm{~mm}$ & Yes‡ \\
\hline & & Right & & Normal & Normal & Abnormal & Yes & $2 \mathrm{~mm}$ & \\
\hline \multirow[t]{2}{*}{3} & $\mathrm{~F}$ & Left & 12.4 & Normal & Normal & Normal & Yes (10) & $1 \mathrm{~mm}$ & No \\
\hline & & Right & & Normal & Abnormal & Abnormal & Yes & $2 \mathrm{~mm}$ & \\
\hline \multirow[t]{2}{*}{4} & M & Left & 12.5 & Normal & Abnormal & Abnormal & No & $15 \mathrm{~mm}$ & No \\
\hline & & Right & & Abnormal & Abnormal & Abnormal & No & $9 \mathrm{~mm}$ & \\
\hline \multirow[t]{2}{*}{5} & $\mathrm{~F}$ & Left & 25.3 & Normal & Normal & Not done & Yes (23) & $1 \mathrm{~mm}$ & Yes $\ddagger$ \\
\hline & & Right & & Normal & Normal & Not done & Yes & Nil & \\
\hline \multirow[t]{2}{*}{6} & M & Left & 15.5 & Normal & Abnormal & Abnormal & No & $7 \mathrm{~mm}$ & Yes $\$$ \\
\hline & & Right & & Normal & Normal & Abnormal & No & $4 \mathrm{~mm}$ & \\
\hline \multirow[t]{2}{*}{7} & $\mathrm{~F}$ & Left & 14.0 & Normal & Normal & Not done & No & $4 \mathrm{~mm}$ & Yes $\$$ \\
\hline & & Right & & Normal & Normal & Not done & No & $3 \mathrm{~mm}$ & \\
\hline \multirow[t]{2}{*}{8} & $M$ & Left & 27.8 & Abnormal & Abnormal & Not done & No & $12 \mathrm{~mm}$ & Yes $\$$ \\
\hline & & Right & & Abnormal & Normal & Normal` & No & $5 \mathrm{~mm}$ & \\
\hline \multirow[t]{2}{*}{9} & M & Left & 15.5 & Normal & Abnormal & Not done & No & $13 \mathrm{~mm}$ & Yesף \\
\hline & & Right & & Normal & Abnormal & Not done & No & $9 \mathrm{~mm}$ & \\
\hline \multirow[t]{2}{*}{10} & $\mathrm{~F}$ & Left & 16.6 & Normal & Normal & Abnormal & No & $8 \mathrm{~mm}$ & Yesף \\
\hline & & Right & & Normal & Normal & Abnormal & No & $6 \mathrm{~mm}$ & \\
\hline \multirow[t]{2}{*}{11} & M & Left & 25.9 & Normal & Abnormal & Not done & No & $10 \mathrm{~mm}$ & No \\
\hline & & Right & & Normal & Abnormal & Not done & No & $18 \mathrm{~mm}$ & \\
\hline \multirow[t]{2}{*}{12} & M & Left & 12.4 & Normal & Abnormal & Abnormal & Yes $(\mathrm{CT} 11) \dagger$ & $8 \mathrm{~mm}$ & Yes \\
\hline & & Right & & Normal & Abnormal & Abnormal & Yes & $10 \mathrm{~mm}$ & \\
\hline \multirow[t]{2}{*}{13} & M & Left & 13 & Normal & Abnormal & Not done & No & $18 \mathrm{~mm}$ & Yes \\
\hline & & Right & & Normal & Abnormal & Not done & No & $12 \mathrm{~mm}$ & \\
\hline \multirow[t]{2}{*}{14} & $M$ & Left & 12.1 & Normal & Normal & Normal & No & $2 \mathrm{~mm}$ & No \\
\hline & & Right & & Normal & Normal & Normal & No & $3 \mathrm{~mm}$ & \\
\hline
\end{tabular}

Patients 1 and 2, 3 and 4, 6 and 7, and 9 and 10 are sibs.

$\star$ ABR performed 6 years later. $†$ ABR abnormal. $¥$ Missense mutation. $§$ Large deletion. $\uparrow$ Splice site mutation.

mutations. A child who presents with NF2 with no family history is likely to represent a new mutation of the NF2 gene. If there is no suggestive family history, the risk to parent and sibs is still low (probably $<1 \%$ ). The cases presented here of two parents being affected after a child is to our knowledge the first such report. There is also no objective evidence that VS disease is worse in females than males. ${ }^{14}$ All four of the female sibs in table 2 had smaller VS at initial scan than their male counterparts.

Children of affected patients should be considered to be at $50 \%$ risk of NF2 and screening for NF2 can start at birth. ${ }^{5}$ Cataracts can affect vision in early life and other tumour implications are present in the first 10 years of life. Formal screening for VS should start at 10 years, as it is rare for tumours to occur before that time. Audiological tests including ABR are still a useful adjunct to MRI and can occur annually from 10 years of age. As surgery would only be contemplated for tumours at about $6 \mathrm{~mm}$ and tumour growth averages $2 \mathrm{~mm}$ per year, three yearly screening with MRI in a subject with no tumours is probably sufficient. The initial MRI scan could be at around 12 years of age. Once tumours are present screening should probably be annual. Spinal tumours are found very frequently on MRI, as many as $90 \%$ having evidence of these in some studies. ${ }^{15}$ However, only $25-30 \%$ require a spinal operation for a symptomatic tumour. ${ }^{1}$ Nonetheless, a full annual neurological examination is probably a wise precaution. In most families it is now possible to develop a genetic test so screening can be targeted on affected subjects only. Uptake of such testing in childhood and adult life is high. ${ }^{16}$ Using the data from this paper even without DNA tests the residual chance of having NF2 in a subject at $50 \%$ risk can be reduced to around $30 \%$, $10 \%$, and $5 \%$ if MRI is negative at 15,25 , and 35 years respectively.
${ }^{\star}$ Department of Medical Genetics, St Mary's Hospital, Hathersage Road, Manchester M13 0fH, UK

†Centre for Human Communication and Deafness, Manchester

University, Oxford Road, Manchester M13 9PL, UK

$\ddagger$ Department of Radiology, Manchester Royal Infirmary, Oxford Road, Manchester M13 9WL, UK

$\$$ Department of Otolaryngology, Manchester Royal Infirmary, Oxford Road, Manchester M13 9WL, UK

Correspondence to: Dr Evans, gevans@central.cmht.nwest.nhs.uk

1 Evans DGR, Huson SM, Donnai D, Neary W, Blair V, Newton V, Harris R. A clinical study of type 2 neurofibromatosis. $Q \mathcal{F}$ Med 1992;84:603-18.

2 Neary WJ, Newton VE, Vidler M, Ramsden RT, Lye RH, Dutton JEM, Richardson PL, Harris R, Evans DGR, Strachan T. A clinical, genetic and audiological study of patients and families with bilateral acoustic neurofibromatosis. F Laryngol Otol 1993;107:6-11.

3 Evans DGR, Wallace A, Wu CL, Trueman L, Ramsden RT, Strachan T. Somatic mosaicism: a common mechanism for sporadic disease in tumor pomatic mosaicism: a common mechanism for sporadic disease in tumor
prone syndromes? Lessons from type 2 neurofibromatosis. Am f Hum Genet prone syndromes?

4 Evans DGR, Huson SM, Donnai D, Neary W, Blair V, Teare D, Newton V, Strachan T, Harris R. A genetic study of type 2 neurofibromatosis in the United Kingdom. I. Prevalence, mutation rate, fitness, and confirmation of maternal transmission effect on severity. F Med Genet 1992;29:841-6.

5 Evans DGR, Huson SM, Donnai D, Neary W, Blair V, Newton V, Strachan $T$, Harris R. A genetic study of type 2 neurofibromatosis in the United Kingdom. II. Guidelines for genetic counselling. F Med Genet 1992;29:84752.

6 Parry DM, MacCollin M, Kaiser-Kupfer MI, Pulaski K, Nicholson HS, Bolesta M, Eldridge R, Gusella JF. Germline mutations in the neurofibromatosis 2 gene: correlations with disease severity and retinal abnormalities. Am f Hum Genet 1996;59:529-39.

7 Ruttledge MH, Andermann AA, Phelan CM, Claudio JO, Han F, Chretien N, Rangaratnam S, MacCollin M, Short P, Parry D, Michels V, Riccardi VM, Weksburg R, Kitamura K, Bradburn JM, Hall BD, Propping P, Rouleau GA. Type of mutation in the neurofibromatosis type 2 gene (NF2) frequently determines severity of disease. Am f Hum Genet 1996;59:331-42.

8 Evans DGR, Trueman L, Wallace A, Collins S, Strachan T. Genotypephenotype correlations in type 2 neurofibromatosis (NF2): evidence for more severe disease with truncating mutations. F Med Genet 1998;35:450-5.

9 Kluwe L, Bayer S, Baser ME, Hazim W, Haase W, Funsterer C, Mautner VF. Identification of NF2 germline mutations and comparison with neurofibromatosis 2 phenotypes. Hum Genet 1996;98:534-8.

10 Miyamato RT, Campbell RL, Fritsch M, Lochmueller G. Preservation of hearing in neurofibromatosis 2. Otolaryngol Head Neck Surg 1990;103:61924.

11 Slattery WH, Brackmann DE, Hitselberger W. Hearing preservation in neurofibromatosis type 2. Am F Otol 1998;19:638-43.

12 Evans DGR, Ramsden R, Huson SM, Harris R, Lye R, King TT. Type 2 neurofibromatosis: the need for supraregional care? $\mathcal{F}$ Laryngol Otol 1993;107:401-6.

13 Zucman-Rossi J, Legoix P, Der Sarkissian H, Cheret G, Sor F, Bernardi A, Cazes L, Giraud S, Ollagnon E, Lenoir G, Thomas G. NF2 gene in neurofibromatosis type 2 patients. Hum Mol Genet 1998;7:2095-101.

14 Evans DGR, Blair V, Strachan T, Lye RH, Ramsden RT. Variation of expression of the gene for type 2 neurofibromatosis: absence of a gender expression of the gene for type 2 neurofibromatosis: absence of a gender
effect on vestibular schwannomas, but confirmation of a preponderance of effect on vestibular schwannomas, but confirmation of a prof
meningiomas in females. F Laryngol Otol 1995;109:830-5.
J P R JENKINS

J GILLESPIE

R T RAMSDENS 
15 Mautner VF, Lindenau M, Baser ME, Tatagiba M, Haase W, Samii M, Wais $\mathrm{R}$, Pulst SM. The neuro-imaging and clinical spectrum of neurofibromato$\mathrm{R}$, Pulst SM. The neuro-imaging an
sis 2. Neurosurgery 1996;38:880-5.
16 Evans DGR, Maher ER, Macleod R, Davies DR, Craufurd D. Uptake of genetic testing for cancer predisposition. F Med Genet 1997;34:746-8.

F Med Genet 2000;37:947-948

\section{Suggestive evidence for a site specific prostate cancer gene on chromosome $1 \mathrm{p} 36$}

EDITOR-A report was recently published on the localisation of a chromosome segment at $1 \mathrm{p} 36$ which appeared to be linked (two point lod score $=4.74$ ) to a large number of families with multiple cases of early onset (mean age at diagnosis of $<66$ years) prostate cancer (PC) in which a brain tumour had been reported in a first or second degree relative of a PC case. ${ }^{1}$ This result is consistent with epidemiological evidence suggesting a familial relationship between brain cancer and PC as well as numerous studies of $\mathrm{LOH}$ at $1 \mathrm{p} 36$ in brain tumours. ${ }^{1}$ As part of the ACTANE (Anglo/ Canadian/Texan/Australian/Norwegian/EU Biomed) familial PC Consortium, we have genotyped 207 multiple case PC families for five 1 p36 tetranucleotide repeat polymorphisms, which were used by Gibbs et $a l,{ }^{1}$ and performed linkage analysis using GENEHUNTER ${ }^{2}$ with the following genetic map ${ }^{3}$ : D1S1 160 - $3.835 \mathrm{cM}$ - D1S1597 - $4.339 \mathrm{cM}$ - D1S407-2.611 cM - GATA29A05 (=D1S3669) - 6.520 $\mathrm{cM}$ - D1S552. In addition to our interest in assessing our families for evidence of linkage of prostate and primary brain cancer to this region, we also wanted to determine if any other cancer site(s) might be associated with a susceptibility locus in this region. To this end, the family histories of all cancers were abstracted from the databases of several Consortium members and included in the analysis.

Table 1 presents the characteristics of the families; details on how they were ascertained are included in the footnotes. The criteria used for the prostate cancer familial clusters in this study are more relaxed than those suggested by the Hopkins group (referred to as the "Hopkins criteria" in the field). ${ }^{4}$ The linkage analysis results of nine prostate-brain cancer families were partitioned according to mean age at diagnosis of PC in the family; these results are shown in table 2. (Only two of these brain cancers have been confirmed by pathology reports; a glioma diagnosed at 67 years in a man who had three brothers with PC, mean age of diagnosis 66.7 years, and a glioblastoma diagnosed at 69 years in a family with five cases of PC, mean age at diagnosis of 68.2 years). In the total set of nine families, all lod, NPL, and hlod scores maximised at D1S1160. Overall, we found no evidence of linkage of prostate-brain cancer to this region by either parametric (maximum lod score $=-0.06)$ or non-parametric $(\mathrm{NPL}=0.25, \mathrm{p}=0.39)$ analysis. The maximum hlod was 0.07 at an alpha (proportion of families linked) of $48 \%$. This latter estimate is consistent with the observation that four families had positive lod scores and four had negative scores (one family was uninformative, lod=0.0). Partitioning the families by mean age at diagnosis of PC resulted in suggestive, but not significant differential linkage with five early onset families (mean age at diagnosis $<66$ years) providing a maximum lod score of 0.48 , whereas the remainder of the families appeared unlinked according to both lod score $(-0.54)$ and NPL score $(-0.20)$. These results are consistent with the lod scores of Gibbs et $a l^{1}$ for families with a history of brain tumours when partitioned for average age
Table 1 Number of ACTANE families by source and number affected

\begin{tabular}{llccc}
\hline \multirow{5}{*}{ Source } & \multicolumn{3}{l}{ No of cases per family } & \\
\cline { 2 - 5 } & 2 & $3-4$ & $5+$ & Total \\
\hline UK & 31 & 31 & 4 & 66 \\
Canada & 39 & 34 & 7 & 80 \\
Texas & 3 & 6 & 3 & 12 \\
Australia & 13 & 22 & 1 & 36 \\
Norway & 2 & 2 & 2 & 6 \\
EU Biomed & 3 & 3 & 1 & 7 \\
Total & 91 & 98 & 18 & 207 \\
\hline
\end{tabular}

The criteria for inclusion in ACTANE are two related PC family members (first/second degree) where one case is $<65$ years at $\mathrm{PC}$ diagnosis, or $\geqslant 3$ or more $\mathrm{PC}$ cases in a cluster at any age.

Cases were verified by patient history and/or medical record/pathology report in the UK, Canada, Texas, and EU, and by cancer registration and medical records in Norway and Australia.

Table 2 Linkage results from nine prostate-brain cancer families

\begin{tabular}{lllllll}
\hline $\begin{array}{l}\text { Mean age at } \\
\text { Dx }\end{array}$ & $\begin{array}{l}\text { No of } \\
\text { families }\end{array}$ & Max lod & NPL & $p$ & Het lod & $\alpha$ \\
\hline$<66$ y & 5 & 0.48 & 0.51 & 0.29 & 0.48 & 1.00 \\
$\geqslant 66$ y & 4 & -0.54 & -0.20 & 0.55 & 0.00 & 0.00 \\
Total & 9 & -0.06 & 0.25 & 0.39 & 0.07 & 0.48 \\
\hline
\end{tabular}

$\alpha=$ the proportion of families linked.

at onset of prostate cancer, 3.65 ( $<66$ years) and -1.84 ( $\geqslant 66$ years).

We then generated lod and NPL scores for all 207 families and sorted them according to these linkage results as well as by their mean age at PC diagnosis. In no case did a family history of any cancer at another site appear to cluster or be associated with linkage to $1 \mathrm{p} 36$ or with mean age at PC diagnosis. This analysis included examination by number and mean age at diagnosis of breast cancer in first degree relatives and all relatives, by number and mean age at diagnosis of ovarian cancers, number and mean age at diagnosis of colorectal cancer, stomach and pancreatic cancer, malignant melanoma, or uterine cancer. Although none of the family history groupings gave a positive lod score generally, they gave a positive score when the mean age at onset of PC was early. We therefore hypothesised that it might not be the family history of brain cancer that was responsible for positive linkage to $1 \mathrm{p} 36$ but, instead, the family history of early age at PC diagnosis per se.

Table 3 presents the linkage analysis results for the entire ACTANE pedigree set subdivided according to mean age at diagnosis of affected men in the family. The four age groups presented in table 3 were chosen to give approximately equal representation and are listed from the youngest ( $\leqslant 59$ years) to the oldest ( $\geqslant 80$ years). The large negative lod score for all the families, -9.66 , rejects overall linkage to this region under the presumed genetic model of Carter et al. ${ }^{4}$ However, NPL score (1.02, $\left.\mathrm{p}=0.15\right)$ and maximum hlod $(0.93$, alpha $=0.24)$ are consistent with the possibilities that either PC in a proportion of these families is the result of an autosomal dominant gene located at $1 \mathrm{p} 36$, or that alternative genetic models better explain the excess allele sharing among men with PC. Recessive and X linked models have not yet been tested in our family set. Over the three subgroups of families with the earliest mean age at diagnosis, the sequential maximum lods (0.49, $-2.89,-5.78)$, NPL scores $(1.60,1.02,0.13)$, and heterogeneity lod scores $(1.17,0.59,0.00)$ all indicate a 
Table 3 Linkage results from all 207 ACTANE families

\begin{tabular}{|c|c|c|c|c|c|c|c|c|c|c|}
\hline $\begin{array}{l}\text { Mean age at onset } \\
\text { (y) }\end{array}$ & No of families & Max lod & Map* & NPL & $p$ & Map & Het lod & $a$ & Map & $p$ value \\
\hline$\leqslant 59$ & 33 & 0.49 & 17.30 & 1.60 & 0.06 & 17.30 & 1.17 & 0.62 & 17.30 & 0.067 \\
\hline $60-69$ & 71 & -2.89 & 14.69 & 1.02 & 0.15 & 10.78 & 0.59 & 0.30 & 10.78 & 0.260 \\
\hline $70-79$ & 55 & -5.78 & 17.30 & 0.13 & 0.44 & 3.83 & 0.00 & 0.00 & - & 1.000 \\
\hline$\geqslant 80$ & 48 & 0.95 & 10.78 & 0.31 & 0.37 & 10.78 & 0.95 & 0.88 & 10.78 & 0.110 \\
\hline Total & 207 & -9.66 & 15.99 & 1.02 & 0.15 & 3.83 & 1.93 & 0.24 & 12.08 & 0.011 \\
\hline
\end{tabular}

${ }^{\star}$ Map designates the genetic map distance (cM) from D1S1160 at which the maximum linkage score occurred.

greater possibility of linkage the earlier the mean age at PC diagnosis. The NPL score in the group with the earliest mean age at diagnosis is close to being nominally significant $(p=0.06)$, whereas for the other groups this score is not significant $(\mathrm{p}=0.15,0.44$, and 0.37 , respectively). Also, as mean age of PC diagnosis increased, the estimated proportion of linked families decreased from $62 \%$ to $30 \%$ to $0 \%$, also consistent with a general effect related to age at diagnosis. The group with the latest age at diagnosis does not appear to follow this pattern, but there are only 48 families in this class, and it might be expected that there would be a higher proportion of phenocopies in the upper liability class and this would decrease the power to detect linkage in this group. Although the reasons for this inconsistency are at present unclear, based on the results in the three youngest age groups, we feel that early age at diagnosis remains associated with an increased probability of linkage.

Our families provided no evidence that the putative familial prostate cancer locus, $C A P B$, at $1 \mathrm{p} 36^{1}$ is linked with primary brain tumours, or indeed cancer at any site other than the prostate. Although the five brain-prostate families with early mean age at diagnosis of PC did partition overall lod and NPL scores, we consider that because of the small number of families and the appearance of an age linkage score association when the families were subdivided by cancer at any site it remains unwarranted to postulate that susceptibility to brain tumours is increased by the inheritance of an altered gene in the 1 p36 region. We found a possible overall association of linkage scores with mean age at diagnosis since families with earlier onset disease gave higher scores. Although not statistically significant, this result is similar to that found for $\mathrm{HPC1}^{5}$ and $\mathrm{PCAP}^{6}$ as well as with other familial cancers such as breast and ovarian cancer. ${ }^{7}$ We note that table 6 of Gibbs et al ${ }^{1}$ suggested the possibility of linkage in 63 early onset PC families in that the lod scores were positive when the recombination fraction was $20 \%$ or more. However, linkage was tested only at D1S407 and hlod scores were not reported. Our maximum lod, NPL, and hlod scores generally occurred 5 to $9 \mathrm{cM}$ centromeric to this position, so further analysis in this region in their PC family set would be of interest. There are several possibilities for the failure to detect linkage with the prostate cancer/primary brain phenotype in our families. The first is that the analysis by Gibbs et $a l^{1}$ may have led to a false finding arising from multiple subgroup analysis, which always has the risk of showing significant association by chance alone. The other, more interesting possibility, from the gene hunting perspective, is that it is not the primary brain phenotype per se that is linked to this region, but rather early onset PC, and it is this association with early onset disease which is important.

This study was supported by The Cancer Research Campaign, The EU BIOMED Programme Contract BMH4-CT96-1229, and The National Health and Medical Research Council of Australia. We would like to thank all the men and their families who took part in this study, Le Fond de la Recherche en Sant du Quebec (FRSQ), and Endorecherche. J Simard is a Senior Scientist from FRSQ. We would like to thank Martine Tranchant for her skilful technical assistance.

MICHAEL BADZIOCH ${ }^{\star} ¥$ ROS EELES $†$ GILLES LEBLANC $\ddagger$ WILLIAM D FOULKESS GRAHAM GILES STEVE EDWARDS + DAVID GOLDGAR * JOHN L HOPPER ${ }^{\star \star}$ D T BISHOP+† PAL MØLLER KETIL HEIMDAL $\neq \ddagger$ DOUGLAS EASTONSS THE CRC/BPG UK FAMILIAL PROSTATE CANCER STUDY COORDINATORS AND COLLABORATORS

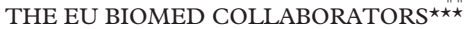
JACQUES SIMARD $\ddagger$

*Unit of Genetic Epidemiology, International Agency for Research on Cancer, Lyon, France

†CRC Section of Cancer Genetics, Institute of Cancer Research and Royal Marsden NHS Trust, Sutton, Surrey, UK

$\ddagger$ Laboratory of Hereditary Cancers, MRC Group of Molecular

Endocrinology, CHUL Research Centre, Quebec, Canada

$§$ Department of Medicine and Human Genetics, McGill University,

Montreal General Hospital, Montreal, Quebec, Canada

-Cancer Epidemiology Centre, Anti-Cancer Council of Victoria, Carlton, Australia

${ }^{\star \star}$ Centre for Genetic Epidemiology, The University of Melbourne, Carlton, Australia

††ICRF Genetic Epidemiology Laboratory, St Fames's Hospital, Leeds, $U K$

¥Unit of Medical Genetics, The Norwegian Radium Hospital, Oslo, Norway

SSCRC Genetic Epidemiology Unit, Strangeways Research Laboratories, Cambridge, UK

१'David Dearnaley, Robert Shearer, Audrey Ardern-fones, Annette Murkin, Rachel Fackson, Dawn Teare, and the CRC/BPG collaborators (ist available on request from $\mathrm{Dr} R$ Eeles)

${ }^{\star \star \star}$ Names and addresses available on request from Professor D T Bishop

Correspondence to: Dr Eeles, Section of Cancer Genetics, Institute of Cancer Research, Downs Road, Sutton, Surrey SM2 5PT, UK, ros@ icr.ac.uk

¥Present address: Division of Medical Genetics, Box 357720, University of Washington Medical Center, Seattle, WA 98195, USA

1 Gibbs M, Stanford JL, McIndoe RA, Jarvik GP, Kolb S, Goode EL, Chakrabarti L, Schuster EF, Buckley VA, Miller EL, Brandzel S, Li S, Hood L, Ostrander EA. Evidence for a rare prostate cancer-susceptibility locus at chromosome 1p36. Am f Hum Genet 1999;64:776-8.

2 Kruglyak L, Daly MJ, Reeve-Daly MP, Lander ES. Parametric and non-parametric linkage analysis: a unified multipoint approach. Am F Hum Genet 1996;58:1347-63.

3 Collins A, Teague J, Keats BJ, Morton NE. Linkage map integration. Genomics 1996;36:157-62.

4 Carter BS, Beaty TH, Steinberg GD, Childs B, Walsh PC. Mendelian inheritance of familial prostate cancer. Proc Natl Acad Sci USA 1992;89:336771

$5 \mathrm{Xu}$ J. Combined analysis of hereditary prostate cancer linkage to 1q24-25: results from 772 hereditary prostate cancer families from the International Consortium for Prostate Cancer Genetics. Am F Hum Genet 2000;66:94557.

6 Berthon P, Valeri A, Cohen-Akenine A, Drelon E, Paiss T, Wohr G, Latil A, Millasseau P, Mellah I, Cohen N, Blanche H, Bellane-Chantelot C, Demenais F, Teillac P, Le Duc A, de Petriconi R, Hautmann R, Chumakov I, Bachner L, Maitland NJ, Lidereau R, Vogel W, Fournier G, Mangin P, Cussenot $\mathrm{O}$. Predisposing gene for early-onset prostate cancer, localized on chromosome 1q42.2-43. Am 7 Hum Genet 1998;62:1416-24.

7 Easton DF, Ford D, Bishop DT. Breast and ovarian cancer incidence in BRCA1 mutation carriers in the Breast Cancer Linkage Consortium. Am f Hum Genet 1995;56:265-71. 


\section{Comorbidity of}

\section{5,10-methylenetetrahydrofolate} reductase and methionine synthase gene polymorphisms and risk for neural tube defects

EDITOR - Neural tube defects (NTDs) are among the most common and devastating birth defects. NTDs result from an incomplete closure of the neural tube, and include malformations of the skull, brain, meninges, spinal cord, and vertebral column. Recent evidence suggests that closure of the neural tube occurs in five separate sites which then fuse during the fourth week of gestation; NTDs occur when one site fails to close or two sites fail to fuse. ${ }^{1}$

During the last decade, periconceptional folic acid supplementation has been shown to reduce the risk of occurrence $^{2}$ and recurrence ${ }^{3}$ of NTDs. Women with an NTD affected pregnancy do not usually have overt signs of folate deficiency, although decreased erythrocyte folate concentration, the index known to reflect whole body folate stores, has been reported. ${ }^{45}$ In addition, it has been reported that women with NTD pregnancies have raised homocysteine concentrations in plasma and amniotic fluid, ${ }^{6}{ }^{7}$ suggesting that folate metabolism may be altered in these women.

5,10-methylenetetrahydrofolate reductase (MTHFR) catalyses the reaction from 5,10-methylenetetrahydrofolate to 5-methyltetrahydrofolate, which serves as methyl donor for the remethylation of homocysteine to methionine. ${ }^{8}$ A substitution (C to $\mathrm{T}$ ) at the highly conserved nucleotide 677 of the MTHFR gene has been described, which results in the conversion of an alanine (Ala) to a valine (Val) residue and increased in vitro thermolability of the enzyme. ${ }^{9}$ In vivo, the thermolabile $M T H F R$ mutant is known to result in raised plasma homocysteine concentrations when folate nutriture is inadequate. ${ }^{10}$ The frequency of homozygosity for this mutation is approximately $9 \%$ for various populations, but is higher in French Canadian, Italian, and Hispanic populations, and lower in African-American populations. ${ }^{911-13}$

The C677T mutation has been reported to be a genetic risk factor for NTDs. ${ }^{11}{ }^{14-17}$ However, the significance of this mutation as an NTD risk factor in different populations has recently been questioned. Speer $e t a l^{20}$ found no evidence of MTHFR C677T polymorphism as a risk factor for lumbosacral spina bifida in American white patients. Weitkamp et $a l^{1}$ also reported that the C677T polymorphism in MTHFR was not associated with NTD risk in a population of mixed ethnic origins. Papapetrou et $a l^{18}$ found no evidence for an association between the 677T allele and the incidence of NTDs in a British population. Similarly, in French, German, and American populations, the distribution of the C677T mutation was the same in fetuses with NTDs and controls. ${ }^{12} 1922$ Ubbink et $a^{23}$ reported that homozygosity for the C677T mutation does not constitute a genetic risk factor for NTDs in rural South African blacks. The low frequency of MTHFR C677T polymorphism in African-Americans, ${ }^{13}$ coupled with the lower incidence of NTDs in blacks, ${ }^{24}$ suggests that analysis of the association between MTHFR polymorphisms and NTD risk in a large cohort of African-Americans would provide new information relative to the importance of this association in this population group. These investigations suggest that the frequency of this mutation and its associated risk for NTD may be population dependent or dependent on folate nutriture. It is possible that the MTHFR mutation predisposes the fetus to the development of NTDs, but they only occur if the maternal and/or fetal folate status are suboptimal; hence, periconceptional folic acid supplementation may overcome this genetic defect. Therefore, a careful evaluation of the effect of polymorphism in association with folate nutriture is warranted.

We recently reported that C677T MTHFR polymorphisms and raised homocysteine levels in amniotic fluid appeared to be disproportionately associated with NTDs spanning the cervical-lumbar spine, lumbosacral spine, and occipital encephalocele..$^{25}$ These results suggest that periconceptional folic acid supplementation may prevent defects at these sites, but not at other sites of neural tube closure.

The gene for human methionine synthase (MS), which catalyses the reaction to form methionine from homocysteine, has recently been cloned, and a common polymorphism has also been identified. ${ }^{27-29}$ The polymorphism is an A to G substitution at base pair (bp) 2756, converting an aspartic acid (Asp) residue into a glycine (Gly). Although MS plays an important role in homocysteine metabolism, this polymorphism has not been reported to be a risk factor for NTD formation, ${ }^{30-33}$ and, to our knowledge, comorbidity of MTHFR and MS polymorphisms for NTDs has never been evaluated. Potential comorbidity of these enzymes may be of significance because MS and MTHFR are both key enzymes in homocysteine metabolism, and altered homocysteine metabolism has been implicated in the development of NTDs. ${ }^{67}$

We determined $M T H F R$ and $M S$ genotypes using DNA isolated from amniotic fluid cells of fetuses with NTDs and of those without any apparent malformations, and evaluated potential associations between polymorphisms in these two genes as a risk factor for the development of NTDs. The study was approved by the Institutional Review Board of the University of Alabama at Birmingham. The computerised genetics database at the University of Alabama Prenatal Genetics Clinic was used to identify cases in which NTDs were diagnosed by ultrasound and amniocentesis, and confirmed by neonatal examination or necropsy, between 1988 and 1997. Excess stored second trimester amniotic fluid samples from 82 women with fetuses with confirmed NTDs (cases) and from 84 women with normal pregnancies (controls) were analysed. For each case selected, we identified control samples obtained from women who had undergone amniocentesis at the same clinic but had a fetus confirmed to be normal by ultrasound, karyotype, and newborn examination. Each acceptable control was randomly assigned a computer generated priority number (SASS RANUI function) and sorted accordingly. Samples were then retrieved from storage according to their priority number; the first adequate sample located was selected as a control. Cases and controls were matched for race, maternal age, and month and year of amniocentesis. The case and control groups each had a composition of $83 \%$ white, $16 \%$ AfricanAmerican, and $1 \%$ other. The mean (SD) maternal ages of cases and controls were not significantly different (26.3 (SD 5.3) and 28.1 (SD 4.9) years, respectively).

The amniotic fluid samples were collected aseptically under ultrasound guidance by an experienced operator, and were stored at $-70^{\circ} \mathrm{C}$ until analysis. A $200 \mu \mathrm{l}$ aliquot of amniotic fluid was centrifuged for five minutes at $13000 \times g$. After removing $150 \mu \mathrm{l}$ of supernatant, the remaining pellet $(50 \mu \mathrm{l})$ was suspended in $300 \mu \mathrm{l}$ Cell Lysis Solution and DNA was isolated (Puregene DNA Isolation Kit, Gentra Systems, Minneapolis, MN). Isolated DNA was resus- 
Table 1 Odds ratios and 95\% confidence intervals of 5,10-methylenetetrahydrofolate reductase (MTHFR) and methionine synthase (MS) genotypes in fetuses with NTDs (cases) and controls

\begin{tabular}{lllll}
\hline Genotype & NTDs (cases) & Controls & $\begin{array}{l}\text { Odds } \\
\text { ratio }\end{array}$ & $\begin{array}{l}95 \% \\
\text { confidence } \\
\text { interval }\end{array}$ \\
\hline MTHFR & & & & \\
Ala/Ala & $43 / 82(52 \%)$ & $63 / 76(83 \%)$ & 1.0 & \\
Ala/Val & $30 / 82(37 \%)$ & $11 / 76(14 \%)$ & 4.0 & $1.8-8.8$ \\
Val/Val & $9 / 82(11 \%)$ & $2 / 76(3 \%)$ & 6.6 & $1.3-24.9$ \\
MS & & & \\
Asp/Asp & $59 / 77(77 \%)$ & $70 / 84(83 \%)$ & 1.0 & \\
Asp/Gly & $18 / 77(23 \%)$ & $13 / 84(14 \%)$ & 1.6 & $0.7-3.6$ \\
Gly/Gly & $0 / 77(0 \%)$ & $1 / 84(1 \%)$ & - & - \\
\hline
\end{tabular}

pended in $25 \mu \mathrm{l}$ Tris-EDTA buffer and stored at $-20^{\circ} \mathrm{C}$ until analysis. The C677T mutation in the MTHFR gene was determined by polymerase chain reaction (PCR) amplification of DNA using an exonic and intronic primer pair that generates a $198 \mathrm{bp}$ fragment. ${ }^{9}$ Thirty eight cycles of PCR were performed for one minute at $94^{\circ} \mathrm{C}$, one minute at $60^{\circ} \mathrm{C}$, and two minutes at $72^{\circ} \mathrm{C}$, followed by a 10 minute elongation at $72^{\circ} \mathrm{C}$ at the end of the cycles. The A2756G polymorphism in the $M S$ gene was determined by PCR amplification using a primer pair that generates a $189 \mathrm{bp}$ fragment. ${ }^{28}$ Thirty eight cycles of PCR were performed for 45 seconds at $95^{\circ} \mathrm{C}, 35$ seconds at $55^{\circ} \mathrm{C}$, and 75 seconds at $72^{\circ} \mathrm{C}$. An aliquot of the PCR product was digested overnight with HinfI restriction endonuclease (for detecting $M T H F R)^{9}$ or with HaeIII (for detecting $M S$ ).$^{28}$ The reaction products were subjected to electrophoresis using a $1.8 \%$ agarose gel. The homozygous normal MTHFR and MS alleles are not digested by their respective restriction endonucleases, whereas the polymorphisms create recognition sequences which are digested. The non-mutated (Ala/Ala) MTHFR PCR product is $198 \mathrm{bp}$ long. The homozygous mutant (Val/ Val) allele is thus digested completely by the enzyme and gives a $175 \mathrm{bp}$ fragment and a $23 \mathrm{bp}$ fragment. The latter runs off the gel and is not visible after electrophoresis. The heterozygous genotype (Ala/Val) yields both the 198 and 175 bp fragments upon HinfI digestion. Similarly, the nonmutated (Asp/Asp), homozygous mutant (Gly/Gly), and heterozygous (Asp/Gly) genotypes of $M S$ yield 189, 159, and 189 plus $159 \mathrm{bp}$ bands, respectively.

As shown in table 1, we found that the C677T Ala/Val or Val/Val MTHFR genotype was more prevalent in NTD cases than in controls. When Ala/Val and Val/Val genotypes were combined, $48 \%$ of NTD cases had both alleles, compared with $17 \%$ of controls. There was a 4.0 -fold increased risk for NTDs in fetuses having the Ala/Val genotype (95\% confidence interval 1.8-8.8), and the risk increased to 6.6fold in fetuses with the Val/Val genotype (95\% confidence interval 1.3-24.9). The fetal MS A2756G Gly/Gly and Asp/Gly genotypes were not associated with risk of NTD (table 1). Furthermore, we also found no association between combined MTHFR and MS polymorphisms and risk of NTDs (table 2).

Table 2 Odds ratios and 95\% confidence intervals of 5,10-methylenetetrahydrofolate reductase (MTHFR) and methione synthase (MS) genotypes in fetuses with NTDs (cases) and controls

\begin{tabular}{|c|c|c|c|c|c|}
\hline $\begin{array}{l}\text { MTHFR } \\
\text { genotype }\end{array}$ & $M S$ genotype & $\begin{array}{l}\text { NTDs } \\
\text { (cases) }\end{array}$ & Controls & $\begin{array}{l}\text { Odds } \\
\text { ratio }\end{array}$ & $\begin{array}{l}95 \% \\
\text { confidence } \\
\text { interval }\end{array}$ \\
\hline \multirow[t]{3}{*}{ Ala/Ala } & Asp/Asp & 32 & 53 & 1.0 & \\
\hline & Asp/Gly & 8 & 9 & 1.5 & $0.5-4.2$ \\
\hline & Gly/Gly & 0 & 1 & - & - \\
\hline \multirow[t]{3}{*}{$\mathrm{Ala} / \mathrm{Val}$} & Asp/Asp & 22 & 10 & 1.0 & \\
\hline & Asp/Gly & 7 & 1 & 3.2 & $0.3-29.4$ \\
\hline & Gly/Gly & 0 & 0 & - & - \\
\hline \multirow[t]{3}{*}{ Val/Val } & Asp/Asp & 5 & 1 & 1.0 & \\
\hline & Asp/Gly & 3 & 1 & & \\
\hline & Gly/Gly & 0 & 0 & - & - \\
\hline
\end{tabular}

Our findings using amniotic fluid cells indicate that fetuses homozygous or heterozygous for the $\mathrm{C}$ to $\mathrm{T}$ substitution in the MTHFR gene are at increased risk for NTDs. In order to compare our results to those of others, we summarised the MTHFR genotype frequencies in previously reported NTD cases from all studies with $\geqslant 50$ subjects (table 3). We selected studies with NTD cases exceeding 50 subjects. Our study, reporting the MTHFR genotype of 82 NTD cases and 76 controls, is the fourth largest study in terms of the number of NTD cases. Our results are similar to those of previous studies which suggested that either homozygosity or heterozygosity for the C677T mutation in the fetal MTHFR gene is a risk factor for NTDs. A meta-analysis of the available data indicated that homozygosity for the C677T mutation resulted in an approximately two-fold increase of risk for NTDs. ${ }^{11}$ In the study reported here, we found that NTD risk was increased in fetuses having the $\mathrm{Val} / \mathrm{Val}$ and Ala/Val genotypes. When compared to previous studies, our odds ratios for both heterozygous and homozygous MTHFR C677T genotype frequencies in NTD cases are higher than those previously reported. The mechanism accounting for the higher ratios is unknown, but may relate to the ethnic or geographical composition or the folate nutriture of our study population. Folate nutriture is mentioned here because previous studies have shown that folic acid supplementation decreases the incidence of NTDs. ${ }^{2}{ }^{3}$

Our finding of no association between the A2756G (Gly/ Gly) polymorphism in the $M S$ gene and the occurrence of the NTD phenotype is similar to that of van der Put et al, ${ }^{30}$ who reported that there is no increased prevalence of the Asp/Gly or Gly/Gly genotypes in fetuses with NTDs or their mothers. They found that the prevalence in controls of the Asp/Asp, Asp/Gly, and Gly/Gly genotypes was $71 \%, 26 \%$, and $3 \%$, respectively, which is similar to our values of $84 \%$, $14 \%$, and $3 \%$ in controls presented here. Shaw et $a l^{\beta 1}$ and Morrison et $a l^{2}$ also reported that overall percentages of Asp/Gly and Gly/Gly were not increased in infants with NTDs. Christensen et $a l^{33}$ presented data suggesting that the homozygous mutant genotype for the A2756G polymorphism in methionine synthase was associated with a reduced risk for NTD in children. Given the importance of MS in homocysteine metabolism, it is tempting to speculate that during the course of evolution, some mutations of $M S$ were so deleterious that they were lethal to the fetus and were thus not propagated.

To our knowledge, this is the first reported study of interactions between frequently occurring polymorphisms of two genes involved in folate metabolism. We did not find strong associations between MTHFR and MS polymorphisms and the risk of NTDs. van der Put et $a b^{4}$ recently hypothesised that combined heterozygosity for two common MTHFR mutations may be an additional risk factor for NTDs. The significance, if any, of the weak $M S / M T H F R$ associations that we observed in this study requires further evaluation, and possible confounding factors resulting from genetic associations involved in folate metabolism as well as folate nutriture may warrant further investigation.

Table 3 Heterozygous and homozygous MTHFR C677T genotype frequencies in published NTD cases

\begin{tabular}{llllll}
\hline $\begin{array}{l}\text { No of } \\
\text { NTD } \\
\text { cases }\end{array}$ & $\begin{array}{l}\text { No } \\
\text { heterozygous } \\
\text { (\%) }\end{array}$ & $\begin{array}{l}\text { No } \\
\text { homozygous } \\
(\%)\end{array}$ & $\begin{array}{l}\text { Homozygous } \\
\text { odds ratio }\end{array}$ & $\begin{array}{l}\text { 95\% } \\
\text { confidence } \\
\text { interval }\end{array}$ & Reference \\
\hline 214 & $100(47)$ & $41(19)$ & Not reported & - & 12 \\
153 & Not reported & $29(19)$ & 2.6 & $1.4-4.8$ & 16 \\
137 & $60(44)$ & $19(14)$ & Not reported & - & 19 \\
82 & $32(39)$ & $15(18)$ & 3.5 & $1.3-9.4$ & 14 \\
56 & $26(46)$ & $11(20)$ & 2.2 & $0.8-6.0$ & 26 \\
55 & $26(47)$ & $7(13)$ & 2.9 & $1.0-7.9$ & 15 \\
82 & $30(37)$ & $9(11)$ & 6.6 & $1.3-24.9$ & Our study \\
\hline
\end{tabular}


In conclusion, our data support previous studies suggesting that the C677T mutation in MTHFR is associated with increased risk for NTDs. Although a common polymorphism in the $M S$ gene was not a strong risk factor for NTDs, associations between MTHFR and $M S$ polymorphisms slightly increased the risk. Further research is warranted to evaluate comorbidity of $M T H F R$ and $M S$ polymorphisms in a large population.

This work was supported in part by the National Institutes of Health, grant
number HD 32901, the Agency for Health Care Policy, grant number 282-92number HD 32901, the Agency for Health Care Policy, grant number 282-92Birmingham.

GARY L JOHANNING* T TAMURA*

KELLEY E JOHNSTON ${ }^{\star}$ KATHARINE D WENSTROM†

${ }^{\star}$ Department of Nutrition Sciences, 340 Webb Building, The University of Alabama at Birmingham, Birmingham, Alabama 35294-3360, USA †The Center for Obstetric Research, Department of Obstetrics and Gynecology, The University of Alabama at Birmingham, Birmingham, Alabama, USA

Correspondence to: Dr Johanning, garyj@uab.edu

1 Van Allen MI, Kalousek DK, Chernoff GF, Juriloff D, Harris M, McGillivray BC, Young SL, Langlois S, MacLeod PM, Chitayat D, Friedman JM, Wilson RD, McFadden D, Pantzar J, Ritchie S, Hall JG. Evidence for multi-site closure of the neural tube in humans. Am $\mathcal{f}$ Med Genet 1993;47:723-43.

2 Czeizel AE, Dudàs I. Prevention of the first occurrence of neural-tube defects by periconceptional vitamin supplementation. N Engl f Med 1992; 327:1832-5.

3 MRC Vitamin Study Research Group. Prevention of neural tube defects: results of the Medical Research Council Vitamin Study. Lancet 1991;338: 131-7.

4 Kirke PN, Molloy AM, Daly LE, Burke H, Weir DG, Scott JM. Maternal plasma folate and vitamin $\mathrm{B} 12$ are independent risk factors for neural tube plasma folate and vitamin B12 are

5 van der Put NMJ, Thomas CMG, Eskes TKAB, Trijbels FJM, Steegers-Theunissen RPM, Mariman ECM, De Graaf-Hess A, Smeitink Steegers-Theunissen RPM, Mariman ECM, De Graaf-Hess A, Smeitink
JAM, Blom HJ. Altered folate and vitamin B12 metabolism in families with JAM, Blom HJ. Altered folate and vitamin B12 m
spina bifida offspring. $O \mathcal{F M e d} 1997 ; 90: 505-10$

spina bifida offspring. $Q$ f Med 1997;90:505-10.
6 Mills JL, McPartlin JM, Kirke PN, Lee YJ, Conley MR, Weir DG, Scott JM. Homocysteine metabolism in pregnancies complicated by neural-tube defects. Lancet 1995;345:149-51.

7 Steegers-Theunissen RPM, Boers GH, Blom HJ, Nijhuis JG, Thomas CMG, Borm GF, Eskes TK. Neural tube defects and elevated homocysteine levels in amniotic fluid. Am $\mathcal{F}$ Obstet Gynecol 1995;172:1436-41.

8 Finkelstein JD. Methionine metabolism in mammals. F Nutr Biochem 1990; 1:228-37.

9 Frosst P, Blom HJ, Milos R, Goyette P, Sheppard CA, Matthews RG, Boers GJH, den Heijer M, Kluijtmans LAJ, van den Heuvel LP, Rozen R. A candidate genetic risk factor for vascular disease: a common mutation in methylenetetrahydrofolate reductase. Nat Genet 1995;10:111-13.

10 Harmon DL, Woodside JV, Yarnell JWG, McMaster D, Young IS, McCrum EE, Gey KF, Whitehead AS, Evans AE. The common 'thermolabile' variant of methylene tetrahydrofolate reductase is a major determinant of mild ant of methylene tetrahydrofolate reductase is a major
hyperhomocysteinaemia. $O \mathcal{F}$ Med 1996;89:571-7.

11 van der Put NMJ, Eskes TKAB, Blom HJ. Is the common C677 $\rightarrow$ T mutation in the methylenetetrahydrofolate reductase gene a risk factor for neution in the methylenetetrahydrofolate reductase gene a risk
ral tube defects? A meta-analysis. $O \mathcal{F}$ Med $1997 ; 90: 111-15$.

12 Shaw GM, Rozen R, Finnell RH, Wasserman CR, Lammer EJ. Maternal vitamin use, genetic variation of infant methylenetetrahydrofolate reductase, and risk for spina bifida. Am $\mathcal{F}$ Epidemiol 1998;148:30-7.

13 Stevenson RE, Schwartz CE, Du YZ, Adams MJ Jr. Differences in methylenetetrahydrofolate reductase genotype frequencies, between whites and blacks. Am f Hum Genet 1996;60:229-30.
14 Whitehead AS, Gallagher P, Mills JL, Kirke PN, Burke H, Molloy AM, Weir DG, Shields DC, Scott JM. A genetic defect in 5,10 methylenetetrahydrofolate reductase in neural tube defects. $Q f$ Med $1995 ; 88: 763-6$.

15 van der Put NMJ, Steegers-Theunissen RPM, Frosst P, Trijbels FJM, Eskes TKAB, van den Heuvel LP, Mariman ECM, den Heyer M, Rozen R, Blom HJ. Mutated methylenetetrahydrofolate reductase as a risk factor for spina bifida. Lancet 1995;346:1070-1

16 Kirke PN, Mills JL, Whitehead AS, Molloy A, Scott JM. Methylenetetrahydrofolate reductase mutation and neural tube defects. Lancet 1996;348:1037-8.

17 Ou CY, Stevenson RE, Brown VK, Schwartz CE, Allen WP, Khoury MJ, Rozen R, Oakley GP Jr, Adams MJ Jr. 5,10 methylenetetrahydrofolate reductase genetic polymorphism as a risk factor for neural tube defects. $\mathrm{Am}$ f Med Genet 1996;63:610-14.

18 Papapetrou C, Lynch SA, Burn J, Edwards YH. Methylenetetrahydrofolate reductase and neural tube defects. Lancet 1996;348:58.

19 Koch MC, Stegmann K, Ziegler A, Schröter B, Ermert A. Evaluation of the MTHFR C677T allele and the MTHFR gene locus in a German spina bifida population. Eur F Pediatr 1998;157:487-92.

20 Speer MC, Worley G, Mackey JF, Melvin E, Oakes JW, George TM, the NTD Collaborative Group. The thermolabile variant of methylenetetrahydrofolate reductase (MTHFR) is not a major risk factor for neural tube defect in American Caucasians. Neurogenetics 1997;1:149-50

21 Weitkamp LR, Tackels DC, Hunter AGW, Holmes LB, Schwartz CE. Heterozygote advantage of the MTHFR gene in patients with neural-tube defect and their relatives. Lancet 1998;351:1554-5.

22 Mornet E, Muller F, Lenvoisé-Furet A, Delezoide AL, Col JY, Simon-Bouy B, Serre JL. Screening of the C677T mutation on the methylenetetrahydrofolate reductase gene in French patients with neural tube defects. Hum Genet 1997;100:512-14.

23 Ubbink JB, Christianson A, Bester MJ, Van Allen MI, Venter PA, Delport R, Blom HJ, van der Merwe A, Potgieter H, Vermaak WJH. Folate status, homocysteine metabolism, and methylene tetrahydrofolate reductase genotype in rural South African blacks with a history of pregnancy complicated type in rural South African blacks with a history of prects. Metabolism 1999;48:269-74

24 Motulsky AG. Nutritional ecogenetics: homocysteine-related arteriosclerotic vascular disease, neural tube defects, and folic acid. Am f Hum Genet 1996;58:17-20.

25 Wenstrom KD, Johanning GL, Owen J, Johnston KE, Acton S, Cliver S, Tamura T. Amniotic fluid homocysteine levels, 5,10methylenetetrahydrofolate reductase genotypes, and neural tube closure sites. Am $\mathcal{F}$ Med Genet 2000;90:6-11.

26 Wenstrom KD, Johanning GL, Owen J, Johnston KE, Acton S, Tamura T. Role of amniotic fluid homocysteine level and of fetal 5,10methylenetetrahydrofolate reductase genotype in the etiology of neural tube defects. Am $\mathcal{F}$ Med Genet 2000;90:12-16.

27 Li YN, Gulati S, Baker PJ, Brody LC, Banerjee R, Kruger WD. Cloning, mapping and RNA analysis of the human methionine synthase gene. Hum Mol Genet 1996;5:1851-8.

28 Leclerc D, Campeau E, Goyette P, Adjalla CE, Christensen B, Ross M, Eydoux P, Rosenblatt DS, Rozen R, Gravel RA. Human methionine synthase: cDNA cloning and identification of mutations in patients of the $c b l G$ complementation group of folate/cobalamin disorders. Hum Mol Genet 1996;5:1867-74.

29 Chen LH, Liu ML, Hwang HY, Chen LS, Korenberg J, Shane B. Human methionine synthase: cDNA cloning, gene localization, and expression. $f$ Biol Chem 1997;272:3628-34

30 van der Put NMJ, van der Molen EF, Kluijtmans LAJ, Heil SG, Trijbels JMF, Eskes TKAB, van Oppenraaij-Emmerzaal D, Banerjee R, Blom HJ. Sequence analysis of the coding region of human methionine synthase: relevance to hyperhomocysteinaemia in neural-tube defects and vascular disease. Q F Med 1997;90:511-17.

31 Shaw GM, Todoroff K, Finnell RH, Lammer EJ, Leclerc D, Gravel RA, Rozen R. Infant methionine synthase variants and risk for spina bifida. $\mathcal{F}$ Med Genet 1999;36:86-7.

32 Morrison K, Edwards YH, Lynch SA, Burn J, Hol F, Mariman E. Methionine synthase and neural tube defects. F Med Genet 1997;34:958.

33 Christensen B, Arbour L, Tran P, Leclerc D, Sabbaghian N, Platt R, Gilfix BM, Rosenblatt DS, Gravel RA, Forbes P, Rozen R. Genetic polymorphisms in methylenetetrahydrofolate reductase and methionine synthase, folate levels in red blood cells, and risk of neural tube defects. Am 7 Med Genet 1999;84:151-7.

34 van der Put NMJ, Gabreels F, Stevens EMB, Smeitink JAM, Trijbels FJM, Eskes TKAB, van den Heuvel LP, Blom HJ. A second common mutation in the methylenetetrahydrofolate reductase gene: an additional risk factor for neural-tube defects? Am f Hum Genet 1998;62:1044-51.

F Med Genet 2000;37:951-956

\section{Expression of HCM causing mutations: lessons learnt from genotype-phenotype studies of the South African founder MYH7 A797T mutation}

EDITOR-Genotype-phenotype correlations provide another perspective in studies seeking to identify the factors that underlie the clinical variability that is a feature of several inherited diseases. This approach has been particularly revealing in investigations into the molecular causes and phenotypic heterogeneity associated with hypertrophic cardiomyopathy (HCM), a common inherited primary cardiac disorder. ${ }^{12}$ Although, as its name suggests, hypertrophy may be a noticeable feature of the disease, it is not invariant, nor does the degree of hypertrophy necessarily correlate with the risk of sudden cardiac death (SCD), which is the most feared consequence of HCM. ${ }^{34}$

Molecular genetic investigations have shown that HCM is caused by more than 100 distinct mutations in at least seven different sarcomeric protein encoding genes. ${ }^{5}$ When the clinical features of HCM are correlated in a family context with the specific disease causing gene and its associated mutation, a recognisable pattern emerges. Essen- 
tially, mutations in the cardiac $\beta$ myosin heavy chain gene (MYH7) are more often associated with echocardiographically detectable to marked hypertrophy and a variable risk of SCD, usually before the age of 35 years, which generally relates to the specific causative mutation. ${ }^{6}$ In striking contrast, mutations in the cardiac troponin T gene (TNNT2) are most frequently accompanied by subtle, or even undetectable, hypertrophy, yet confer a high risk of SCD in adolescence or young adulthood. ${ }^{3}{ }^{4}$ Between these extremes lie the myosin binding protein $\mathrm{C}$ gene mutations, which are responsible for a considerably later age of onset of a steadily progressive form of hypertrophy, which may result in death from congestive heart failure later in life, more often than SCD. ${ }^{78}$ Further studies are needed before conclusive genotype-phenotype profiles can be defined for mutations in other HCM causing genes. ${ }^{9-11}$

This stratification of HCM into distinguishable subclasses of disease has been used in prognostication and management and counselling of patients with this treatable, but currently incurable, disease. However, it is generally advised that this approach be undertaken with caution, as some phenotypic associations are based on limited patient numbers. ${ }^{12}$ Furthermore, there is concern that data generated for one ethnic group cannot necessarily be extrapolated to others. ${ }^{13}$ As a corollary, evidence suggests that diverse genetic and environmental susceptibility factors may modulate the expression of identified disease causing mutations in the sarcomeric protein encoding genes. $^{14} 15$

We previously described a novel $M Y H 7$ mutation, resulting in the substitution of a threonine $(\mathrm{T})$ residue for an alanine (A) residue at codon 797 (A797T), in two South African HCM patients. Initial impressions, based on the immediate family history of one of these unrelated subjects, were that this mutation was associated with a poor prognosis and frequent SCD, thus prompting further investigation. ${ }^{16}$ It was then found that both parents of the proband carried the MYH7 A797T mutation. Concomitantly, this mutation was identified in another seven apparently unrelated members of a panel of South African HCM patients. Subsequent haplotyping studies showed that the MYH7 A797T mutation was a founder mutation extant in South African subpopulation groups, where it accounted for $25 \%$ of disease causes in a panel of HCM affected probands ${ }^{17}$ making it even more important to investigate its associated phenotype. These studies were further warranted because the mutation carriers in the extended families traced from these probands shared a common ancestor and provided a large patient base in which to establish genotype-phenotype correlations.

We show that the MYH7 A797T mutation is generally associated with a favourable prognosis, but that it is important to consider the influence of both genetic and environmental modifiers on the disease profile, when using genotype-phenotype correlations in patient management and counselling.

The study subjects were probands belonging to a panel of South African HCM affected subjects and their relatives who could be traced. After obtaining informed consent from subjects or legal guardians, DNA was extracted from peripheral blood samples. ${ }^{18}$ The $M Y H 7$ A797T mutation was detected by PCR based allele specific restriction enzyme analysis. ${ }^{16}$ Mutation positive subjects were clinically evaluated as described previously. ${ }^{14}$ Briefly, echocardiographically determined end diastolic maximum left ventricular wall thickness (LVWT) measurements were obtained at the anterior interventricular septum (IVS) and posterior wall (PW). Echocardiographic diagnosis of HCM was made in the presence of an IVS $\geqslant 13 \mathrm{~mm}$, in the absence of confounding factors. Electrocardiographic diagnosis of HCM was based on the presence of left ventricular hypertrophy (LVH) according to the point system of Romhilt and Estes ${ }^{19}$ or a significant $Q$ wave abnormality. A family history and clinical records were obtained to identify the range of symptoms noted in affected subjects and the number of disease related and sudden cardiac deaths (SCDs) reported among the families studied. The latter data were used to construct KaplanMeier survival curves. $^{20}$ Based on the similarity of phenotype and survival, the survival data from affected subjects in all the families, except those belonging to pedigree 101, were pooled. Pedigree 101 was evaluated separately because both parents in kindred 101a (fig 1) carried the MYH7 A797T mutation and previous haplotype studies had shown them to be related. ${ }^{17}$ Members of the pedigrees are identified by a pedigree number prefix, followed by the subject's identification numbers. The prefix SB identifies probands from whom relatives could not be traced. Pedigrees 101, 124, 131, and 138 were of white descent, while pedigrees 104 and 110 and subjects SB902, SB983, and SB995 were of ethnic admixture. ${ }^{17}$ In order to ascertain that two brothers carrying the MYH7 A797T mutation were monozygotic (MZ) twins, their HinfI digested DNA samples were analysed by Southern blot hybridisation $^{21}$ at hypervariable GTG genetic loci using the $(\text { GTG })_{5}$ fingerprinting probe. ${ }^{22}$

A total of 66 family members of six pedigrees (pedigrees $101,104,110,124,131$, and 138, fig 1) and three probands (SB902, SB983, and SB995) were genotyped for the MYH7 A797T mutation. Of these, 39 were mutation carriers (table 1), including both parents (1.II.2 and 1.II.3) of the proband (1.III.6) of kindred 101a, within pedigree 101 (fig 1). Additionally, three dead sibs of 1.III.6, namely 1.III.1, 1.III.3, and 1.III.5, were diagnosed with HCM at necropsy, implying that they were likely to have inherited at least one copy of the mutant allele from one of their carrier parents. Of these subjects, 1.III.1 was definitely a heterozygous mutation carrier, as one of her fraternal twin offspring (1.IV.2) had inherited the mutation, while the other (1.IV.1) had not. Similarly, dead subject 1.III.3 could not have been a homozygous mutation carrier, as he also had one non-carrier child (1.IV.3). No further assumptions could be made about the carrier status of dead subject 1.III.5, who died childless. No living homozygous mutation carriers were detected in this branch of pedigree 101.

Thirty five of the 39 living mutation carriers were clinically examined, while 1. III.10, 4.II.3, 4.III.1, and 38.III.1 declined clinical investigation. Subjects 38.II.1, 38.II.6, and 38.III.3 were assessed only by ECG and 4.I.1, 4.II.1, and 10.I.1 only by echocardiography.

The mutation was associated with echocardiographically detectable hypertrophy of the IVS (LVWT $\geqslant 13 \mathrm{~mm}$ ) in 17 subjects (table 1), and although not to the same extent, the left PW and/or apex were also abnormal, with measurements of greater than $11 \mathrm{~mm}$, in 11 of these subjects (table 1). Additionally, there were three mutation carriers whose LVWT measurements were $\geqslant 11$ but $<13 \mathrm{~mm}$. Moreover, SB902 and SB983 had undergone myectomy to reduce outflow tract obstruction, as well as mitral valve replacement. The mean LVWT, calculated for all mutation carriers $\geqslant 16$ years, was $17.1 \mathrm{~mm}$ (SD 8.6), while the median LVWT was $13 \mathrm{~mm}$.

Blood pressure measurements were below 160/95 mm $\mathrm{Hg}$ in 27 of the 29 mutation carriers for whom records were available (table 1), with the exceptions being two brothers, 31.III. 6 and 31.III. 8 (160/110 and 150/100 mm $\mathrm{Hg}$, respectively). Only three of these 29 mutation carriers were receiving blood pressure lowering medication at the 
time of the initial examination, namely, 31.III.6, who suffered kidney disease, and 31.III.8 and 31.III.1.

Only four subjects had electrocardiographically detectable LVH, evaluated by the point system of Romhilt and Estes $^{19}$; these subjects had also shown an LVWT of $\geqslant 13$ $\mathrm{mm}$ (table 1). Additionally, 1.III.6 had had a pacemaker inserted. A further 12 subjects had other ECG abnormalities often noted in HCM, while their LVWT values varied between 10 and $40 \mathrm{~mm}$. Of the remaining 15 subjects who did not display any ECG abnormalities, nine also did not meet the echocardiographic diagnostic criterion, while two had not been investigated by echocardiography and three were less than 16 years old (table 1 ).
Disease penetrance among all mutation carriers was $61 \%$ (19/35 subjects), based on subjects older than 16 years for whom an LVWT of $\geqslant 13 \mathrm{~mm}$ was measured (32 subjects, table 1) or who were diagnosed with HCM at necropsy (three subjects).

The symptomatic presentation of mutation carriers varied. Six of the 35 subjects for whom data were available complained of syncope or presyncope (1.II.2, 1.II.8, 1.III.6, 1.III.8, 31.III.4, SB902), three experienced dyspnoea (1.II.3, 1.III.8, 4.II.1), four suffered palpitations (1.II.8, 4.I.1, 31.III.1, 38.II.4), while six experienced both dyspnoea and palpitations (1.III.6, 1.IV.2, 10.II.1, SB902, SB983, SB995). Five subjects experienced angina (1.II.8,

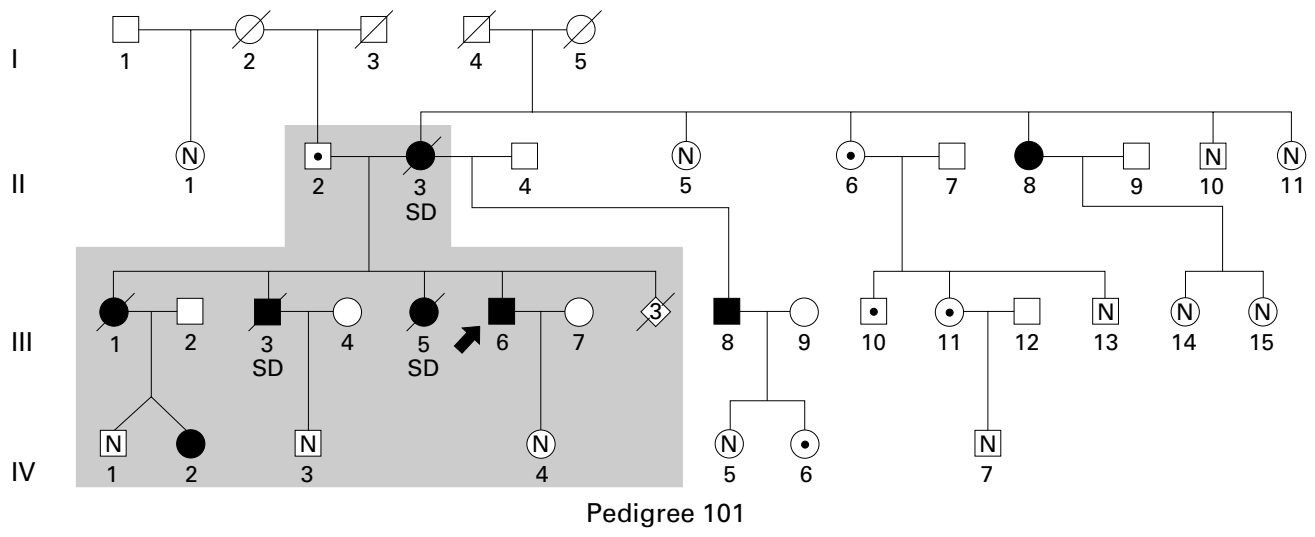

I

II

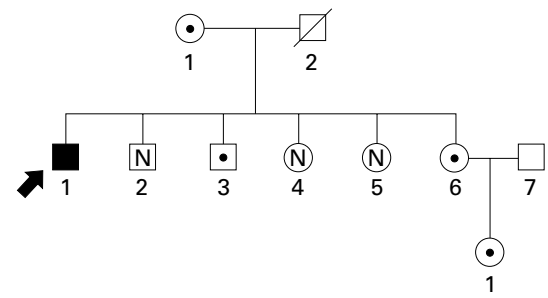

Pedigree 104

I

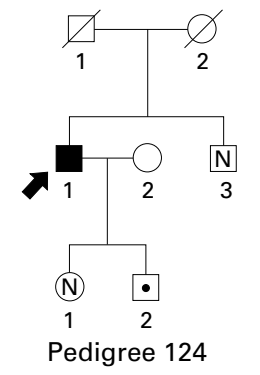

।

II

III

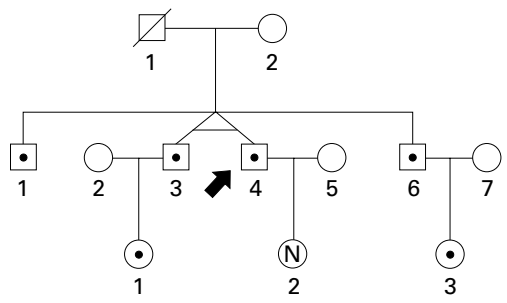

Pedigree 138

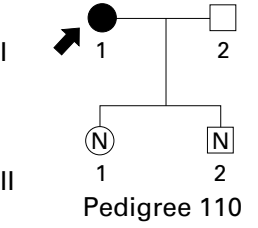

$\square \bigcirc$ Not investigated

$\mathrm{N}$ (N) Clinically unaffected, mutation absent

- Clinically unaffected, mutation present

Clinically affected, mutation present

SD Sudden death

$\diamond$ Unknown gender

Proband

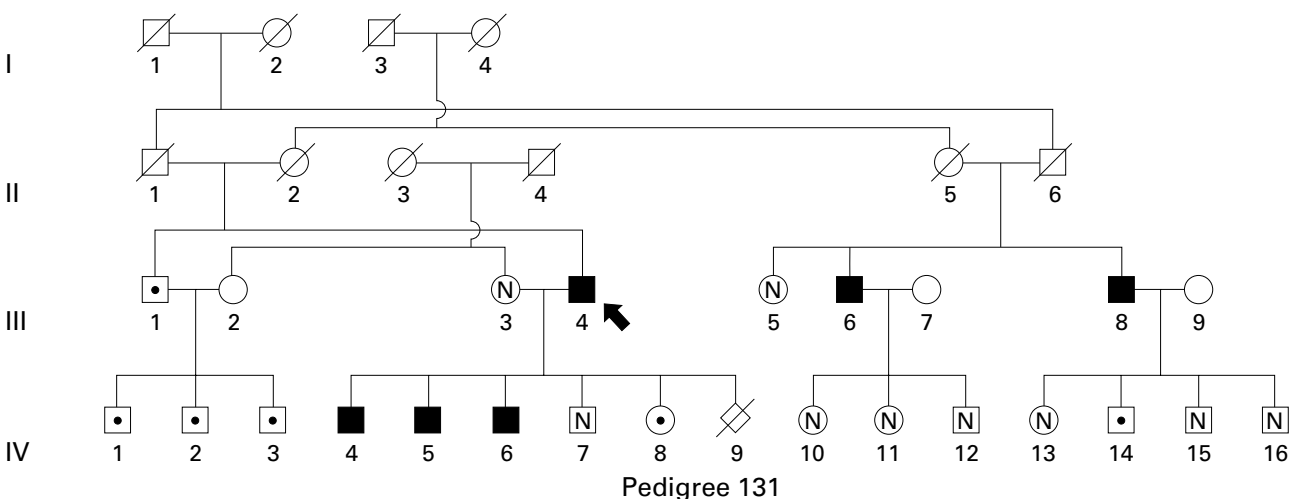

Figure 1 Pedigrees in which the MYH7 A797T mutation segregated. The genotypic and phenotypic status of subjects is indicated in the key. Kindred $101 a$ is shown on a shaded background. 
1.III.6, 38.II.4, SB902, SB995), two suffered cardiac failure (1.II.2, 4.I.1), while three subjects developed both angina and cardiac failure (1.II.3, 4.II.1, SB983). However, further investigation of possible underlying ischaemic heart disease was not undertaken. Of the 35 clinically assessed mutation carriers, 19 subjects, of whom four were under 16 years of age, had no reported symptoms.

Proband 38.II.4 (fig 1) presented with chest pain and palpitations at the age of 38 years. He showed an LVWT of $12.7 \mathrm{~mm}$ at both the IVS and the left PW, and while his ECG tracings showed abnormal repolarisation and increased voltages (table 1), they did not meet the diagnostic criterion of $\mathrm{LVH} .{ }^{19}$ However, taken together, the mild LVH, non-specific ECG changes, and symptoms, were likely to be HCM related. In contrast, his twin brother, 38.II.3, who was shown to be identical by band sharing on GTG fingerprinting, was symptom free, and exhibited an LVWT of $10 \mathrm{~mm}$ at the PW and $9 \mathrm{~mm}$ at the IVS. Although on ECG, 38.II.3 exhibited the same repolarisation abnormality and increased voltages as his twin, all other parameters, including similar blood pressure values, were normal. It was established from the proband's history that, while he had always been physically active, playing rugby football in high school and continuing to participate in competitive recreational cycling at the age of 38 years, his twin brother had generally avoided sport and exercise.

In kindred 101a, three of the four offspring of parents 1.II.2 and 1.II.3 had suffered SCD (fig 1). These events occurred in 1.III.1, 1.III.3, and 1.III.5 at 26 years, 24 years, and 17 years of age, while they were walking, playing tennis, and during a period of heightened emotion, respec- tively. Three of their mother's pregnancies had terminated in spontaneous abortions and she suffered SCD while sedentary at the age of 58 years. In contrast, no sudden, or disease related, deaths were known to have occurred in the recent generations of any of the other pedigrees, including the remainder of pedigree 101 . In pedigree 131 , one pregnancy in 31.II.3 had miscarried. The hypertensive father of the proband in pedigree 138 had died at 58 years of myocardial infarction, probably resulting from ischaemic heart disease. The Kaplan-Meier product limit curves for survival of the subjects with the MYH7 A797T mutation belonging to pedigree 101 and that of the rest of the families with this mutation, as well as that of South African families carrying the R92W mutation in TNNT2, ${ }^{3}$ are shown in fig 2 . While survival in the other pedigrees was unimpeded, survival in pedigree 101 was comparable to that of subjects bearing the TNNT2 R92W mutation with its previously described poor prognosis.

In this study, we have investigated the clinical phenotype associated with the HCM causative MYH7 A797T mutation in 35 mutation carriers, of whom 32 were members of six different apparently unrelated pedigrees, and three were from families who could not be traced. The present study shows that, although the initial impressions were to the contrary, ${ }^{16}$ the MYH7 A797T mutation was generally associated with a good prognosis and normal life span, except in kindred 101a (figs 1 and 2).

However, despite the usually favourable prognosis, the mutation was generally associated with echocardiographically detectable to overt hypertrophy, which was often marked (table 1). Two mutation carriers, SB902 and

Table 1 Echocardiographic and electrocardiographic features present in subjects carrying the A797T MYH7 mutation

\begin{tabular}{|c|c|c|c|c|c|c|c|c|c|c|c|c|}
\hline \multirow[b]{2}{*}{ Subject No } & \multirow[b]{2}{*}{$\begin{array}{l}\text { Sex/age } \\
(y)\end{array}$} & \multicolumn{3}{|c|}{ Echocardiographic } & \multicolumn{7}{|c|}{ Electrocardiographic } & \multirow[b]{2}{*}{$B P$} \\
\hline & & $\begin{array}{l}I V S \\
(\mathrm{~mm})\end{array}$ & $\begin{array}{l}P W \\
(\mathrm{~mm})\end{array}$ & $\begin{array}{l}\text { Area of } \\
\text { hypertrophy }\end{array}$ & $A S H$ & $S A M$ & Abn rep & Inc volts & $\begin{array}{l}\text { Abn } Q \\
\text { waves }\end{array}$ & $\uparrow$ Atria & $L V H$ & \\
\hline 1.II. 2 & $M / 58$ & 12 & 10 & Ivs + apex & $\mathrm{y}$ & $\mathrm{n}$ & $\mathrm{y}$ & $\mathrm{n}$ & $\mathrm{n}$ & $\mathrm{n}$ & $\mathrm{n}$ & $130 / 80$ \\
\hline 1.II. 3 & $\mathrm{~F} / 55$ & 22 & 10 & Ivs & $\mathrm{y}$ & $\mathrm{n}$ & $\mathrm{y}$ & $\mathrm{n}$ & $\mathrm{y}$ & $\mathrm{y}$ & $\mathrm{n}$ & $140 / 80$ \\
\hline 1.II. 6 & $\mathrm{~F} / 53$ & 9 & 8 & NA & $\mathrm{n}$ & $\mathrm{n}$ & $\mathrm{n}$ & $\mathrm{n}$ & $\mathrm{n}$ & $\mathrm{n}$ & $\mathrm{n}$ & $110 / 80$ \\
\hline 1.II. 8 & $\mathrm{~F} / 47$ & 14 & 9 & Ivs & $\mathrm{y}$ & $\mathrm{n}$ & $\mathrm{n}$ & $\mathrm{n}$ & $\mathrm{n}$ & $\mathrm{n}$ & $\mathrm{n}$ & $150 / 90$ \\
\hline 1.III.6 & $\mathrm{M} / 34$ & 36 & 13 & Ivs + pw & $\mathrm{y}$ & $\mathrm{y}$ & $\mathrm{PM}$ & PM & $\mathrm{PM}$ & PM & PM & $140 / 80$ \\
\hline 1.III.8 & $\mathrm{M} / 29$ & 13 & 13 & Ivs + pw & $\mathrm{n}$ & $\mathrm{n}$ & $\mathrm{y}$ & $\mathrm{n}$ & $\mathrm{n}$ & $\mathrm{n}$ & $\mathrm{n}$ & $120 / 70$ \\
\hline 1.III. 10 & $\mathrm{M} / 30$ & NI & NI & NI & NI & NI & NI & NI & NI & NI & NI & NI \\
\hline 1.III. 11 & $\mathrm{~F} / 27$ & 10 & 8 & NA & $\mathrm{n}$ & $\mathrm{n}$ & $\mathrm{n}$ & $\mathrm{n}$ & $\mathrm{n}$ & $\mathrm{n}$ & $\mathrm{n}$ & $110 / 70$ \\
\hline 1.IV.2 & $\mathrm{F} / 14$ & 13 & 9 & Ivs & $\mathrm{y}$ & $\mathrm{y}$ & $\mathrm{y}$ & $\mathrm{n}$ & $\mathrm{y}$ & $\mathrm{n}$ & $\mathrm{n}$ & $100 / 50$ \\
\hline $1 . \mathrm{IV} .6$ & $\mathrm{~F} / 8$ & 6 & 6 & NA & $\mathrm{n}$ & $\mathrm{n}$ & $\mathrm{n}$ & $\mathrm{n}$ & $\mathrm{n}$ & $\mathrm{n}$ & $\mathrm{n}$ & na \\
\hline 4.I.1 & $\mathrm{F} / 70$ & 8 & 8 & NA & NA & $\mathrm{n}$ & na & na & na & na & na & na \\
\hline 4.II. 1 & $\mathrm{M} / 48$ & 24 & 12 & Ivs + pw & $\mathrm{y}$ & $\mathrm{y}$ & na & na & na & na & na & na \\
\hline 4.II. 3 & $\mathrm{M} / \mathrm{na}$ & NI & NI & NI & NI & NI & NI & NI & NI & NI & NI & NI \\
\hline 4.II. 6 & $\mathrm{~F} / 33$ & 9 & 9 & NA & NA & $\mathrm{n}$ & $\mathrm{n}$ & $\mathrm{n}$ & $\mathrm{n}$ & $\mathrm{n}$ & $\mathrm{n}$ & $120 / 80$ \\
\hline 4.III.1 & $\mathrm{F} / 10$ & NI & NI & NI & NI & NI & NI & NI & NI & NI & NI & NI \\
\hline$\overline{10 . I .1}$ & $\mathrm{~F} / 32$ & 24 & 10 & Ivs & $\mathrm{y}$ & $\mathrm{n}$ & na & na & na & na & na & $100 / 70$ \\
\hline 24.II.1 & $\mathrm{M} / 56$ & 28 & 16 & Ivs & $\mathrm{y}$ & $\mathrm{y}$ & $\mathrm{y}$ & $\mathrm{y}$ & $\mathrm{n}$ & $\mathrm{n}$ & $\mathrm{n}$ & $150 / 80$ \\
\hline 24.III. 2 & $\mathrm{M} / 29$ & 12 & 12 & Ivs + pw & NA & $\mathrm{n}$ & $\mathrm{n}$ & $\mathrm{n}$ & $\mathrm{n}$ & $\mathrm{n}$ & $\mathrm{n}$ & $130 / 80$ \\
\hline 31.III. 1 & $\mathrm{M} / 52$ & 10 & 10 & NA & $\mathrm{n}$ & $\mathrm{n}$ & $\mathrm{y}$ & $\mathrm{n}$ & $\mathrm{n}$ & $\mathrm{n}$ & $\mathrm{n}$ & $130 / 95$ \\
\hline 31.III. 4 & $\mathrm{M} / 51$ & 18 & 11 & Ivs + apex & $\mathrm{y}$ & $\mathrm{n}$ & $\mathrm{y}$ & $\mathrm{n}$ & $\mathrm{n}$ & $\mathrm{n}$ & $\mathrm{n}$ & $125 / 85$ \\
\hline 31.III. 6 & $\mathrm{M} / 57$ & 13 & 12 & $\mathrm{Ivs}+\mathrm{apex}+\mathrm{pw}$ & $\mathrm{n}$ & $\mathrm{n}$ & $\mathrm{y}$ & $\mathrm{n}$ & $\mathrm{y}$ & $\mathrm{n}$ & $\mathrm{n}$ & $160 / 110$ \\
\hline 31.III. 8 & $\mathrm{M} / 54$ & 13 & 12 & $\mathrm{Ivs}+\mathrm{apex}+\mathrm{pw}$ & $\mathrm{n}$ & $\mathrm{n}$ & $\mathrm{y}$ & $\mathrm{n}$ & $\mathrm{y}$ & $\mathrm{y}$ & $\mathrm{y}$ & $150 / 100$ \\
\hline 31.IV.1 & $\mathrm{M} / 20$ & 10 & 10 & NA & $\mathrm{n}$ & $\mathrm{n}$ & $\mathrm{y}$ & $\mathrm{n}$ & $\mathrm{n}$ & $\mathrm{n}$ & $\mathrm{n}$ & $130 / 80$ \\
\hline 31.IV.2 & $\mathrm{M} / 18$ & 9 & 10 & NA & $\mathrm{n}$ & $\mathrm{n}$ & $\mathrm{n}$ & $\mathrm{n}$ & $\mathrm{n}$ & $\mathrm{n}$ & $\mathrm{n}$ & $120 / 60$ \\
\hline 31.IV.3 & $\mathrm{M} / 15$ & 7 & 7 & $\mathrm{NA}$ & NA & $\mathrm{n}$ & $\mathrm{n}$ & $\mathrm{n}$ & $\mathrm{n}$ & $\mathrm{n}$ & $\mathrm{n}$ & $120 / 75$ \\
\hline 31.IV.4 & $\mathrm{M} / 23$ & 26 & 11 & $\mathrm{Ivs}+\mathrm{pw}$ & $\mathrm{n}$ & $\mathrm{y}$ & $\mathrm{y}$ & $\mathrm{n}$ & $\mathrm{n}$ & $\mathrm{n}$ & $\mathrm{y}$ & $130 / 60$ \\
\hline 31.IV.5 & $\mathrm{M} / 22$ & 23 & 8 & Ivs & $\mathrm{n}$ & $\mathrm{y}$ & $\mathrm{n}$ & $\mathrm{n}$ & $\mathrm{n}$ & $\mathrm{n}$ & $\mathrm{n}$ & $120 / 70$ \\
\hline 31.IV.6 & $\mathrm{M} / 19$ & 40 & na & Ivs + apex & $\mathrm{y}$ & $\mathrm{y}$ & $\mathrm{y}$ & $\mathrm{n}$ & $\mathrm{n}$ & $\mathrm{n}$ & $\mathrm{n}$ & $110 / 70$ \\
\hline 31.IV. 8 & $\mathrm{~F} / 15$ & 10 & 10 & NA & NA & $\mathrm{n}$ & $\mathrm{n}$ & $\mathrm{n}$ & $\mathrm{n}$ & $\mathrm{n}$ & $\mathrm{n}$ & $140 / 90$ \\
\hline 31.IV.14 & $\mathrm{M} / 27$ & 9 & 9 & NA & $\mathrm{n}$ & $\mathrm{n}$ & $\mathrm{n}$ & $\mathrm{n}$ & $\mathrm{n}$ & $\mathrm{n}$ & $\mathrm{n}$ & $140 / 90$ \\
\hline 38.II.1 & $\mathrm{M} / 40$ & na & na & na & na & na & $\mathrm{n}$ & $\mathrm{n}$ & $\mathrm{n}$ & $\mathrm{n}$ & $\mathrm{n}$ & na \\
\hline 38.II.3 & $\mathrm{M} / 38$ & 9 & 10 & NA & NA & $\mathrm{n}$ & $\mathrm{y}$ & $\mathrm{y}$ & $\mathrm{n}$ & $\mathrm{n}$ & $\mathrm{n}$ & $140 / 90$ \\
\hline 38.II. 4 & $\mathrm{M} / 38$ & 12.7 & 12.7 & Ivs + apex & $\mathrm{n}$ & $\mathrm{n}$ & $\mathrm{y}$ & $\mathrm{y}$ & $\mathrm{n}$ & $\mathrm{n}$ & $\mathrm{n}$ & $145 / 90$ \\
\hline 38.II. 6 & $\mathrm{M} / 35$ & na & na & na & na & na & $\mathrm{n}$ & $\mathrm{n}$ & $\mathrm{n}$ & $\mathrm{n}$ & $\mathrm{n}$ & na \\
\hline 38.III. 1 & $\mathrm{~F} / 12$ & NI & NI & NI & NI & NI & NI & NI & NI & NI & NI & NI \\
\hline 38. III. 3 & $\mathrm{~F} / 13$ & na & na & na & na & na & $\mathrm{n}$ & $\mathrm{n}$ & $\mathrm{n}$ & $\mathrm{n}$ & $\mathrm{n}$ & na \\
\hline & $\mathrm{F} / 27$ & $22^{\star}$ & $13^{\star}$ & Ivs + pw & $\mathrm{y}$ & $\mathrm{y}$ & $\mathrm{y}$ & $\mathrm{n}$ & $\mathrm{y}$ & $\mathrm{y}$ & $\mathrm{y}$ & $110 / 60$ \\
\hline $\mathrm{sB}_{983}$ & $\mathrm{~F} / 62$ & $16^{\star}$ & $16^{\star}$ & Ivs + pw & $\mathrm{y}$ & $\mathrm{y}$ & $\mathrm{y}$ & $\mathrm{n}$ & $\mathrm{y}$ & $\mathrm{y}$ & $\mathrm{y}$ & $140 / 70$ \\
\hline sB 995 & $\mathrm{M} / 49$ & 25 & 15 & Ivs + pw & $\mathrm{y}$ & $\mathrm{y}$ & $\mathrm{n}$ & $\mathrm{n}$ & $\mathrm{n}$ & $\mathrm{n}$ & $\mathrm{n}$ & $140 / 85$ \\
\hline
\end{tabular}

Abn $\mathrm{Q}$ waves = abnormal $\mathrm{Q}$ waves, Abn rep = abnormal repolarisation, Age = age at diagnosis, ASH = asymmetrical septal hypertrophy, $\uparrow$ Atria $=$ enlarged atria, BP $=$ blood pressure $(\mathrm{mm} \mathrm{Hg})$, Inc volts $=$ increased voltages, IVS $(\mathrm{mm})=$ maximum end diastolic interventricular septal thickness in mm, Ivs $=$ interventricular septum, $\mathrm{LVH}=$ left ventricular hypertrophy by Romhilt and Este's criteria, PW $(\mathrm{mm})=$ maximum end diastolic posterior wall thickness in mm, pw $=$ posterior left ventricular free wall, $\mathrm{SAM}=$ systolic anterior motion of the mitral valve, $\mathrm{y}=$ feature present, $\mathrm{n}=$ feature absent, $\mathrm{NA}=$ not applicable, $\mathrm{na}=\mathrm{records}$ not available, $\mathrm{NI}=\mathrm{not}$ investigated clinically, ${ }^{\star}=$ post myectomy values. Subjects under 16 years old are underlined. 
SB983, had undergone septal myectomy, to reduce outflow tract obstruction resulting from their cardiac hypertrophy, as well as mitral valve replacement. The mean (SD) LVWT in all the pedigrees, excluding pedigree 101, was 17.8 (SD $8.7 \mathrm{~mm}$ ), with a range of $8-40 \mathrm{~mm}$ for subjects over 16 years old (table 1). In pedigree 101, the mean (SD) LVWT was similar to these values, namely 16.6 (SD $9.6 \mathrm{~mm}$ ), with a range of 9-36 $\mathrm{mm}$, which was shown by ANOVA to have no statistically significant difference from the rest of the families with this mutation.

When considering survival, the only exception to the good prognosis associated with the MYH7 A797T mutation was in pedigree 101 . Here, the high frequency of SCD was restricted to kindred 101a (figs 1 and 2), in which haplotyping studies had previously indicated that the parents of the proband, both of whom carried the MYH7 A797T mutation, shared a common ancestor. ${ }^{17}$ Three of the four offspring of the related mutation carrier parents in kindred 101a had died suddenly, before the age of 27 years. It is unlikely that these deaths resulted from a dosage effect of the mutant myosin protein, as at least two of them (1.III.1 and 1.III.3) could not have been homozygous mutation carriers by virtue of their non-carrier offspring (fig 1). In contrast to the poor prognosis observed in kindred 101a, the mutation was not associated with any disease related deaths in the rest of pedigree 101, nor in the other families carrying the MYH7 A797T mutation (figs 1 and 2).

The data generated from genotype-phenotype assessments has led to speculation that HCM is not a simple monogenic disorder, as frequently the clinical manifestations and course of the disease differ even between subjects in the same family. ${ }^{14}{ }^{15}$ For example, in the present study, there was marked variation in the degree of LVWT associated with the MYH7 A797T mutation within members of the same pedigree (table 1), indicating that the phenotypic expression of HCM causing mutations is modulated by additional factors. Whether these factors are genetic or environmental, and what the nature of the interplay between these factors and the major HCM causing mutations are, has been a topic of discussion in recent papers. ${ }^{15} 2324$

It can be speculated that the distinctive survival curve seen in pedigree 101 may result from the influence of genetic factors. In view of the shared ancestry of the parents in the nuclear family, it is possible that their offspring, who were deduced not to be MYH7 A797T homozygotes, may have been homozygous for susceptibility alleles at other loci that play a role in modulating expression of the main disease causative gene. Further support for the influence of deleterious homozygosity is that while the proband, 1.III.6, the remaining living child of parents sharing a common ancestor, showed overt septal hypertrophy $(36 \mathrm{~mm})$, and had undergone pacemaker implantation, his half brother, 1.III.8, showed moderate hypertrophy $(13 \mathrm{~mm})$. However, as the degree of relatedness of the parents in kindred 101a could not be established, this proposal remains speculative. It is unlikely that environmental factors alone could account for the malignant phenotype seen only in kindred 101a, as the clinical course associated with the founder mutation was benign in all other affected families, whose individual members were exposed to varied environments and life style.

Evidence that environmental factors may also play a role in modulating the expression of main locus HCM causing mutations is provided by the divergent clinical presentation associated with the MYH7 A797T mutation in the identical twin brothers in pedigree 138 . Whereas, the physically active twin, 38.II.4, was symptomatic and showed an LVWT of $12.7 \mathrm{~mm}$, with the hypertrophy appearing concentric and concentrated around the apex, the LVWT in his asymptomatic brother, 38.II.3, measured only 10 $\mathrm{mm}$. Earlier studies have also documented heterogeneity in the clinical expression of HCM in MZ twins, ${ }^{24}{ }^{25}$ but this is the first report of $\mathrm{MZ}$ twins genotyped for a specific HCM causing mutation, in which clinical differences may directly relate to exercise. The influence of physical activity on the expression of the hypertrophic phenotype in HCM has been a cause of speculation, as exercise is known to produce the hypertrophy seen in "athletes' heart". ${ }^{26}$ However, although these twins were considered genetically identical, it cannot be excluded that epigenetic factors, or indeed environmental influences other than exercise, could also have played a role in the dissimilar development of hypertrophy.

Currently, genotype-phenotype correlation studies provide the best available route to informed and accurate prognosis for improved patient management and risk stratification, with the caveat that these correlations should be based on substantial numbers of subjects drawn from the relevant ethnic group. In addition, it may also be prudent to consider

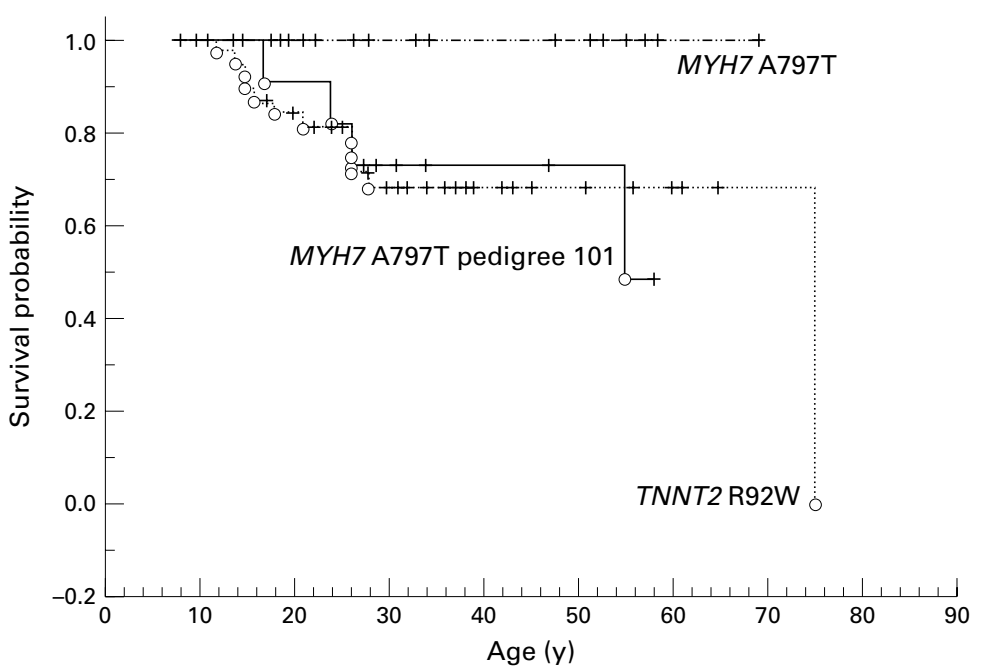

Figure 2 A comparison of Kaplan-Meier product limit curves for survival in subjects carrying the MYH7 A797T mutation and those carrying the previously reported TNNT2 R92W mutation. ${ }^{17}$ Survival data were combined and plotted for all MYH7 A797T families except for pedigree 101. Survival in pedigree 101 was similar to that of subjects with the TNNT2 R92W mutation ( $p=0.9)$, but was significantly worse than in the other families with the MYH7 A797T mutation ( $p=0.024)$. 
the possible effects of shared ancestry and exercise on the clinical expression of a specific mutation, especially in subpopulation groups with known founder effects.

Although these examples of divergent phenotypic expression in kindred 101a and the twins in pedigree 138 are based on small numbers, they lend support to the notion that HCM is not a simple monogenic disorder and that both genetic and environmental factors are modifiers of the disease phenotype. A strategy followed in studies of disease phenotypes with multifactorial aetiology is to reduce the complexity of analysis by investigating genetically homogeneous subjects. The presence of the founder MYH7 A797T mutation suggests that the families harbouring it share a degree of common ancestry. We therefore propose that the presence of this HCM causing mutation with incomplete penetrance, in a substantial group of related people, provides an opportunity to investigate the role of additional factors involved in the development of the disease phenotype. Only when these factors are known will the puzzling variability in the clinical expression which is a feature of HCM mutations, and the true pathophysiology of this disease, be understood.

We wish to thank the patients and their families for participating in this study, as well as the physicians who referred patients and collected samples. The work was supported by the South African Medical Research Council and the Harry and Doris Crossley Fund of the University of Stellenbosch.

JOHANNA MOOLMAN-SMOOK* WILLEM DE LANGE* VALERIE CORFIELD* PAUL BRINK†

${ }^{\star}$ US/MRC Centre for Molecular and Cellular Biology, Department of Medical Biochemistry, University of Stellenbosch Medical School, PO Box 19063, Tygerberg 7505, South Africa

tDepartment of Internal Medicine, University of Stellenbosch Medical School and Tygerberg Hospital, Tygerberg, South Africa

Correspondence to: Dr Corfield, VCl@gerga.sun.ac.za

1 Maron BJ, Gardin JM, Flack JM, Gidding SS, Kurosaki TT, Bild DE. Prevalence of hypertrophic cardiomyopathy in a general population of
young adults: echocardiographic analysis of 4111 subjects in the CARDIA young adults: echocardiographic and

2 McKenna WJ, Watkins HC. Hypertrophic cardiomyopathy. In: Scriver CR, Beaudet AL, Sly WS, Valle D. eds. The metabolic and molecular bases of inherited disease. Vol III, 7th ed. New York: McGraw-Hill Health Professions Division, 1995:4253-72.

3 Moolman JC, Corfield VA, Posen B, Ngumbela K, Seidman C, Brink PA, Watkins H. Sudden death due to troponin T mutations. $\mathcal{F}$ Am Coll Cardiol 1997;29:549-55

4 Watkins H, McKenna WJ, Thierfelder L, Suk HJ, Anan R, O’Donoghue A, Spirito P, Matsumori A, Moravec C, Seidman JG, Seidman CE. Mutations in the genes for cardiac troponin $\mathrm{T}$ and $\alpha$-tropomyosin in hypertrophic cardiomyopathy. N Engl F Med 1995;332:1058-64.

5 Bonne G, Carrier L, Richard P, Hainque B, Schwartz K. Familial hypertrophic cardiomyopathy: from mutations to functional defects. Circ Res 1998;83:580-93.
6 Watkins H, Rosenzweig T, Hwang DS, Levi T, McKenna W, Seidman CE, Seidman JG. Characteristics and prognostic implications of myosin Seidman JG. Characteristics and prognostic implications of myosin missense mutations

7 Niimura H, Bachinski LL, Sangwatanaroj S, Watkins H, Chudley AE, McKenna W, Kristinsson A, Roberts R, Sole M, Maron BJ, Seidman JG, Seidman CE. Mutations in the gene for cardiac myosin-binding protein C and late-onset familial hypertrophic cardiomyopathy. $N$ Engl f Med 1998;338:1248-57.

8 Yu B, French JA, Carrier L, Jeremy RW, McTaggart DR, Nicholson MR, Hambly B, Semsarian C, Richmond DR, Schwartz K, Trent RJ. Molecular pathology of familial hypertrophic cardiomyopathy caused by mutations in the cardiac myosin binding protein C gene. $\mathcal{f}$ Med Genet 1998;35:205-10.

9 Yamauchi-Takihara K, Nakajima-Taniguchi C, Matsui H, Fujio Y, Kunisada K, Nagata S, Kishimoto T. Clinical implications of hypertrophic cardiomyopathy associated with mutations in the alpha-tropomyosin gene. Heart 1996;76:63-5.

10 Flavigny J, Richard P, Isnard R, Carrier L, Charron P, Bonne G, Forissier JF, Desnos M, Dubourg O, Komajda M, Schwartz K, Hainque B. Identification of two novel mutations in the ventricular regulatory myosin light chain gene (MYL2) associated with familial and classical forms of light chain gene (MYL2) associated with familial and class
hypertrophic cardiomyopathy. f Mol Med 1998;76:208-14.

11 Kimura A, Harada H, Park JE, Hishi H, Satoh M, Takahashi M, Hiroi S, Sasaoka T, Ohbuchi N, Nakamura T, Koyanagi T, Hwang TH, Choo JA, Chung KS, Hasegawa A, Nagai R, Okazaki O, Nakamura H, Matsuzaki M, Sakamoto T, Toshima H, Koga Y, Imaizumi T, Sasazuki T. Mutations in the cardiac troponin I gene associated with hypertrophic cardiomyopathy. Nat Genet 1997;16:379-82.

12 Schwartz K, Carrier L, Cuicheney P, Komajda M. Molecular basis of familial cardiomyopathies. Circulation 1995;91:532-40.

13 Epstein ND, Cohn GM, Cyran F, Fananapazir L. Difference in clinical expression of hypertrophic cardiomyopathy associated with two distinct mutations in the $\beta$-myosin heavy chain gene: a $908 \mathrm{Leu}-\mathrm{Val}$ mutation and a 403 Arg-Gin mutation. Circulation 1992;86:345-52.

14 Posen BM, Moolman JC, Corfield VA, Brink PA. Clinical and prognostic evaluation of familial hypertrophic cardiomyopathy in two South African families with different cardiac $\beta$ myosin heavy chain gene mutations. $\mathrm{Br}$ Heart F 1995; 74:40-6.

15 Coviello DA, Maron BJ, Spirito P, Watkins H, Vosberg HP, Thierfelder L, Schoen FJ, Seidman JG, Seidman CE. Clinical features of hypertrophic cardiomyopathy caused by mutation of a "hot spot" in the alphacardiomyopathy caused by mutation of a "hot spot
tropomyosin gene. $\mathcal{F A m}$ Coll Cardiol 1997;29:635-40.

16 Moolman JC, Brink PA, Corfield VA. Identification of a novel Ala797Thr mutation in exon 21 of MYH7. Hum Mutat 1995;6:197-8.

17 Moolman-Smook JC, De Lange WJ, Bruwer ECD, Brink PA, Corfield VA. The origins of hypertrophic cardiomyopathy-causing mutations in two South African sub-populations: a unique profile of both independent and founder events. Am F Hum Genet 1999;65:1308-20.

18 Corfield VA, Moolman JC, Martel R, Brink PA. Polymerase chain reactionbased detection of MN blood group-specific sequences in the human genome. Transfusion 1993;33:119-24.

19 Romhilt DW, Estes EH. A point score system for the ECG diagnosis of left ventricular hypertrophy. Am Heart f 1968;75:752-8.

20 Kaplan EL, Meier P. Nonparametric estimation from incomplete observations. F Am Stat Assoc 1958;53:457-81.

21 Southern E. Detection of specific sequences among DNA fragments separated by gel electrophoresis. f Mol Biol 1975;98:503-17.

22 Schäfer R, Zischler H, Epplen JT. (CAG), a very informative oligonucleotide probe for DNA fingerprinting. Nucleic Acids Res 1988;16:5196.

23 Tesson F, Dufour C, Moolman JC, Carrier L, Al-Mahdavi S, Chojnowska L Dubourg O, Soubrier F, Brink P, Komajda M, Guicheney P, Schwartz K, Feingold J. The influence of the angiotensin- 1 converting enzyme genotype in familial hypertrophic cardiomyopathy varies with the disease gene mutation. 7 Mol Cell Cardiol 1996;29:831-8.

24 Ko YL, Tang TK, Chen JJ, Hsieh YY, Wu CW, Lien WP. Idiopathic hypertrophic cardiomyopathy in identical twins. Morphological heterogeneity of the left ventricle. Chest 1992;102:783-5.

25 Reid JM, Houston AB, Lundmark E. Hypertrophic cardiomyopathy in identical twins. Br Heart $\mathcal{F}$ 1989;62:384-8.

26 Woodiwiss AJ, Norton G. Exercise-induced cardiac hypertrophy is associated with an increased myocardial compliance. 7 Appl Physiol 1995;78:1303-11.

\section{Germline and somatic mosaicism in achondroplasia}

EDITOR-We describe a sib recurrence in achondroplasia with parents of normal stature. Both affected offspring carry the same causal mutation (G1138C) in the fibroblast growth factor receptor 3 (FGFR3) gene. Despite having no clinical features of achondroplasia, a proportion of the mother's peripheral blood leucocytes also contained the mutant FGFR3 allele. We conclude she is a germline and somatic mosaic for achondroplasia and that both children have inherited the condition from her. To our knowledge, this is the first confirmed case of germline mosaicism in achondroplasia.

\section{F Med Genet 2000;37:956-958}

Achondroplasia is the commonest form of short limbed dwarfism (birth incidence estimated at between 1:10 000 and $1: 70000)^{1}$ and is transmitted as an autosomal dominant trait. As is often the case among dominant traits, a high proportion of cases are new mutations but achondroplasia is unusual in that the great majority are caused by one of two mutations at the same nucleotide in the transmembrane domain of the FGFR3 gene (G1138A transition and $\mathrm{G} 1138 \mathrm{C}$ transversion). ${ }^{1}$ In common with other FGFR3 mutations which cause skeletal dysplasia, the pathogenic effect of the achondroplasia mutations is thought to be altered mitogenesis and/or differentiation owing to constitutive activation of the receptor. ${ }^{2}$ There is a marked paternal age effect in achondroplasia and it has recently been shown that new mutations in achondroplasia are almost exclusively of paternal origin. ${ }^{3}$ We received 
peripheral blood DNA from a family with two children with achondroplasia; both parents were of normal stature. They had a total of four children of whom the second and fourth were affected. The mother was 27 years of age and the father 53 years at the birth of their second affected child. Our first thoughts in this case, taking into account the age of the father, were that the affected sibs were the result of two independent new mutations in the paternal germline, as would be expected to occur by chance as a very rare event.

To determine the FGFR3 mutation(s) in the affected offspring, blood was collected from the affected children and from both parents. DNA was extracted and exon 10 of the FGFR3 gene was amplified and products were digested with the restriction enzymes $B f m \mathrm{I}$ and $M s p \mathrm{I}$. The G1138A transition creates a restriction site for $B f m I$ whereas the G1138C transversion creates a restriction site for $M s p I$. Analysis showed that both children were heterozygous for the rare G1138C transversion. The father did not have the mutation in his blood but, surprisingly, the mother did. However, the ratio of the G1138C allele compared to the wild type allele was less than the $1: 1$, which would be expected for a straightforward heterozygote (fig 1). The relative proportion of the $\mathrm{G} 1138 \mathrm{C}$ allele in the mother's blood leucocytes was determined using primer extension ${ }^{4}$ (fig 1) followed by densitometry. The proportion of the mutant allele in the mother was found to be $28 \%$. She has a height of $169 \mathrm{~cm}$, span of $171 \mathrm{~cm}$, upper segment/lower segment 0.09 , left hand $17.6 \mathrm{~cm}$, and head circumference of $58 \mathrm{~cm}$. Apart from her slightly larger head size and mild obesity her appearance is normal.

We conclude that, despite her normal appearance, the mother is a germline and somatic mosaic for the G1138C mutation and both her affected children have inherited the mutant allele from her. Given the mother's relatively high proportion of mutant alleles, her lack of phenotypic expression is surprising; a hypochondroplasia-like phenotype, which is less severe than achondroplasia, might have been expected. The most likely explanation for this is the tissue specific distribution of the mosaicism, although the mutant allele is present in $28 \%$ of her peripheral blood leucocytes it may be at lower levels in her chondrocytes.

Germline and somatic mosaicism are both reasonably common features of genetic disorders. For example, in Duchenne muscular dystrophy and osteogenesis imperfecta, $15 \%$ and $6 \%$ of cases, respectively, inherit the condition from a detectably mosaic parent. ${ }^{5}$ Germline mosaicism results from a mutation in gamete precursors which then continue to divide, whereas combined germline and somatic mosaicism arises when the mutation occurs very early in development before the germline and somatic lineages have separated. As achondroplasia is a common condition which arises from a highly mutable nucleotide, high frequencies of mosaicism might have been expected. Surprisingly, the frequency of germline mosaicism as evidenced by sib recurrence is very low. A few cases of recurrence have been reported, ${ }^{5}$ but so infrequently that it has been calculated that they could be accounted for by independent mutations alone. Clinical reports of somatic mosaicism in achondroplasia are also extremely rare. ${ }^{7}$ For some reason, somatic and germline mosaics occur much more rarely in achondroplasia than in many other dominant traits. One possibility is that for reasons as yet unclear, FGFR3 nucleotide 1138 is only hypermutable in the male germline. Alternatively, there could be somatic selection against cells carrying the mutant allele. Interestingly, Apert syndrome, which is mainly caused by either of two point mutations in FGFR2, also seems to have low levels of germline mosaicism. ${ }^{5}$ This apparent low incidence of somatic mutation is at variance with recent

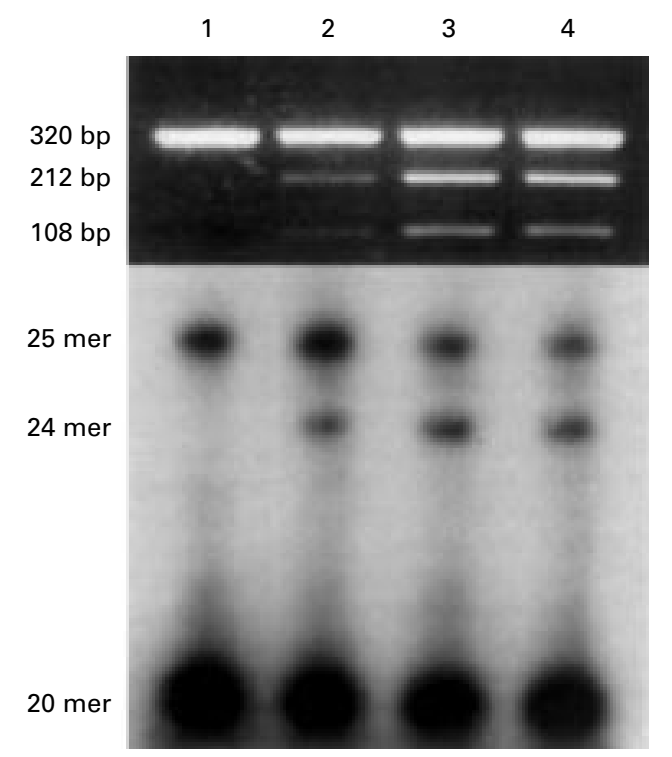

Figure 1 (Upper panel). Digestion of 320 bp FGFR3 genomic PCR product with MspI. Lanes 1, father; 2, mother; 3, first affected child; 4, second affected child. Primers used were

5'-GGAGATCTTGTGCACGGTGG-3' and

5'-GCGCGTGCTGAGGTTCTGAG-3'. (Lower panel) Primer

extension was carried out with primer

5'-GATGAACAGGAAGAAGCCCA-3' (which binds 4 bp downstream of nucleotide 1138) using methods described in Loughlin et al. ${ }^{4}$ The primer was end labelled with $\gamma^{32} P d A T P$ and the extension mix contained $d A, d T$, $d C$, and $d d G$. The $20 \mathrm{mer}$ primer was extended by 4 bp for the achondroplastic G1138C allele and by 5 bp for the wild type allele as shown below (added nucleotides are shown underlined, nucleotide 1138 is shown in bold).

Wild type template: 5'-CGGGGTGGGCTTCTTCCTGTTCATC-3' Extended primer

(25mer). 3'-ddGCCCCACCCGAAGAAGGACAAGTAG-5'

Extended primer

(24mer): 3'-ddGCCCACCCGAAGAAGGACAAGTAG-5'

The products were then separated by electrophoresis through a $15 \%$

denaturing polyacrylamide gel. The relative intensity of the $24 \mathrm{mer}$ and

25 mer products was used to calculate the proportion of achondroplastic to wild type allele. Lane order and PCR primers as above.

findings that somatic activating mutations of FGFR3 are relatively common in multiple myeloma ${ }^{8}$ and carcinomas. ${ }^{9}$ However, all the FGFR3 mutations so far identified in these malignant neoplasms are identical to activating mutations that cause thanatophoric dysplasia. The greater severity of this phenotype in comparison to achondroplasia is thought to be a reflection of the more strongly activating nature of the thanatophoric dysplasia mutations. ${ }^{10}$ That only these highly activating FGFR3 mutations have so far been found in neoplasms may suggest that the achondroplasia mutations, when they occur in somatic cells, do not activate the receptor to a level that it becomes oncogenic.

This is the first confirmed report of germline and somatic mosaicism for an achondroplasia mutation. FGFR3 nucleotide 1138 appears to be highly mutable in the male germline, but somatic mutations resulting in mosaicism are rare. The reasons for this discrepancy are unknown but are clearly of importance to the understanding of mutagenesis. The observation that the mother has a normal appearance, despite a high proportion of the achondroplastic allele in her somatic tissues, exemplifies the fine balance that the fibroblast growth factors play in morphological determination. 
BRUCE BENNETTS + BRYAN SYKES*

${ }^{\star}$ Cellular Genetics Group, Oxford University, Institute of Molecular Medicine, The fohn Radcliffe, Oxford OX3 9DS, UK

†Department of Clinical Genetics, The New Children's Hospital, Sydney, NSW 2124, Australia

Correspondence to: Dr Henderson, shenderson@hammer.imm.ox.ac.uk

1 Bellus GA, Hefferon TW, Rosa I, Luna O, Hecht JT, Horton WA, Machado M, Kaitila I, McIntosh I, Francomano CA. Achondroplasia is defined by recurrent G380R mutations of FGFR3. Am F Hum Genet 1995;56:368-73. 2 Webster MK, Donoghue J. FGFR activation in skeletal disorders: too much of a good thing. Trends Genet 1997;13:178-82.

3 Wilkin DJ, Szabo JK, Cameron R, Henderson S, Bellus GA, Mack ML, Kaitila I, Loughlin J, Munnich A, Sykes B, Bonaventure J, Francamano CA. Mutations in fibroblast growth factor receptor 3 in sporadic cases of achondroplasia occur exclusively on the paternally derived chromosome. Am ₹ Hum Genet 1998;63:711-16.
4 Loughlin J, Irven C, Athanosou N, Carr A, Sykes B. Differential allelic expression of the type II collagen gene (COL2A1) in osteoarthritic cartilage. Am f Hum Genet 1995;56:1186-93

5 Zlotogora J. Germ line mosaicism. Hum Genet 1998;102:381-6.

6 Reiser CA, Pauli RM, Hall JG. Achondroplasia: unexpected familial recurrence. Am f Med Genet 1984;19:245-50.

7 Rimoin DL, McKusick VA. Somatic mosaicism in an achondroplastic dwarf. Birth Defects 1969;5:17-19.

8 Chesi M, Nardini E, Brents LA, Schrock E, Ried T, Kuehl WM, Bergsagel PL. Frequent translocation $\mathrm{t}(4 ; 14)$ (p16.3; $\mathrm{q} 32.3)$ in multiple myeloma is associated with increased expression and activating mutations of fibroblast growth factor receptor 3. Nat Genet 1997;16:260-3.

9 Capellen D, De Oliveira C, Ricol D, Gill Diez de Medina S, Bourdin J, Sastre-Garau X, Chopin D, Thiery JP, Radanyi F. Frequent activating mutations of FGFR3 in human bladder and cervix carcinomas. Nat Genet 1999;23:18-21.

10 Naski MC, Wang Q, Xu J, Ornitz DM. Graded activation of fibroblast growth factor receptor 3 by mutations causing achondroplasia and thanatophoric dysplasia. Nat Genet 1996;13:233-7.

\section{Achondroplasia with the FGFR3 $1138 \mathrm{~g} \rightarrow \mathrm{a}(\mathrm{G} 380 \mathrm{R})$ mutation in two sibs sharing a $4 \mathrm{p}$ haplotype derived from their unaffected father}

EDITOR - The study of achondroplasia, the most frequent skeletal dysplasia in man, has contributed several important insights into both developmental biology and human genetics, such as the recognition of the paternal age effect for dominant mutations, ${ }^{12}$ the first indication of the importance of FGFR molecules in growth and development, ${ }^{3}$ and the identification of the nucleotide with the highest mutation rate known so far in man, nucleotide 1138 of the FGFR3 gene. ${ }^{4}$ Most cases of achondroplasia are associated with the $\mathrm{g} \rightarrow \mathrm{a}$ transition at nucleotide 1138 of FGFR3. ${ }^{4}$

In spite of the frequency of achondroplasia, the birth of two or more children with achondroplasia to unaffected parents is surprisingly rare, with only a few examples published. ${ }^{56}$ One instance of half sibs with achondroplasia born to the same father has been reported. ${ }^{7}$ In contrast, observations of achondroplasia in people more distantly related are relatively more common. ${ }^{8-10}$ Thus, it is uncertain whether instances of achondroplasia in sibs born to unaffected parents are caused by somatic mosaicism (as suggested by the observation of three affected sibs from normal parents ${ }^{67}$ ) or by independent chance events. ${ }^{8}$ Undoubtedly, somatic or germinal mosaicism for achondroplasia must be orders of magnitude rarer than for osteogenesis imperfecta or other dominant conditions. ${ }^{11}$

Approximately, $90 \%$ of cases of achondroplasia are caused by de novo mutations, and all de novo achondroplasia mutations studied so far were found to have occurred on paternal chromosomes. ${ }^{12}$ We observed achondroplasia with characteristic clinical and radiographic signs in a brother and sister born to parents of normal stature, lacking any clinical sign of either hypochondroplasia or achondroplasia, aged 28 years (mother) and 25 years (father) at the time of birth of the first child (fig 1 ). The family agreed to have the molecular mechanism of recurrence investigated and consented to venepuncture and buccal smears. Both children were heterozygous (in leucocyte DNA) for the g1138a (G380R) FGFR3 mutation, while that mutation was not found in parental leucocyte or buccal smear DNA by either SSCP analysis or direct sequencing of PCR products. This made parental somatic mosaicism unlikely.

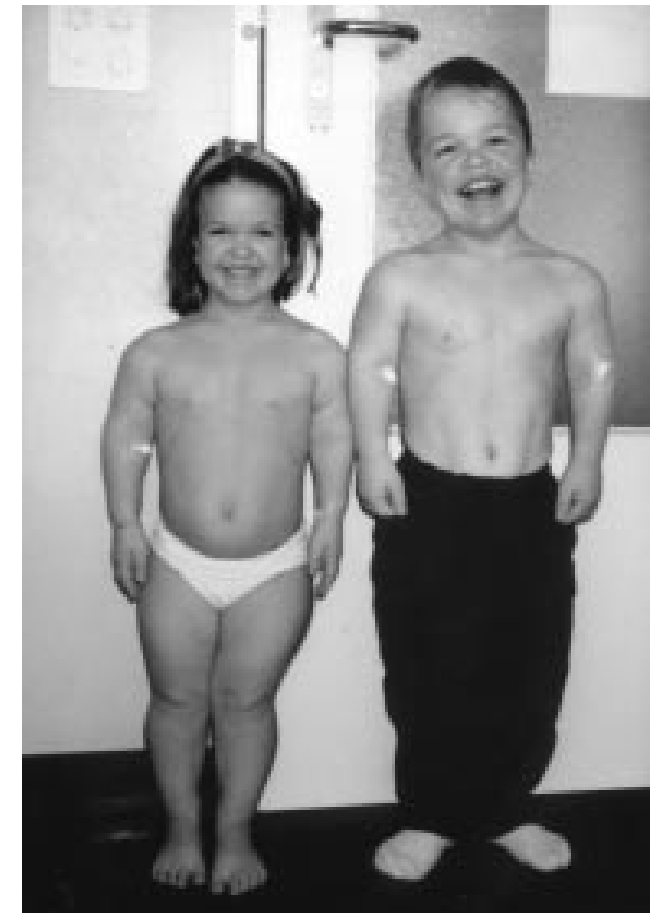

Figure 1 Clinical appearance of the brother (right) and sister (left) with achondroplasia aged 12 and 10 years, respectively.

To investigate the origin of the mutation shared by the two affected sibs, inheritance of VNTR alleles on chromosome $4 \mathrm{p}$ was studied (fig 2). The affected children had two different maternal haplotypes but shared a paternal $4 \mathrm{p}$ haplotype encompassing the FGFR3 locus. As the FGFR3 g1138a mutation occurs exclusively on paternal chromosomes, and the affected children had two different maternal $4 \mathrm{p}$ haplotypes, the most likely explanations for these findings would be either two independent mutational events occurring by chance on the same paternal haplotype, or mosaicism at the spermatogonial level (before meiosis I) in the father. Paternal sperm was not available and the hypothesis of gonadal mosaicism could not be further substantiated.

We conclude that recurrence of achondroplasia in this family was associated with de novo mutational event(s) occurring in the paternal germline, as is the case in sporadic cases, ${ }^{12}$ but could not distinguish between paternal gonadal mosaicism or the chance occurrence of two independent mutation events. ${ }^{8}$ The apparent rarity of 


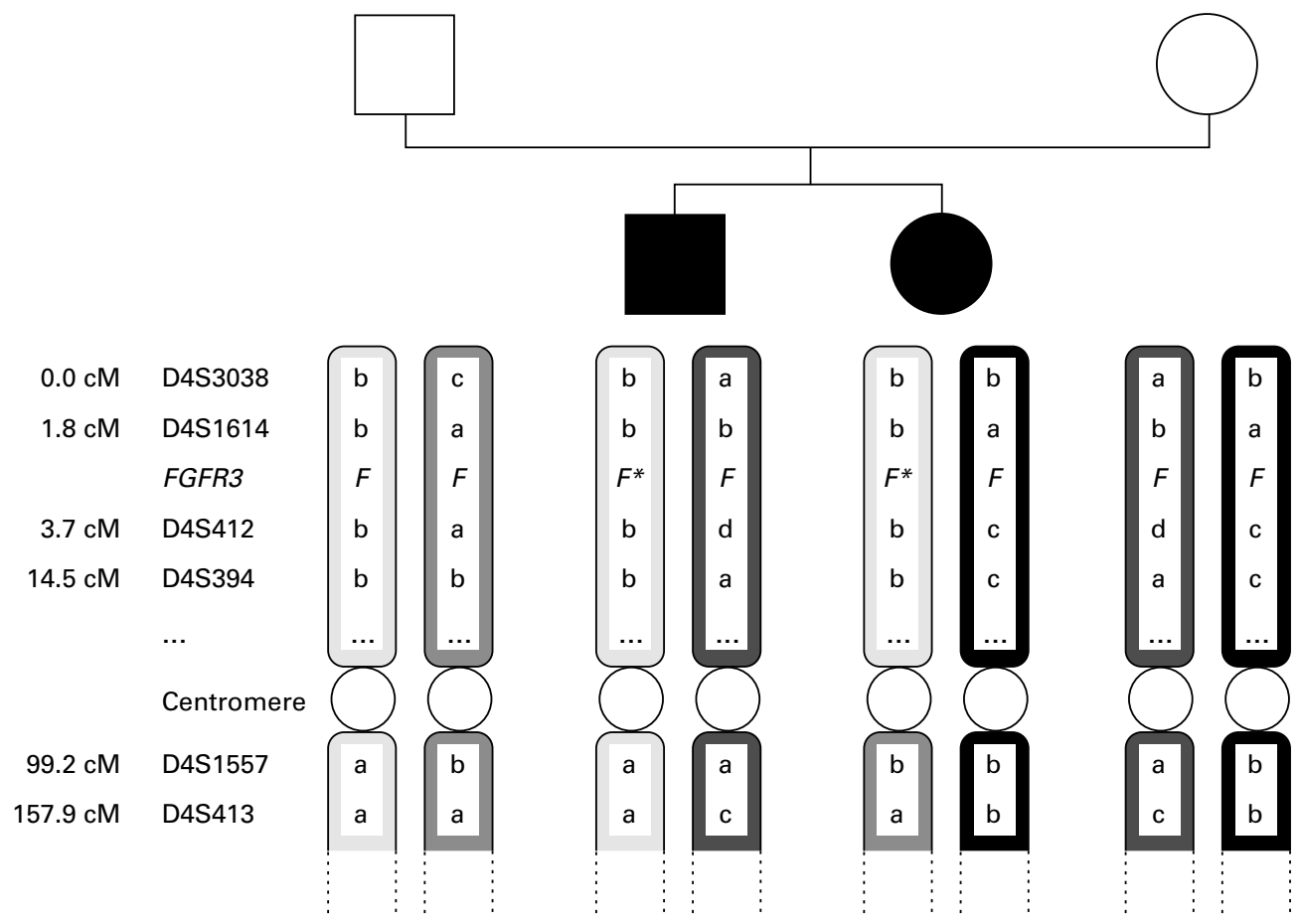

Figure 2 Inheritance of chromosome 4 markers in the nuclear family. The markers are indicated on the left together with their genetic distance in centimorgans from the 4p telomere according to the GB4 map (http://www.ncbi.nlm.nih.gov/genemap98). F indicates the position of the FGFR3 locus and the asterisk indicates the presence of the achondroplasia mutation; its assignment to the paternal haplotype is not experimentally proven (but see text). The children have inherited two different chromosome 4 haplotypes from their mother, while they share a paternal haplotype on 4p encompassing the FGFR3 locus.

somatic mosaicism for FGFR3 mutations in spite of the high mutation rate in achondroplasia remains unexplained.

This work was supported by the Swiss National Foundation (32-57272.99 and 32-42198.94) and the Bonizzi-Theler-Stiftung Zürich.

DIANA SOBETZKO* SUZANNE BRAGA† ANNA RÜDEBERG† ANDREA SUPERTI-FURGA*

*Division of Metabolic and Molecular Paediatrics, Department of Paediatrics, University of Zurich, University Children's Hospital, Steinwiesstrasse 75, CH-8032 Zürich, Switzerland

†Division of Medical Genetics, Department of Paediatrics, University of Berne, Switzerland

Correspondence to: Dr Superti-Furga, asuperti@access.unizh.ch

1 Penrose LS. Parental age in achondroplasia and mongolism. Am $\mathcal{f}$ Hum Genet 1957;9:167-9.

2 Orioli IM, Castilla EE, Scarano G, Mastroiacovo P. Effect of paternal age in achondroplasia, thanatophoric dysplasia, and osteogenesis imperfecta. Am f Med Genet 1995;59:209-17.
3 Passos-Bueno MR, Wilcox WR, Jabs EW, Sertie AL, Alonso LG, Kitoh H. Clinical spectrum of fibroblast growth factor receptor mutations. Hum Mutat 1999;14:115-25

4 Bellus GA, Hefferon TW, Ortiz de Luna RI, Hecht JT, Horton WA, Machado M, Kaitila I, McIntosh I, Francomano CA. Achondroplasia is defined by recurrent G380R mutations of FGFR3. Am f Hum Genet 1995;56:36873

5 Bowen P. Achondroplasia in two sisters with normal parents. Birth Defects 1974; X:31-6.

6 Fryns JP, Kleczowska A, Verresen H, van den Berghe H. Germinal mosaicism in achondroplasia: a family with 3 affected siblings of normal parents. Clin Genet 1983;24:156-8.

7 Philip N, Auger M, Mattei JF, Giraud F. Achondroplasia in sibs of normal parents. F Med Genet 1988;25:857-9.

8 Reiser CA, Pauli RM, Hall JG. Achondroplasia: unexpected familial recurrence. Am f Med Genet 1984;19:245-50.

9 Opitz JM. Editorial comment: "unstable premutation" in achondroplasia: penetrance vs. phenotrance. Am F Med Genet 1984;19:251-4

10 Fitzsimmons JS. Brief clinical report: familial occurrence of achondroplasia. Am f Med Genet 1985;22:609-13.

11 Zlotogora J. Germ line mosaicism. Hum Genet 1998;102:381-6.

12 Wilkin DJ, Szabo JK, Cameron R, Henderson S, Bellus GA, Mack ML, Kaitila I, Loughlin J, Munnich A, Sykes B, Bonaventure J, Francomano CA. Mutations in fibroblast growth-factor receptor 3 in sporadic cases of achondroplasia occur exclusively on the paternally derived chromosome. Am f Hum Genet 1998;63:711-16.

\section{Homozygous deletion of $S H O X$ in a mentally retarded male with Langer mesomelic dysplasia}

EDITOR-Langer mesomelic dysplasia (LMD) is a rare skeletal dysplasia characterised by severe short stature owing to shortening and maldevelopment of the mesomelic and rhizomelic segments of the limbs. Associated malformations are rarely reported and intellect is normal in all affected subjects reported to date. ${ }^{1-5}$ The clinical observation has been made that the parents of subjects with LMD often have short stature, most commonly with the associated clinical and radiographic appearances of LériWeill dyschondrosteosis (DC). ${ }^{6}$ This dominantly transmitted condition is characterised by moderate short stature predominantly because of short mesomelic limb segments. It is often associated with the Madelung deformity of the wrist, comprising bowing of the radius and dorsal dislocation of the distal ulna. This observation has led to the suggestion that LMD is the homozygous expression of the mutant gene for DC. ${ }^{5} 6$

Shears et $a l^{7}$ and Belin et $a l^{8}$ recently showed that the molecular defect in DC is mutation within or deletion of the SHOX gene located within the primary pseudoautosomal region of the $\mathrm{X}$ and $\mathrm{Y}$ chromosomes. Deletion or 


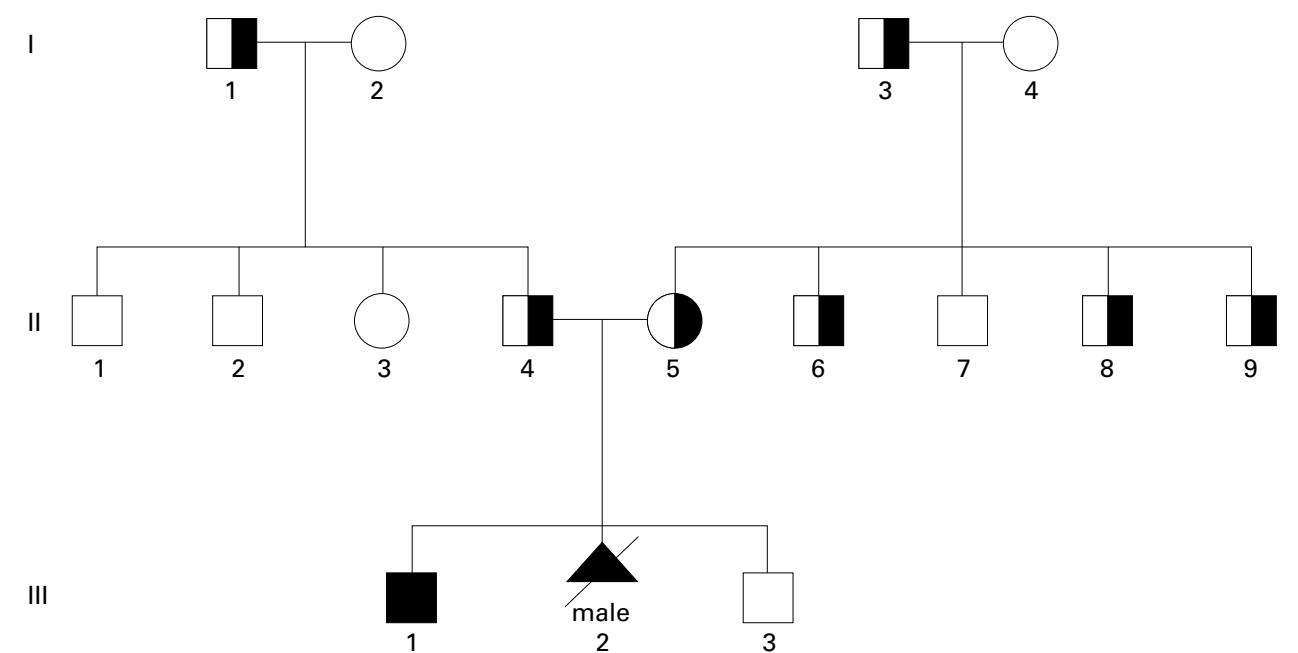

Figure 1 Pedigree of the family. Half filled symbols indicate subjects with dyschondrosteosis, filled symbols indicate Langer mesomelic dwarfism.

mutation of SHOX has also been shown to lead to short stature without overt bone dysplasia. ${ }^{10}$ Belin et $a l^{8}$ documented the molecular analysis of a 24 week fetus of a female patient with DC and a pseudoautosomal deletion encompassing SHOX. The fetus had a 45,X karyotype and the radiographic appearances of LMD. They showed that the Xp chromosomal haplotype at the SHOX locus retained by this fetus was the maternal one, encompassing the deleted $S H O X$ gene, rendering the fetus nullizygous for $S H O X$. Shears et al reported that deletions of SHOX alleles were derived from both parents in a 20 week fetus with radiographic appearances of LMD. These findings in fetuses were the first molecular evidence to support nullizygosity for SHOX as the cause of LMD; however, molecular confirmation in a living patient with LMD has not been previously described.

We present a description of a mentally retarded boy with LMD and his parents, both of whom have DC and normal intellect. Molecular analysis shows that each parent is hemizygously deleted at the SHOX locus and that the proband has inherited both alleles harbouring the deletions, confirming this as the aetiology of LMD.

The patient, a male, was the first born child to non-consanguineous parents both of whom had short stature (fig 1, III.1). He was delivered by caesarean section for fetal distress at 35 weeks' gestation. He was in good condition immediately after delivery. His birth weight was 1480 $\mathrm{g}(-2.6 \mathrm{SD})$, length was $33 \mathrm{~cm}(-4.3 \mathrm{SD})$, and $\mathrm{OFC}$ was $28 \mathrm{~cm}(-3 \mathrm{SD})$. Severe rhizomelic and mesomelic shortening of all four limbs was immediately obvious on delivery and subsequent radiographic findings were consistent with LMD (fig 2). He required gavage feeding for two weeks and developmental progress in the first two years of life was appreciably delayed with expressive language being particularly slow to develop. At review aged 12 years he remained severely mentally retarded. He had no speech, was not toilet trained, and could only assist in dressing by raising his hands and feet. He was ambulatory but walked with a swaying gait and with flexion at the hips to retain balance. In the year before review he had developed generalised seizures which were satisfactorily controlled with valproate. He was $97 \mathrm{~cm}$ tall (-7.2 SD) with a weight of 17 $\mathrm{kg}(-3.6 \mathrm{SD})$ and OFC of $49.5 \mathrm{~cm}(-3.0 \mathrm{SD})$. There was marked rhizomelic and mesomelic shortening of all limbs (fig 3). The hands and feet were of normal size, although there was partial soft tissue syndactyly and camptodactyly of digits $2-5$, and clinodactyly of the fifth digits bilaterally in the hands. Both hands showed ulnar deviation at the wrists and both big toes were proximally placed. There were no other anomalies present except for a large gap between the central maxillary incisors and a mild pectus excavatum deformity. There was no mandibular hypoplasia. Pubertal status was Tanner stage 3.
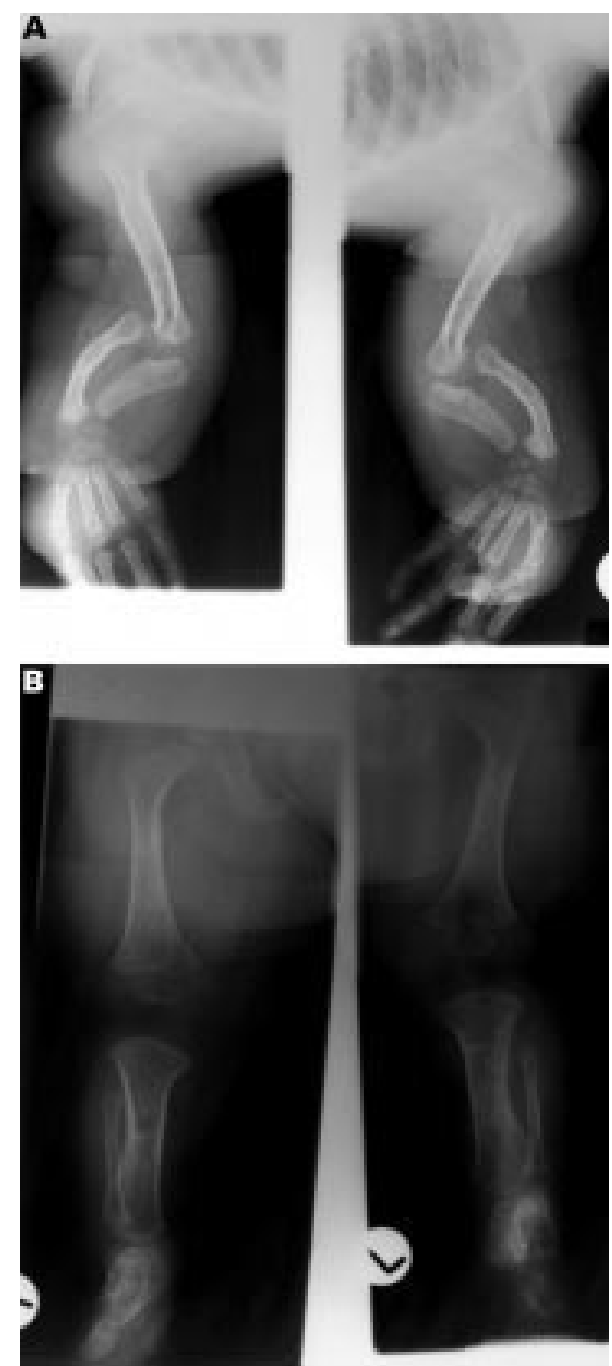

Figure 2 Radiographs of the proband. (A) AP view of the upper limbs. All of the long bones are shortened and undermodelled. The radius is bowed and there is distal ulnar hypoplasia. (B) The lower limbs. The long bones are short and undermodelled. Metaphyseal flaring and proximal fibular hypoplasia are present. 


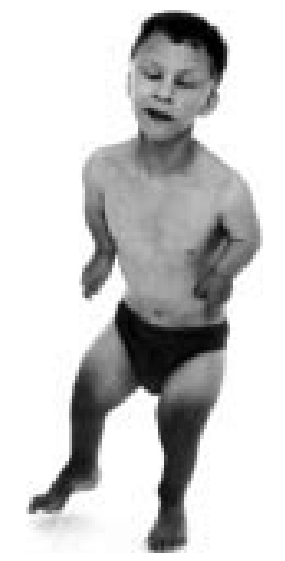

Figure 3 Clinical appearance of the proband, aged 12 years. Rhizomelic and mesomelic limb shortening is present. Syndactyly and camptodactyly is present in the hands. Proximal placement of the big toes is evident.
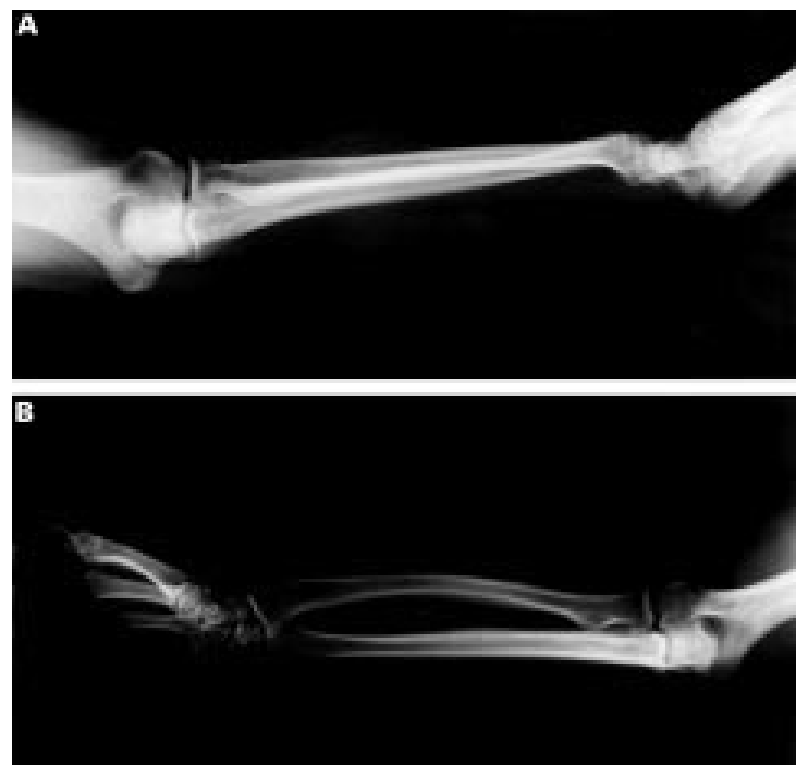

Figure 4 Radiographic appearance of the forearm of the parents of the proband. (A) Lateral view of the mother's forearm (II.5) showing dorsal dislocation of the ulna. (B) AP view of the paternal forearm (II.4)

showing bowing and thickening of the midshaft of the radius.

Investigations have included a normal CT scan of the brain at 3 years and an interictal EEG performed at 13 years, which showed no frank epileptiform activity or asymmetry although there was a marked excess of theta activity and no well defined alpha rhythm. Results of a karyotype, fragile $\mathrm{X}$ molecular testing, and urine organic acid profile were normal.

The father of the proband (II.4) was $162 \mathrm{~cm}$ tall $(-2.3$ $\mathrm{SD}$ ) and the mother (II.5) was $145 \mathrm{~cm}(-2.7 \mathrm{SD})$. Both parents were of normal intellect. They had short arms and legs, most pronounced in the mesomelic segments. A bilateral wrist deformity was clinically present in both, comprising a subluxation of the distal ulna and resulting in a mild limitation in supination. The mother's deformity was more pronounced than that of the father. Radiographs showed a Madelung deformity with bowing and thickening of the middle third of the radii (fig 4). The couple's second pregnancy, a male (III.2), had been terminated in the second trimester owing to detection of severely shortened limbs on ultrasound. No necropsy was performed. A brother of the proband (III.3), aged 6 years, was noted to be of normal intellect, $112.3 \mathrm{~cm}$ tall $(-0.7 \mathrm{SD})$, and to have normal body proportions. Multiple members of the extended family exhibited short stature and the same
II

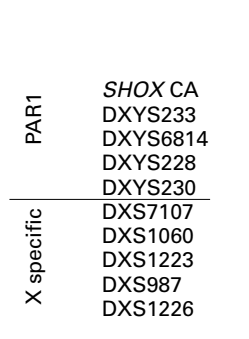

III

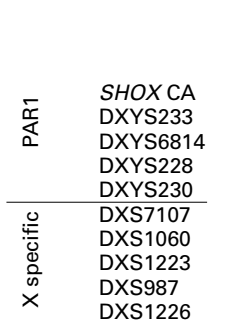

B
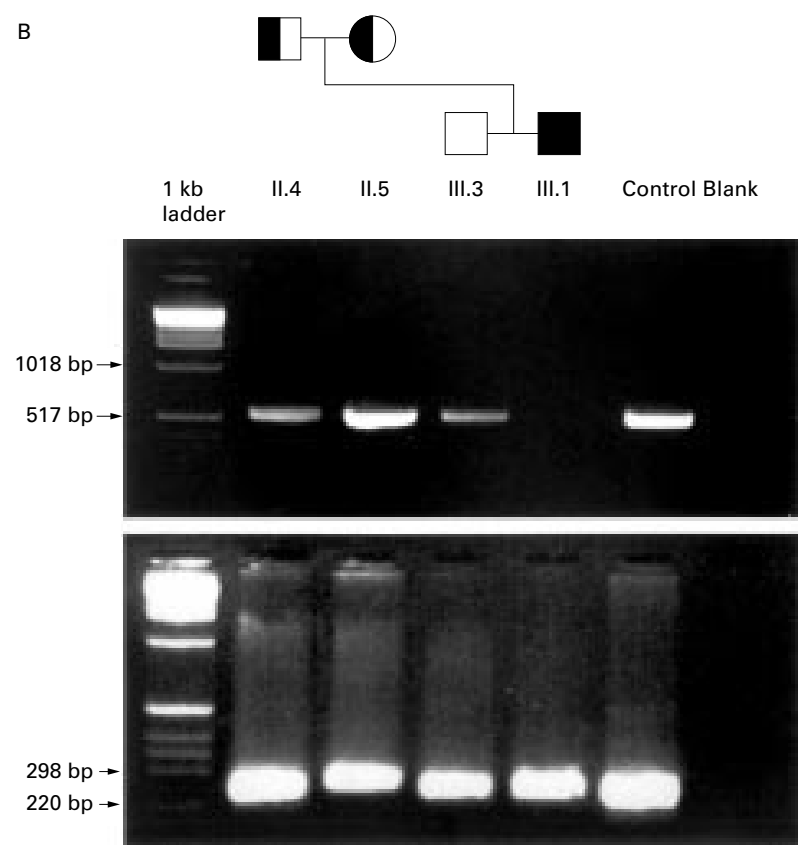

Figure 5 (A) Haplotypes of markers on $X p / Y p$ showing the maternal deletion and compatible with a paternal deletion. The obligate crossover in male meiosis is seen. (B) PCR of SHOX exon 2 (band at $517 \mathrm{bp}$ ) showing that no PCR product was obtained with DNA from the proband (III.1). No PCR product was obtained in the proband for any of the $S H O X$ exons or for the SHOX CA repeat (data not shown). The lower panel shows that PCR product is obtained in the proband with control primers at the locus DXS230 (band between 220 bp and 298 bp).

appearance at the wrist although none of them was available for clinical examination. No other member of the extended family has intellectual impairment.

Blood samples were obtained from II.4, II.5, III.1, and III.3, and microsatellite analysis, fluorescence in situ hybridisation (FISH), and Southern blotting were performed to examine the region around the SHOX locus. Fluorescent labelled primers were used to amplify the pseudoautosomal microsatellite markers DXYS233, DXYS228, DXYS6814, DXYS230, and the SHOX CA repeat in the 5'UTR of SHOX exon $1 .^{7}$ Microsatellite analysis of the X specific markers DXS7107, DXS1060, DXS1223, DXS987, and DXS1226 was also undertaken. 

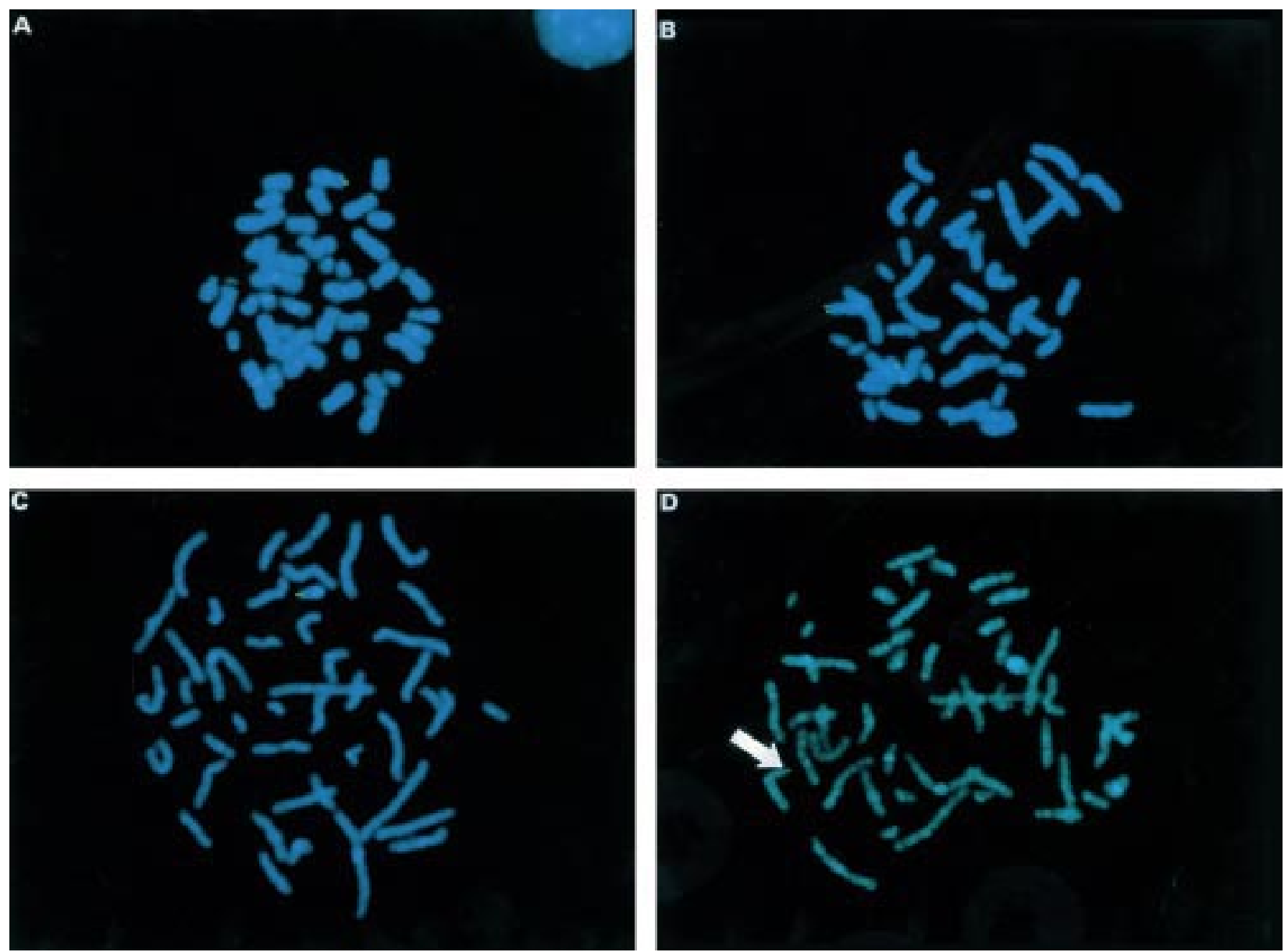

Figure 6 FISH studies with cosmid 34F5. (A) The mother of the proband (II.5), showing a deletion on one X chromosome. (B) The father of the proband (II.4), showing a signal on the $X$ and the $Y$ chromosomes. (C) The proband (III.1) showing a deletion on the $X$ chromosome but a signal on the $Y$. (D) The maternal uncle of the proband (II.6) showing a deletion on the Y chromosome and a retained signal on the $X$ (arrowed).

Results showed that the proband (III.1) did not inherit an allele at the DXYS233 locus from his mother (II.5), indicating a maternal PAR1 deletion (fig 5A). A paternally derived allele at DXYS233 was present. No PCR product was obtained with the proband's DNA for the SHOX CA repeat, and the parents could both be either hemizygous or homozygous at this locus. In addition, since the proband's DNA failed to amplify with primers for each exon of SHOX (fig 5B), we concluded that there was a homozygous deletion encompassing $S H O X$ in the proband. Heterozygosity in the proband for the more proximal PAR1 microsatellite markers DXYS6814, DXYS228, and DXYS230 indicates that neither deletion extends into the $\mathrm{X}$ specific region, but both are confined to the pseudoautosomal region. The normal brother of the proband (III.3) has inherited the opposite maternal and paternal haplotypes to the proband.

FISH was performed on metaphase spreads of lymphocytes obtained from whole blood or from transformed lymphoblastoid lines. ${ }^{11}$ Cosmid LLNOYCO3'M'34F5, which contains $S H O X$ exons $1-5 b$, was obtained from the Lawrence Livermore Y chromosome specific library and was labelled by nick translation with biotin-16 dUTP (Gibco BRL BioNick Labeling System). A total of 15 metaphases were analysed using a Leitz DMLB fluorescence microscope and images were captured and stored using Applied Imaging software. A hemizygous deletion of SHOX was shown in the mother (fig 6A). However, in the father, signals were visible on both the $\mathrm{X}$ and $\mathrm{Y}$ chromosomes (fig 6B) and in the proband an $\mathrm{X}$ chromosome deletion was present but there was a signal on the Y (fig 6C). We therefore performed Southern blotting to show the paternally derived SHOX deletion.

A Southern blot of HindIII digested genomic DNA of II.4, II.5, III.1, and III.3 was hybridised with a probe for SHOX exons 3 to 4 . The blot was then stripped and rehybridised with a dosage control probe from chromosome 22 (TBX1, IMAGE cDNA clone 1876034). Probe labelling and detection was performed using the Gene Images ${ }^{\mathrm{TM}}$ system (Amersham). There was no signal with the SHOX probe in the proband, III.1 (upper panel, fig 7), but the dosage control probe signal was present (lower panel, fig 7 ), confirming that the proband is homozygously deleted for SHOX. A dosage effect was shown with the SHOX probe in the parents of the proband, II.4 and II.5. These lanes both showed a weaker intensity signal than the normal sib, III.3. The dosage control probe showed equal signals in all lanes indicating that the parents are hemizygously deleted for SHOX.

A variety of dominantly transmitted disorders, such as achondroplasia, aniridia, and Waardenburg syndrome, express a more severe phenotype when present in the homozygous form. ${ }^{12}$ Langer mesomelic dysplasia has long been considered the homozygous expression of DC on purely clinical grounds, but until the demonstration of the molecular defect underlying the disorder, definitive evidence has been lacking. This report is the first confirmation in a living patient that nullizygosity for $S H O X$ causes LMD. Both parents had the clinical and radiographic appearances of DC and both harboured heterozygous deletions of one SHOX allele. 

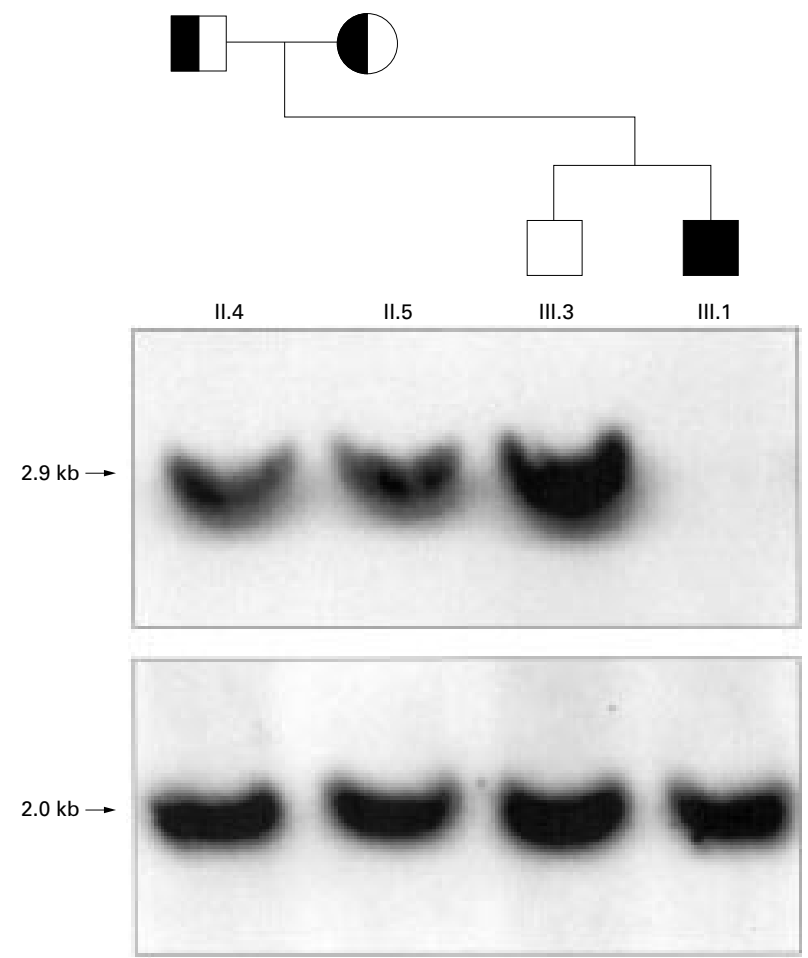

Figure 7 Southern blot of HindIII digested genomic DNA of II. 4, II.5, III.1, and III. 3 hybridised with a SHOX probe (genomic PCR product of SHOX exons 3 to 4). The probe detects a $2.9 \mathrm{~kb}$ band which is absent in III.1, indicating a homozygous deletion (upper panel). The band strength in III. 3 is of greater intensity than in II. 4 and II.5, whereas the control probe hybridises to a $2 \mathrm{~kb}$ band and shows equal signal intensity in all lanes (lower panel). This dosage effect shows that II. 4 and II. 5 are heterozygous for SHOX deletions.

The SHOX gene is located within the primary pseudoautosomal region (PAR1) at the telomere of the short arm of the $\mathrm{X}$ and $\mathrm{Y}$ chromosomes. This region escapes $\mathrm{X}$ inactivation in females and participates in obligate recombination during male meiosis. Consequently, DC segregates as an apparently "autosomal" dominant disorder. This is illustrated by the normal statured male sib of the proband who has inherited the two intact SHOX alleles, the paternal $\mathrm{Y}$ chromosome having undergone meiotic recombination with a breakpoint centromeric to the SHOX locus. The obligate requirement for crossing over in PAR1 may predispose to a higher rate of mispairing with resultant deletions in this very localised chromosomal region. An accurate estimation of the frequency of such events is difficult since it is likely that DC is underdiagnosed within the general population owing to the wide clinical spectrum. Analysis of the small number of patients with DC examined with molecular methods so far has indicated that deletion is a common mode of mutation in this disorder. The studies of Shears et $a l^{T}$ and Belin et $a l^{8}$ showed that 12 out of 14 cases were the result of deletions encompassing the SHOX locus, the remaining two being point mutations.

It is interesting to note that there are no previous reports of an association of mental retardation with LMD, although it has been described previously in association with DC. Shears et al noted minor dysmorphic features and learning disabilities in a pair of female monozygotic twins with DC. They postulated that this might be explained by deletion of contiguous genes; however, in this case the responsible deletion encompassing the SHOX locus extended into the $\mathrm{X}$ specific region and was large enough to be visible on $\mathrm{G}$ banding. Spranger et $a l^{13}$ reported a mother-son pair with DC, the son manifesting in addition mental retardation, myoclonic epilepsy, and chondrodysplasia punctata. Molecular mapping studies showed the extent of the maternally derived deletion to include not only SHOX, but also ARSE, the gene mutated in $\mathrm{X}$ linked chondrodysplasia punctata, and the putative mental retardation locus MRX49. The normal intelligence and seizure free status of the mother suggests that the phenotype of her son was attributable to heterozygosity for the SHOX deletion in addition to nullizygosity for $A R S E$ and possibly $M R X 49 .{ }^{14}$ Thus in both these cases the deletion extended well into the $\mathrm{X}$ specific region and could include established MRX loci. Microsatellite and cytogenetic analysis of the deletions in the present case have indicated that the maternal deletion is more extensive than the paternal deletion, but is still confined within PAR1 and does not extend into the $\mathrm{X}$ specific region. Several MRX loci map close to PAR $1,{ }^{15}$ but to our knowledge none has been reported within PAR1. It is still possible that deletion of contiguous genes may contribute to the mental retardation in the proband of this family if one postulates the existence of a further MRX/Y locus within the pseudoautosomal region. It is worthwhile noting that the parents and other relatives affected by DC do not have intellectual impairment suggesting that the MR resulting from this putative pseudoautosomal gene follows recessive inheritance in this family. In addition, none of the patients from other DC families studied with microdeletions confined to PAR1 have mental retardation. It is likely that most LMD patients without mental retardation are homozygously deleted for SHOX but that one or both of the deletions do not encompass the putative $\mathrm{MRX} / \mathrm{Y}$ locus. They could also carry one or more point mutations which would not be expected to cause mental retardation.

The study of this patient shows that nullizygosity for SHOX causes Langer mesomelic dysplasia and confirms it as the homozygous form of Léri-Weill dyschondrosteosis. The association of LMD with mental retardation in this patient also suggests the existence of a recessively acting pseudoautosomal mental retardation locus.

The first two authors contributed equally to this work. We thank the family for their assistance with this study. DJS is supported by a Research Training Fellowship from the Wellcome Trust, ref 051419/055.

STEPHEN P ROBERTSON* DEBORAH J SHEARS + PAUL OEI $\ddagger$

ROBIN M WINTER PETER J SCAMBLER+ SALIM AFTIMOS $\$$ RAVI SAVARIRAYAN*

^Victorian Clinical Genetics Service, Royal Children's Hospital, Parkville, Victoria, Australia

†Institute of Child Health, London, UK

$\ddagger$ Cytogenetics Laboratory, Starship Children’s Hospital, Auckland, New Zealand

\Northern Regional Genetics Service, Auckland, New Zealand

Dr Robertson, The Institute of Molecular Medicine, The John Radcliffe, Headington, Oxford OX3 9DS, UK, steve.robertson@imm.ox.ac.uk

1 Langer LO. Mesomelic dwarfism of the hypoplastic ulna, fibula and mandible type. Radiology 1967;89:654-60.

2 Espiritu C, Chen H, Woolley PV. Mesomelic dwarfism as the homozygous expression of dyschondrosteosis. Am $\mathcal{F}$ Dis Child 1975;129:375-7.

3 Fryns JP, Mulier F, Van den Berghe H. A patient with Langer type of mesomelic dwarfism. Acta Paediatr Belg 1976;29:193-6.

4 Fryns JP, van den Berghe H. Langer type of mesomelic dwarfism as the possible homozygous expression of dyschondrosteosis. Hum Genet 1979;46:217.

5 Kunze J, Klemm T. Mesomelic dysplasia type Langer - a homozygous state for dyschondrosteosis. Eur $\mathcal{F}$ Pediatr 1980;134:269-72.

6 Léri A, Weill J. Une affection congénitale et symetrique du developement osseux: la dyschondrosteose Bull Mem Soc Med Hosp 1929;35:1491-4.

7 Shears DJ, Vassal, HJ, Goodman FR, Palmer RW, Reardon W, SupertiFurga A, Scambler PJ, Winter RM. Mutation and deletion of the pseudoautosomal gene SHOX cause Leri-Weill dyschondrosteosis. Nat Genet 1998;19:70-3.

8 Belin V, Cusin V, Viot G, Girlich D, Toutain A, Moncla A, Vekemans M, Le Merrer M, Munnich A, Cormier-Daire V. SHOX mutations in dyschonMerrer M, Munnich A, Cormier-Daire V. SHOX mutati

9 Rao E, Weiss B, Fukami M, Rump A, Niesler B, Mertz A, Muroya K, Binder G, Kirsch S, Winkelmann M, Nordsiek G, Heinrich U, Breuning MH, Ranke MB, Rosenthal A, Ogata T, Rappold GA. Pseudoautosomal 
deletions encompassing a novel homeobox gene cause growth failure in idiopathic short stature and Turner syndrome. Nat Genet 1997;16:54-63. 10 Ellison JW, Wardak Z, Young MF, Robey PG, Laig-Webster M, Chiong W. PHOG, a candidate gene for involvement in the short stature of Turner syndrome. Hum Mol Genet 1997;6:1341-7.

11 Pinkel D, Landegent J, Collins C, Fuscoe J, Segraves R, Lucas J, Gray J. Fluorescence in situ hybridisation with human chromosome-specific libraries: detection of trisomy 21 and translocations of chromosome 4. Proc Natl Acad Sci USA 1988;85:9138-42.

12 Zlotogora J. Dominance and homozygosity. Am f Med Genet 1997;68:41216.
13 Spranger S, Schiller S, Jauch A, Wolff K, Rauterberg-Ruland I, Hager D, Tariverdian G, Tröger J, Rappold G. Léri-Weill syndrome as part of a contiguous gene syndrome at Xp22.3. Am F Med Genet 1999;83:367-71.

14 Claes S, Vogels A, Holvoet M, Devriendt K, Raeymaekers P, Cassiman JJ, Fryns JP. Regional localisation of the two genes for nonspecific X-linked mental retardation to Xp22.3-p22.2 (MRX49) and Xp11.3-p11.21 (MRX50). Am ₹ Med Genet 1997;73:474-9.

15 Gedeon A, Donnelly A, Mulley J, Kerr B, Turner G. How many X-linked genes for non specific mental retardation are there? Am f Med Genet 1996; 64:158-62.

\section{Tandem triplication of chromosome $13 \mathrm{q} 14$ with inverted interstitial segment in a 4 year old girl}

EDITOR-Application of chromosome painting has enabled confirmation that an additional segment in a presumed tandem duplication originates from the rearranged chromosome. More recent studies to determine more accurately the exact amount of duplication with cosmid FISH probes have, in a few instances, shown that some of the presumed duplications were in fact triplications of smaller segments. ${ }^{1-7}$ In some of these patients, unequal distances between the FISH signals showed that the middle segment of the tandemly arrayed three segments was in the opposite orientation to the two flanking segments, ${ }^{1{ }^{3} 4}$ thus providing clues to the possible mechanism of formation.

Here we report on the clinical, cytogenetic, and molecular analysis of a patient displaying the same type of triplication for segment 13q14 including the retinoblastoma gene, again with opposite orientation of the middle segment.

The proband was born at term after an uneventful pregnancy to healthy, consanguineous, Turkish parents (third cousins). At the birth, the mother was 23 and the father was 28 years old. The patient's birth weight was $2700 \mathrm{~g}$ $(<10$ th centile). At the age of 4 years, she was referred to a paediatric hospital for evaluation of developmental delay. Her weight $(8 \mathrm{~kg})$, height $(85.0 \mathrm{~cm})$, and head circumference $(43.5 \mathrm{~cm})$ were all far below the $3 \mathrm{rd}$ centile. Her cognitive abilities were estimated to be at the level of a 2 year old (IQ of about 50). Clinical assessment showed the following findings (fig 1): low frontal hairline, prominent antihelices and hypoplastic lobules of the ears, upward slanting palpebral fissures, deep set eyes, a capillary haemangioma next to the right eyebrow, a bulbous nasal

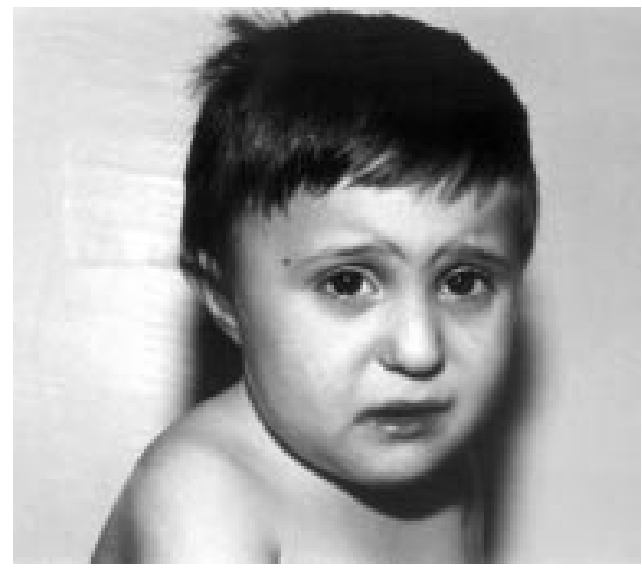

Figure 1 The proband aged 4 years. Note deep set eyes with upward slanting palpebral fissures and bulbous tip of nose. tip, thin upper lip, pointed chin, excessive dental caries, right transverse palmar crease, diminished flexion in the metacarpophalangeal joints of both thumbs, and hypertrichosis of the legs.

Chromosome analysis was performed on GTG banded metaphase preparations of blood lymphocyte cultures of the patient and her parents by standard techniques.

FISH was carried out using probes from four loci on chromosome 13 according to standard protocols (Oncor ${ }^{\circledR}$ Inc) or as previously described. ${ }^{89}$ Loci and their corresponding cosmid probes included D13S118 (c118), the retinoblastoma gene $R B 1, \mathrm{D} 13 \mathrm{~S} 319$ (c319), and D13S25 (c25), all mapping to $13 \mathrm{q} 14$. Cosmid c118 maps to 13q14.1-q14.2 proximal to RB1, while cosmids c319 and c25 both map to $13 \mathrm{q} 14.3$ about $1 \mathrm{Mb}$ distal to the $R B 1$ locus. ${ }^{10}$

FISH analysis was performed using a Zeiss Axioplan epifluorescence microscope and images were recorded either by conventional microphotography or by Photometrics CCD KAF camera (Tuscon, AZ, USA), controlled with Smart Capture imaging software (Vysis Inc, Downers Grove, IL, USA).

Genomic DNA was extracted from peripheral blood of the proband and her parents by standard methods. PCR analysis was performed using primers which amplify dinucleotide repeat polymorphisms. The following loci which map between bands $13 \mathrm{q} 12$ and $13 \mathrm{q} 32$-q34 were tested: D13S221, D13S218, D13S118, D13263, D13S155, D13S284, D13S153, D13S137, D13S124, D13S162, D13S170, and D13S173. PCR products were separated on a $6 \%$ polyacrylamide/urea gel and visualised by silver staining.

GTG banding analysis of the patient's metaphase spreads (resolution of about 400-500 bands/haploid karyotype) showed a female karyotype with 46 chromosomes in all 30 cells examined. One homologue 13 showed an approximate $1 / 4-1 / 3$ increase in length owing to an additional segment in the middle of the long arm. Two narrow bands divided the additional segment into three equal parts, suggesting a triplication of band 13q14 (fig 2). The karyotypes of both parents were normal.

Hybridisation with the $R B 1$ gene probe showed one signal on the normal chromosome and three signals and thus three RB1 copies on the rearranged homologue. The distances between the three signals appeared to be unequal; the distance between the first and second signals seemed to be shorter than that between the second and third signals. Cohybridisation of the $R B 1$ gene probe with differently labelled cosmids c25 or c319, as well as cohybridisation of cosmids c118 and c319, confirmed an interstitial triplication of the whole of band 13q14 (fig 2). In addition, dual colour FISH clearly showed that the middle segment was inverted in orientation; the order of signals was RG-GR-RG or GR-RG-GR ( $R$ stands for red; $G$ stands for green). An order of RG-RG-RG or GR-GR-GR would be expected if the triplication had occurred in direct orientation. Unequal distance between three pairs of signals, with the first two in a row being very close, but both 

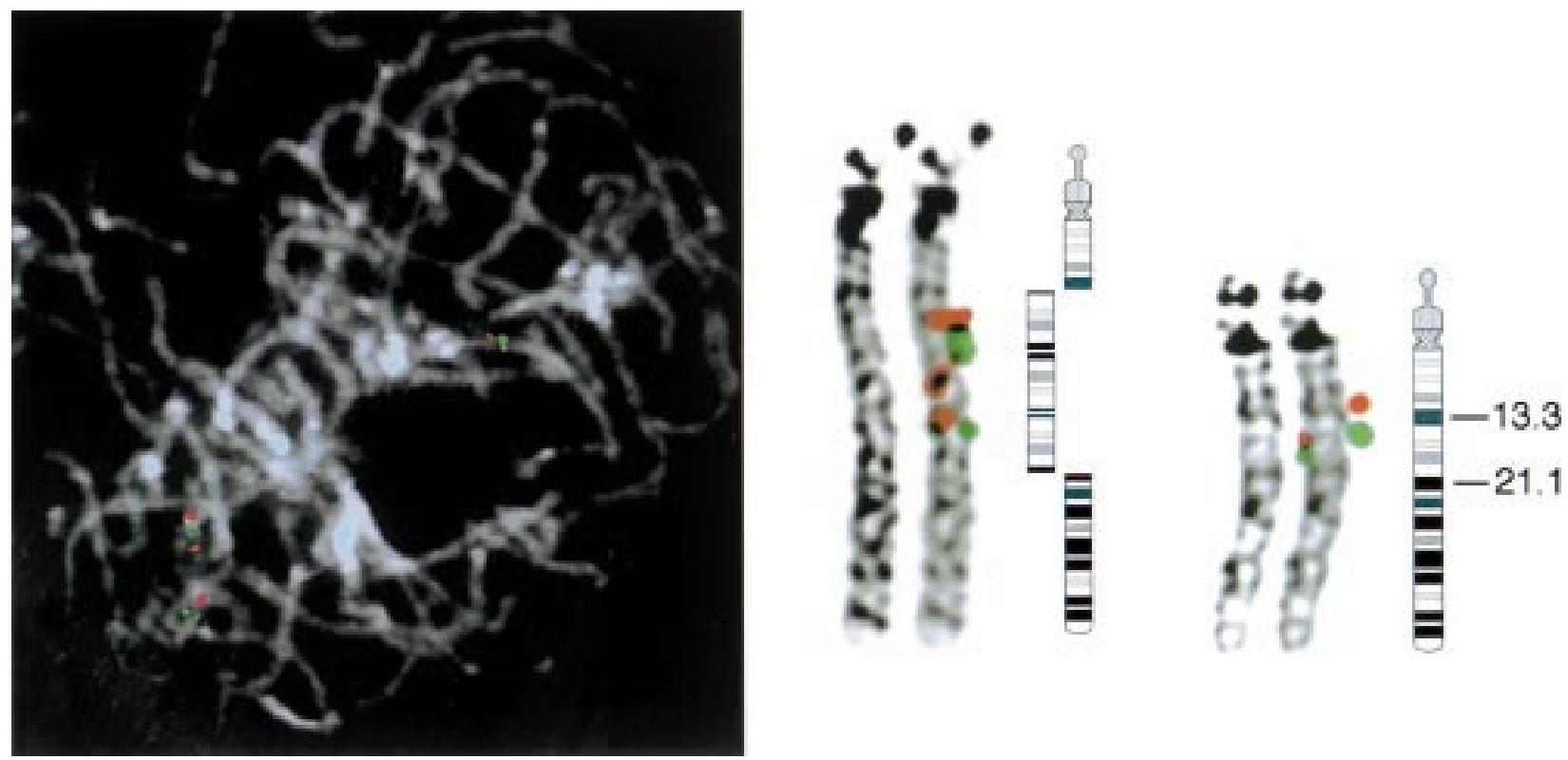

Figure 2 (Right) QFQ banded chromosomes 13 from the proband. Two copies of the $13 q+$ chromosome with signals red-green-green-red-red-green with banding diagram showing the three copies of the triplicated segment with inversion of the middle segment, together with the normal homologue with signals red-green and banded diagram of the normal 13. (Left) Prometaphase with FISH signals using cosmids c118 mapping to $13 q 14.1$ (red) and c319 mapping to $13 q 14.3$ (green); chromosome with triplicated segment on the left with signals red-green-green-red-red-green, normal homologue with signals red-green on the right.

being quite far apart from the third pair of signals, indicates a distal location of the $R B 1$ gene within band $13 \mathrm{q} 14$ (fig 2). FISH and DAPI banding (=850 bands/karyotype) placed the $R B 1$ locus at $13 \mathrm{q} 14.2$. Combining the pattern of GTG bands with the results of DAPI banding, the proximal breakpoint appears to be very distally located in 13q13.3, while the distal breakpoint appears to be very proximally located in 13q21.1 (fig 2).

The patient's karyotype can be described as: $46, \mathrm{XX}$,? $\operatorname{trp}(13)(\mathrm{q}$ ? $14 \mathrm{q}$ ? 14)de novo.fish $\operatorname{trp}(13)(\mathrm{pter} \rightarrow$ q21.1::q21.1 $\rightarrow$ q13.3::q13.3 $\rightarrow$ qter) (D13S118+++, RB1+++, D13S319+++, D13S25+++).

The results of microsatellite polymorphism analysis are shown in table 1 . Two of the 12 loci showed inheritance of one maternal and two paternal alleles. Locus D13S284, which maps to $13 \mathrm{q} 14.3$, displayed three distinct alleles, two being paternal in origin (fig 3). At locus D13S155, which maps to $13 \mathrm{q} 14.3-\mathrm{q} 21.2$, the paternal band was clearly stronger than the maternal band. At locus D13S263, which maps to $13 \mathrm{q} 14.1-\mathrm{q} 14.2$, the paternal band was possibly

Table 1 Summary of the molecular results

\begin{tabular}{lllll}
\hline Marker & Patient & Mother & Father & Genetic distance* $^{*}$ \\
\hline D13S221 & bc & bc & ab & - \\
D13S218 & ac & ac & bc & - \\
D13S263 & ab(b?) & aa & ab & - \\
D13S118 & ab & bb & aa & - \\
D13S153 & ab & ab & ab & $-6 \mathrm{cM}$ \\
D13S137 & bb & ab & ab & - \\
D13S155 & abb & aa & bb & - \\
D13S284 & bcd & ab & cd & $-7 \mathrm{cM}$ \\
D13S124 & ac & cc & ab & $12 \mathrm{cM}$ \\
D13S162 & bc & bd & ac & - \\
D13S170 & bb & bc & ab & - \\
D13S173 & bb & bb & ab & -
\end{tabular}

^Approximate genetic distances according to Généthon and LDB linkage maps. stronger than the maternal one (data not shown). Normal biparental inheritance of loci proximal (D13S221) and distal (D13S170, D13S173) to $13 \mathrm{q} 14$ was seen. These results indicate that the triplication of $13 \mathrm{q} 14$ was paternal in origin and that both paternal chromosomes 13 were involved in its formation.

Clinical observations suggest that, in general, tetrasomy of an autosomal segment causes a similar, but more severe clinical picture than trisomy of the same segment. This has been shown, for example, for $9 p, 18 p$, and 15(q12-q13). ${ }^{11}$ Further, for some segments $(8 \mathrm{p}, 12 \mathrm{p})$ tetrasomy is viable only in a mosaic state while trisomy without mosaicism is compatible with survival. No other patients with tetrasomy for segment 13q14 are yet known. Trisomy of this segment was only detected following cytogenetic investigation of families with several members affected with retinoblastoma; unbalanced familial insertional translocations resulting in 13q14 deletion caused retinoblastoma while those resulting in 13q14 duplication caused a very mild clinical phenotype or even no anomalies. ${ }^{12-14}$ The patients were described as either having "no definite clinical syndrome", ${ }^{12}$ being normal, ${ }^{13}$ or normal with short stature. ${ }^{14}$ Thus, the mild but still distinct phenotype of our proband with triplication as compared to the above mentioned cases with duplication of $13 \mathrm{q} 14$ is in accordance with the previous observations with other chromosomal segments. Duplication of a larger segment (13q12-q22) including $13 \mathrm{q} 14$ was also found in family investigations because of familial occurrence of retinoblastoma. ${ }^{15}$ Not unexpectedly because of the larger size of the duplication, these patients showed mild dysmorphism and mild to moderate mental retardation. Patients with a proximal duplication, $\operatorname{dup}(13)($ pter-q14/q21), show a non-specific pattern of mostly minor anomalies and moderate mental retardation, while patients with a distal $13 \mathrm{q}$ duplication including 13q14, for example, $\operatorname{dup}(13)(q 14 \rightarrow$ qter), show multiple congenital anomalies including postaxial polydactyly and profound mental retardation. ${ }^{16}$

Tetrasomy of (13) (q14.3 $\rightarrow$ q22), that is, most of segment $13 \mathrm{q} 21$, in combination with duplications of the adjacent proximal (13q14.1-q14.3) and distal (13q22-qter) seg- 

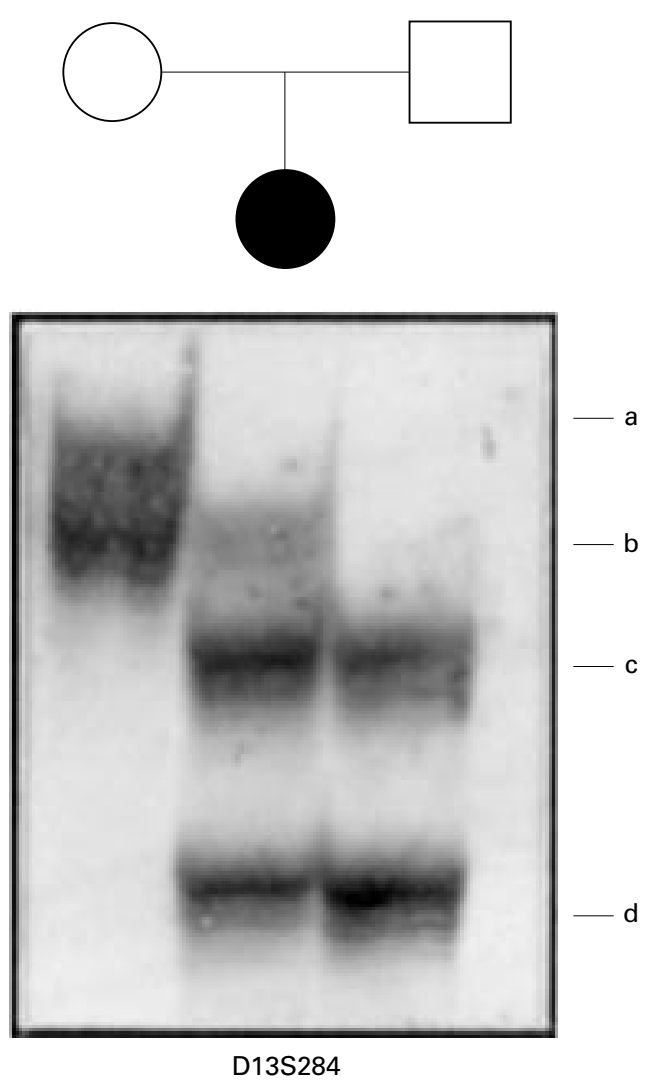

Figure 3 PCR amplification of D13S284 microsatellite locus showing one maternal and two paternal alleles.

ments was determined in a newborn girl with a complex de novo rearrangement. ${ }^{17}$ The proband died shortly after birth with multiple major malformations including a malformation of the brain stem, cerebellar hypoplasia, cloudy corneae, aniridia, microphthalmia and other ocular anomalies, intestinal malrotation, cystic horseshoe kidneys, patent urachus, polydactyly of the fingers and toes, and many others. In this case, it is impossible to attribute single anomalies to duplication versus triplication of specific $13 \mathrm{q}$ segments present in a hyperdiploid state.

While direct or inverted tandem duplications could be formed through unequal crossover or unequal sister chromatic exchange, ${ }^{18}$ triplications of this kind require a more complex mechanism of origin. For a case of triplication of 15q11-q13, meiotic recombination between an inv $\operatorname{dup}(15)(\mathrm{q} 13)$ chromosome and a normal 15 with subsequent loss of the marker was proposed. ${ }^{1}$ A similar mechanism has also been proposed to explain amplification of the dihydrofolate reductase (DHFR) gene in Chinese hamster cells. ${ }^{19}$ Another possible mechanism would be that the parent from whom the aberration stems (in our case the father) would either carry a constitutional paracentric inversion of the triplicated segment or such an inversion would be formed in a prezygotic cell. Although banded chromosome examinations of the father of our proband yielded normal results, a paracentric inversion of just $13 q 14$ could not be excluded unless bicolour FISH studies were performed, which in this case was not possible. Two crossovers within the inversion loop with a $U$ type exchange would result in a tandem triplication with an inverted middle segment.

This type of triplication has so far been reported for the following chromosomal segments: $2 \mathrm{q} 11.2-\mathrm{q} 21,{ }^{7} 2 \mathrm{q} 37,{ }^{2}$ 5p14-p15.33, ${ }^{3} 7$ p21.2-p21.3, ${ }^{4} 9$ p $13-p 22,{ }^{5} 10 q 26,{ }^{6} 13 q 14$ (present report), and 15q11-q13. ${ }^{2021}$ It is interesting to note that in several cases an unequal distance between two FISH signals (the proximal and the middle versus the middle and the distal) indicated that either the middle segment was inverted or, less likely, the middle segment was in normal orientation, but the proximal and distal segments were inverted, ${ }^{146}$ probably, according to the illustrations, the cases of Rauch et $a l^{2}$ and Harrison et $a l^{\beta}$ and the present report. In the other patients, no special attention was paid to the issue of direct versus inverted triplication. In the case of direct orientation of all three segments, the distances between the signals should be of equal length; however, even in the case of an inverted middle segment, the distances would only be of equal length if the FISH probes map to the middle of the triplicated segment at equal distances from the two ends.

It is likely that a proportion of cases of segmental triplication are incorrectly interpreted as duplication while in fact there is triplication of a smaller segment. This could also account for part of the phenotypic variability observed between such patients with presumed similar phenotypes, especially with respect to interstitial segments for which there are few familial insertional translocations and thus proven instances of duplication. Banded chromosome analysis alone will in very few cases allow discrimination between duplication and triplication. We therefore propose that FISH studies using probes mapping to the presumed duplicated segment should constitute part of the diagnostic work up following determination of a tandem duplication through banded chromosome examination and chromosome painting with whole chromosome probes.

The authors thank Drs P Lichter and S Stilgenbauer for YACs from the 13q14 segment. The investigation was supported by the Swiss National Foundation, grant Nos 32-45604.95 and 32-37798.93.

LUKRECIJA BRECEVIC* SEHER BASARAN† FABRIZIO DUTLY * BENNO RÖTHLISBERGER * ALBERT SCHINZEL*

*Institute of Medical Genetics, University of Zürich, Rämistrasse 74, CH-8001 Zürich, Switzerland

†Department of Paediatrics, University of Istanbul, Istanbul, Turkey

Correspondence to: Professor Schinzel, schinzel@medgen.unizh.ch

1 Schinzel AA, Brecevic L, Bernasconi F, Binkert F, Berthet F, Wuilloud A, Robinson WP. Intrachromosomal triplication 15q11-q13. F Med Genet 1994;31:798-803.

2 Rauch A, Pfeiffer RA, Trautmann U. Deletion or triplication of the alpha-3(Vi) collagen gene in three patients with 2 q37 chromosome aberrations and symptoms of collagen-related disorders. Clin Genet 1996;49:27985

3 Harrison KJ, Teshima IE, Silverman MM, Jay V, Unger S, Robinson WP, James A, Levin A, Chitayat D. Partial tetrasomy with triplication of chromosome (5) (p14-p13.33) in a patient with severe multiple congenital anomalies. Am F Med Genet 1998;79:103-7.

4 Rivera H, Bobadilla L, Rolon A, Kunz J, Crolla JA. Intrachromosomal triplication of distal 7p. F Med Genet 1998;35:78-80.

5 Verheij JBGM, Bouman K, van Lingen RA, van Lookeren Campagne JG, Leegte B, van der Veen AY, Hofstra RMW, Buys CHCM, van Essen AJ. Tetrasomy $9 \mathrm{p}$ due to an intrachromosomal triplication of 9p13-p22. Am $\mathcal{F}$ Med Genet 1999;86:168-73.

6 Devriendt K, Matthijs G, Holovoet M, Schoenmakers E, Fryns JP. Triplication of distal chromosome 10q. $\mathcal{F}$ Med Genet 1999;36:242-5.

7 Wang J, Reddy KS, Wang E, Halderman L, Morgan BLG, Lachman RS, Lin Wang J, Reddy KS, Wang E, Halderman L, Morgan BLG, Lachman RS, Lin
HJ, Cornford ME. Interchromosomal triplication of $2 \mathrm{q} 11.2-\mathrm{q} 21$ in a $\mathrm{HJ}$, Cornford ME. Interchromosomal triplication of $2 \mathrm{q} 11.2-\mathrm{q} 21$ in a
severely malformed infant: case report and review of triplications and their severely malformed infant: case report and review of trip
possible mechanisms. Am $\mathcal{F M e d}$ Genet 1999;82:312-17.

8 Arnoldus EPJ, Wiegant J, Noordemeer IA, Wessels JW, Beverstock GC, Grosveld GC, van der Ploeg M, Raap AK. Detection of the Philadelphia chromosome in interphase nuclei. Cytogenet Cell Genet 1990;54:108-11.

9 Driesen MS, Dauwerse JG Wapenaar MC, Meershoek EJ, Mollevanger P, Chen KL, Fischbeck KH, van Ommen GJB. Generation and fluorescent in situ hybridization mapping of yeast artificial chromosomes of $1 \mathrm{p}, 17 \mathrm{p}, 17 \mathrm{q}$ and $19 \mathrm{q}$ from a hybrid cell line by high-density screening of an amplified library. Genomics 1991;11:1079-87.

10 Stilgenbauer S, Leupolt E, Olt S, Weiss G, Schröder M, Fisher K, Bentz M, Lichter P, Döhner H. Heterogeneity of deletions involving RB-1 and D13S25 locus in B-cell chronic lymphocytic leukemia revealed by FISH.
Cancer Res 1995;55:3475-7.

11 Schinzel A. Human cytogenetics database. Oxford Medical Databases Series. Oxford: Oxford University Press, Electronic Publishing, 1994.

12 Rivera H, Turleau C, de Grouchy J, Junien C, Depoisse S, Zucker JM. Retinoblastoma-del(13q14): report of two patients, one with a trisomic sib due to maternal insertion: gene-dosage effect for esterase D. Hum Genet 1981;59:211-14. 
13 Strong LC, Riccardi VM, Ferrell RE, Sparkes RS. Familial retinoblastoma and chromosome 13 deletion transmitted via an insertional translocation. and chromosome 13 deletic

14 Turleau C, de Grouchy J, Chavin-Colin F, Despoisses S, Leblanc A. Two cases of del(13q)-retinoblastoma and two cases of partial trisomy due to a familial insertion. Ann Genet 1983;3:158-60.

15 Riccardi VM, Hittner HM, Francke U, Pippin S, Holmquist GP, Kretzer FL, Ferrell R. Partial triplication and deletion of 13q: study of a family presenting with bilateral retinoblastoma. Clin Genet 1979;15:332-45.

16 Schinzel A. A catalogue of unbalanced chromosome aberrations in man. Berlin: Walter de Gruyter, 1984

17 Chu TW, Teebi AS, Gibson L, Breg WR, Yang-Feng TL. FISH diagnosis of partial trisomy 13 and tetrasomy 13 in a patient with severe trigonocephaly (C) phenotype. Am f Med Genet 1994;52:92-6.
18 Van Dyke DL. Isochromosomes and interstitial tandem direct and inverted duplications. In: Daniel A, ed. The cytogenetics of mammalian autosomal rearrangements. New York: Alan R Liss, 1988:635-65.

19 Ma C, Martin S, Trask B, Hamlin JL. Sister chromatid fusion initiates amplification of the dihydrofolate reductase gene in Chinese hamster cells. Genes Dev 1993;7:605-20.

20 Holowinsky S, Black SH, Howard-Peebles PN, Mutirangura A, Christian S, Ledbetter DH, Reynolds J. Triplication 15q11-13 in two unrelated patients with hypotonia, cognitive delays and visual impairment. Am f Hum Genet 1993;53:A125

21 Long FL, Duckett DP, Billam LJ, Williams DK, Crolla JA. Triplication of $15 \mathrm{q} 11 \rightarrow \mathrm{q} 13$ with inv dup(15) in a female with developmental delay. $\mathcal{F} \mathrm{Med}$ Genet 1998;35:425-8.

\section{The first three mosaic cri du chat syndrome patients with two rearranged cell lines}

EDITOR-Cri du chat syndrome (CdCS) is one of the more common deletion syndromes, involving the short arm of chromosome 5, with an incidence of 1 in 50000 live births. Classically, patients with this syndrome present with microcephaly, a round face, hypertelorism, micrognathia, prominent nasal bridge, epicanthic folds, hypotonia, and severe psychomotor retardation. Infants also exhibit a high pitched cry similar to the mewing of a cat, which is usually considered diagnostic for this syndrome. ${ }^{12}$ Recently, genotype-phenotype studies in CdCS led to the identification of two separate chromosomal regions, hemizygosity for which is associated with specific phenotypes. ${ }^{3}$ A deletion of $5 \mathrm{p} 15.3$ results in the manifestation of a cat-like $\mathrm{cry}^{4}$, while a deletion of $5 \mathrm{p} 15.2$ results in the presentation of the other major clinical features of the syndrome. ${ }^{5}$ Moreover, a region for speech delay in 5 p15.3 has been identified. ${ }^{6}$

From a review of 331 published cases, Niebuhr ${ }^{2}$ estimated that most CdCS cases are the result of de novo deletions (about 80\%), some derive from a familial rearrangement $(12 \%)$, and only a few show other rare cytogenetic aberrations, such as mosaicism (3\%), rings $(2.4 \%)$, and de novo translocations $(3 \%)$. Chromosomal mosaicism in CdCS has been described involving a cell line with a $5 \mathrm{p}$ deletion and a cell line with a normal karyotype. $^{27}$

We describe the first three reported cases of mosaic de novo $5 \mathrm{p}$ anomalies involving two rearranged cell lines in CdCS out of $80(3.75 \%)$ patients from the Italian Register of $\mathrm{CdCS}^{8}$ analysed in a large study of correlation between $5 \mathrm{p}$ deletion and phenotypic effect (Cerruti Mainardi et al, manuscript in preparation).

Patient 1 was the first female child of healthy, unrelated parents. At birth the mother was 29 and the father 31 years old. The pregnancy was complicated by a threatened miscarriage in the 12 th week of gestation. There had been no exposure to alcohol, nicotine, drugs, $x$ rays, or teratogens during pregnancy. Her younger sister was healthy. The family history was unremarkable.

The baby was born by caesarean section because of reduced uterine contractions in the 39th week of gestation. Apgar scores were 7 and 6 at one and five minutes, respectively. Her birth weight was $2750 \mathrm{~g}$ (10th-25th centile), length was $48 \mathrm{~cm}$ (25th centile), and head circumference was $34 \mathrm{~cm}$ (25th-50th centile).

The neonatal course was complicated by transient respiratory distress and metabolic acidosis. In the first days of life, sucking difficulties were reported, requiring nasogas- tric feeding. Neonatal physical examination showed epicanthic folds and hypertelorism. CdCS was suspected because of an abnormal cry and was confirmed by cytogenetic analysis. No significant medical illness was observed during infancy.

On physical examination at the age of 6 years, weight was $20.7 \mathrm{~kg}$ (50th centile), height was $114.5 \mathrm{~cm}$ (50th centile), and head circumference was $49 \mathrm{~cm}$ (3rd-10th centile). Clinical features included a high voice, downward slanting palpebral fissures, broad nasal bridge, hypertelorism, epicanthic folds, slight micrognathia, slightly low set ears, diastasis recti, and flat arches of the feet. Dysmorphism was felt to be mild (fig 1A).

However, developmental delay, evaluated with the Denver Developmental Screening Tests, ${ }^{9}$ was present: she sat with her head steady at 6 months, sat without support at 10 months, and walked well at 2 years. Speech delay was more severe; she spoke her first words at 4 years and could combine two different words at 6 years.

Chromosome analysis of the patient, performed on peripheral blood lymphocytes, showed two cell lines; in $73 \%$ of cells a $5 p$ deletion was observed and in $27 \%$ of cells a $5 \mathrm{p}$ duplication was observed.

FISH analysis performed with specific single locus DNA lambda phage probes spanning $5 \mathrm{p}^{10}$ identified breakpoints both on the deleted chromosome 5 and on the duplicated one. The breakpoint on the deleted chromosome 5 is in p14.1 between D5S769 and D5S711 and the breakpoints on the duplicated chromosome 5 are in p15.2 between D5S778 and D5S751 and in p12 between D5S802 and the centromere. The duplication is inverted.

The cytogenetic and FISH results are summarised in fig $1 \mathrm{~B}$ and $\mathrm{C}$. In conclusion the karyotype was interpreted as: 46,XX,ish del(5) (:p14.1 $\rightarrow$ qter)(D5S711-) [73]/46,XX,ish $\operatorname{dup}(5)(: \mathrm{p} 12 \rightarrow \mathrm{p} 15.2:: \mathrm{p} 15.2 \rightarrow \mathrm{qter})(\mathrm{D} 5 \mathrm{~S} 802++, \quad$ D5S778 ++ , D5S751-)[27]. The parents' and sister's karyotypes were normal.

Molecular analysis performed with microsatellite D5S21 $14^{11}$ indicated the paternal origin of the deleted and the duplicated chromosomes 5 .

Patient 2 was the first female child of healthy, unrelated parents. At birth the mother was 26 and the father 31 . Pregnancy was complicated by bleeding in the first 12 weeks; ultrasound examination showed intrauterine growth retardation. There was exposure to nicotine during pregnancy (15 cigarettes a day). The family history was remarkable for two deaf maternal aunts.

The baby was delivered in the 40th week of gestation. Her birth weight was $2680 \mathrm{~g}$ (3rd-10th centile); length and head circumference were not recorded. The neonatal course was complicated by metabolic acidosis. Cytogenetic analysis, performed in another laboratory because of dysmorphism, showed a karyotype with three cell lines: 46,XX,del(5) (p15)[65]/46,XX[33]/46,XX,dup(5)(p13 $\rightarrow$ pter) [2] . 
During infancy, she suffered from recurrent bronchial and pulmonary infections requiring admission to hospital. There was an episode of seizures and psychomotor development, evaluated with Denver Developmental Screening Tests, ${ }^{9}$ was delayed; she was able to sit at 1 year and to walk and speak her first words at 4 years.

Physical examination at 5 years showed weight $18.5 \mathrm{~kg}$ (50th centile), height $104 \mathrm{~cm}$ (10th-25th centile), and head circumference $47 \mathrm{~cm}$ ( $<3 \mathrm{rd}$ centile). Clinical features included a high voice, broad nasal bridge, hypertelorism, epicanthic folds, myopia and mild convergent strabismus, downturned corners of the mouth, micrognathia, low set ears, left preauricular tag, transverse flexion creases, clinodactyly, diastasis recti, flat arches of the feet, and anteriorly placed anus (fig $2 \mathrm{~A}$ ). She showed severe mental and speech delay and hyperactive behaviour.

Chromosome analysis of the patient, performed on peripheral blood lymphocytes, showed two cell lines; in $76 \%$ of cells a $5 \mathrm{p}$ deletion was observed and in $24 \%$ of cells a chromosome 5 with normal dimensions and banding pattern was observed.

FISH analysis performed with specific single locus DNA lambda phage probes spanning $5 \mathrm{p}^{10}$ established that the apparently normal chromosome 5 really represented a $5 \mathrm{p}$ duplication and identified breakpoints both on the deleted and the duplicated chromosomes 5 . The breakpoint on the deleted chromosome 5 is in p14.3 between D5S25 and D5S28 and the breakpoints on the duplicated chromosome 5 are in p14.3 between D5S25 and D5S28 and in p12 between D5S802 and the centromere. The duplication is inverted.

The cytogenetic and FISH results are summarised in fig $2 \mathrm{~B}$ and $\mathrm{C}$. In conclusion the karyotype was interpreted as: 46,XX, ish del(5) (:p14.3 $\rightarrow$ qter) (D5S28-) [76]/46,XX,ish $\operatorname{dup}(5)(: p 12 \rightarrow$ p14.3::p14.3 $\rightarrow$ qter) (D5S802++,D5S25++, D5S28-)[24]. The parents' karyotypes were normal.

Molecular analysis performed with microsatellite D5S $1981^{11}$ indicated the paternal origin of the deleted chromosome 5.

Patient 3 was the first female child of healthy, unrelated parents. At birth the mother was 30 and the father 33. The pregnancy was uneventful and there was no exposure to alcohol, nicotine, drugs, $x$ rays, or teratogens during pregnancy. Her younger sister and brother were healthy. The family history was unremarkable.

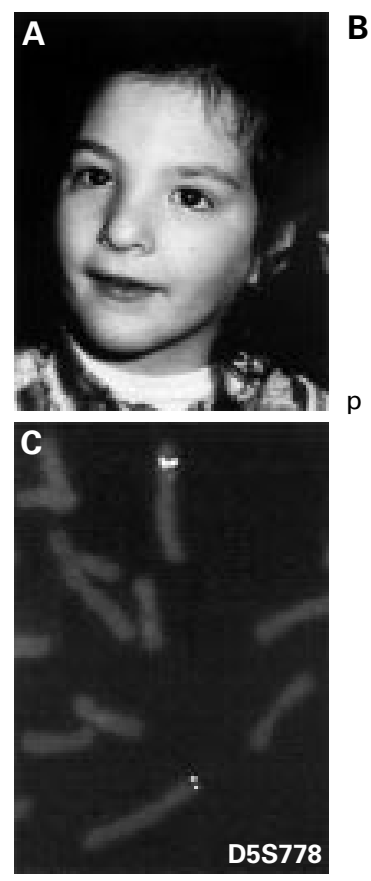

B

Chromosomes 5 in $73 \%$ of cells
Chromosomes 5 in $27 \%$ of cells

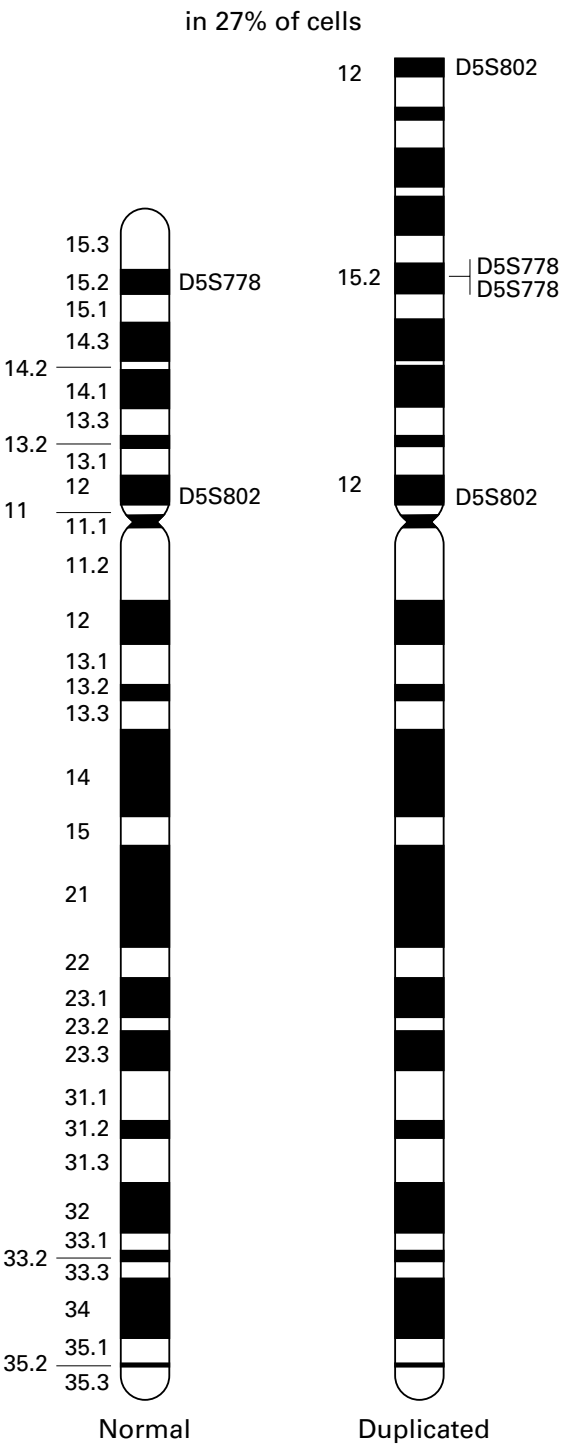

Figure 1 (A) Case 1 aged 6 years. (B) Ideogram of the normal and the abnormal chromosomes 5 in both cell lines. Specific single locus probes used to define breakpoints are shown. (C) FISH performed with D5S778 lambda phage probe shows enhanced medial signal strength on one chromosome 5 consistent with a duplication. 
The baby was delivered at 40 weeks of gestation. Her birth weight was $2600 \mathrm{~g}$ ( $3 \mathrm{rd}-10$ th centile), length was 50 $\mathrm{cm}$ (50th-75th centile), and head circumference was $33 \mathrm{~cm}$ (10th-25th centile). CdCS was suspected because of dysmorphism, microcephaly, and a high pitched monotonous cry and was confirmed by cytogenetic analysis. Talipes of the left foot was observed.

At the ages of $31 / 2$ and $51 / 2$ she underwent two operations for left cholesteatoma. During infancy her psychomotor development, evaluated with Denver Developmental Screening Tests, ${ }^{9}$ was delayed; she was able to grasp objects at 8 months, to sit at 2 years, to say her first words at 3 years, and to walk at $3 \frac{1}{2}$ years. Menarche occurred at 11 years.

On physical examination at 12 years, her weight was 40 $\mathrm{kg}$ (50th centile), height was $137 \mathrm{~cm}$ ( $<3 \mathrm{rd}$ centile), and head circumference was $48 \mathrm{~cm}$ ( $<3 \mathrm{rd}$ centile). Clinical features included a high voice, epicanthic folds, divergent strabismus, micrognathia, a high arched palate, slightly low set ears, incomplete bilateral flexion creases, diastasis recti, flat arches of the feet, and talipes of the left foot (fig 3A). She showed severe mental and speech delay and hyperactive behaviour.

Chromosome analysis of the patient, performed on peripheral blood lymphocytes, showed two cell lines with different $5 p$ deletions: in $78 \%$ of cells the deletion extended from pter to $\mathrm{p} 13$ and in $22 \%$ of cells the deletion extended from pter to p14.3.

FISH analysis performed with specific single locus DNA lambda phage probes spanning $5 \mathrm{p}^{10}$ allowed finer definition of the extent of the deletions. The breakpoint on the more deleted chromosome 5 is in p13 between D5S743 and D5S787 and the breakpoint on the less deleted chromosome 5 is in p14.3 between D5S699 and D5S796. The cytogenetic and FISH results are summarised in fig $3 \mathrm{~B}$ and $\mathrm{C}$.

In conclusion, the karyotype was interpreted as: 46,XX,ish $\operatorname{del}(5)(:$ p13 $\rightarrow$ qter) (D5S787-) [78]/46,XX,ish $\operatorname{del}(5)(: p 14.3 \rightarrow$ qter)(D5S796-) [22]. The parents' karyotypes were normal. Molecular analysis performed with microsatellite D5S1987 ${ }^{11}$ indicated the maternal origin of the deleted chromosome 5.

In summary, as a consequence of these rearrangements of chromosome 5p, at least in peripheral blood lymphocytes, patients 1 and 2 have a partial monosomic cell line and a partial monosomic/trisomic cell line, while patient 3 shows two different partial monosomies.

It is interesting to analyse the CdCS phenotype of patients 1 and 2 in relation to the presence of partial trisomy $5 \mathrm{p}$ in a proportion of cells. Partial trisomy $5 p$ was first described in 1964, ${ }^{12}$ but it is a very rare event. Most partial trisomies $5 \mathrm{p}$ are the consequence of an unbalanced
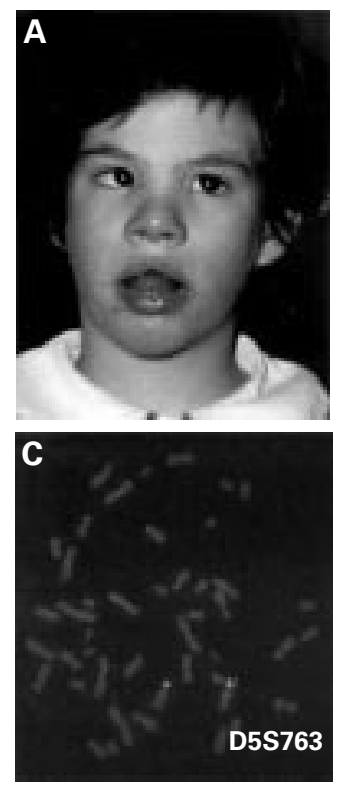

B

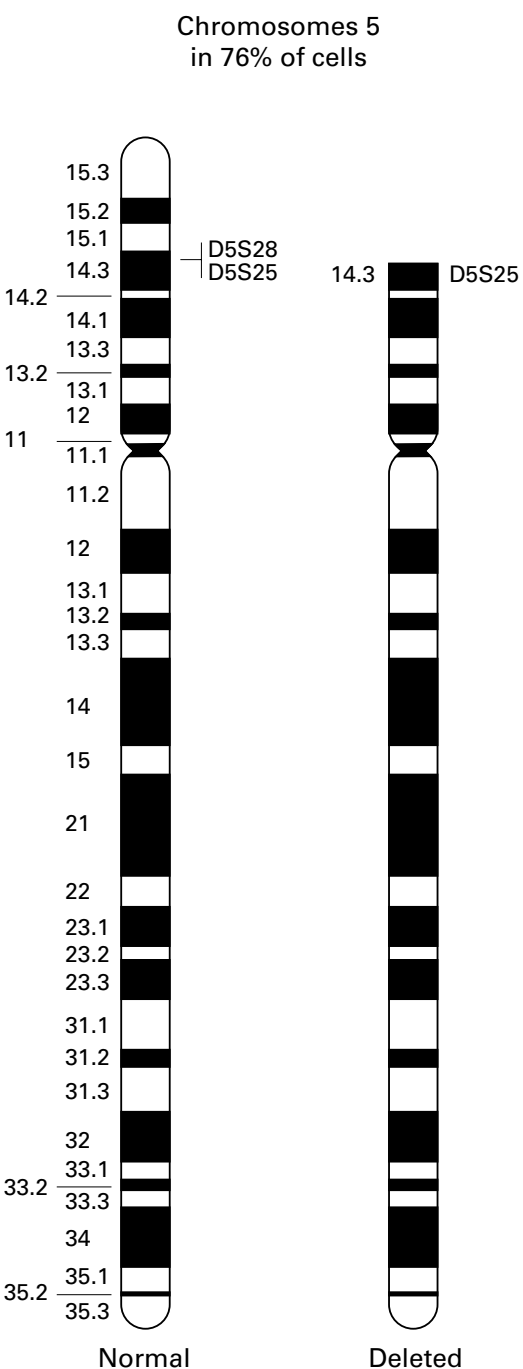

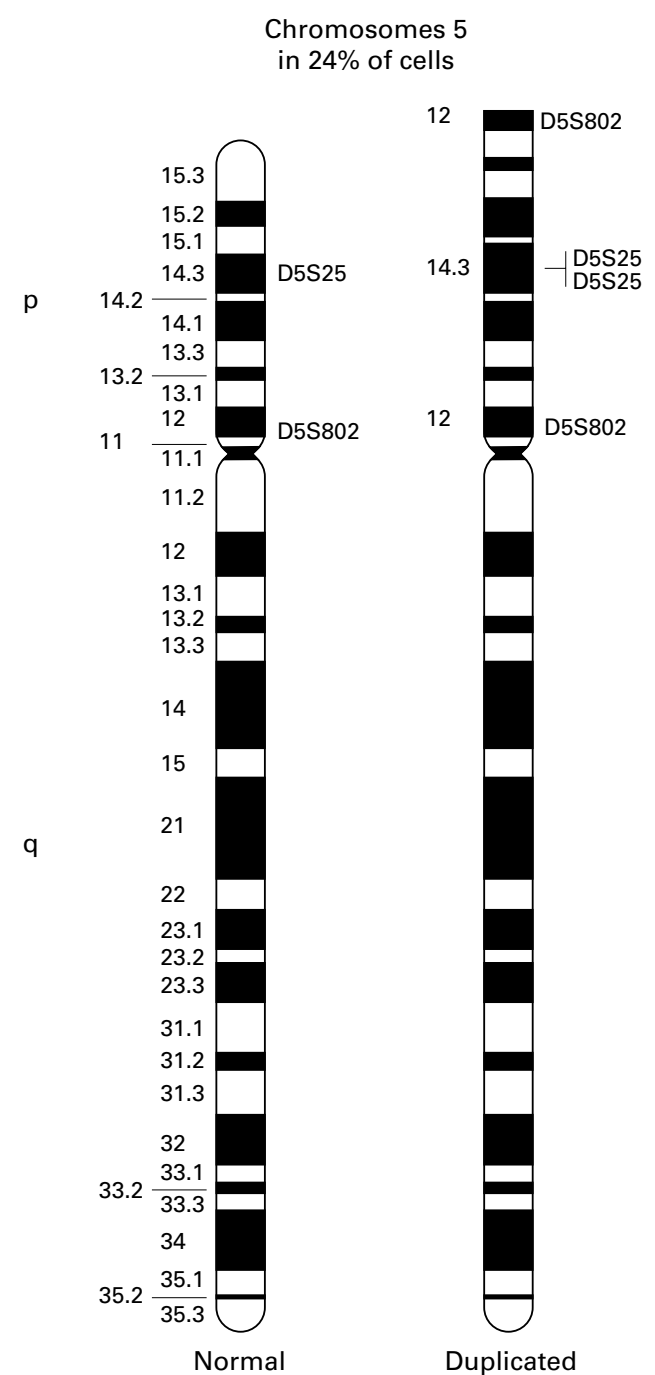

Chromosomes 5

12

Duplicated

Figure 2 (A) Case 2 at 5 years. (B) Ideogram of the normal and the abnormal chromosomes 5 in both cell lines. Specific single locus probes used to define breakpoints are shown. (C) FISH performed with D5S763 lambda phage probe shows a duplication on one chromosome 5. 
translocation with another autosome. However, although some manifestations may differ from case to case because of the effect of the monosomy of the other chromosome involved in the translocation, a clinically recognisable and consistent phenotype is always present and is apparently little influenced by the presence of concomitant autosomal imbalance. The most common manifestations are normal birth weight, macrodolichocephaly, downward slanting palpebral fissures, epicanthus, bulbous nose, low set ears, short big toes, hypotonia, seizures, and psychomotor retardation. Multiple congenital anomalies are present and early death is frequent. ${ }^{13-19}$ The extent of the clinical findings in the reported cases depends on the length of the trisomic portion. The larger the trisomy, the more pronounced are the clinical signs. Physical signs are almost absent when 5p14-ter is involved, while those cases with trisomies of chromosome material including $5 \mathrm{p} 13$ or the complete short arm have more severe multiple congenital anomalies, mental retardation, and growth failure. ${ }^{20}$ Signs and malformations described in patients with partial monosomy $5 p$ and in patients with partial trisomy $5 \mathrm{p}$ compared to those observed in patients 1 and 2 are summarised in table 1 .

Of particular interest are the mild phenotype in patient 1 and the comparison between patients 1 and 2 (figs $1 \mathrm{~A}$ and $2 \mathrm{~A}$ ). From the developmental point of view, the two patients are comparable since they are approximately the same age, the parents' educational levels are similar, and they followed the same therapeutic programme with the same person. Patient 1 shows a CdCS phenotype with the cat-like cry, dysmorphism, and developmental and speech delay. However, her phenotype is very mild in relation to the deletion breakpoint in 5p14.1 (D5S711), especially when compared with the results obtained from a wider study on CdCS (Cerruti Mainardi et al, manuscript in preparation). The large duplication of 5p12-5p15.2 apparently does not produce any significant phenotypic effect. This is contrast to patients with duplication of $5 \mathrm{p}$. Patient 2 shows a severe CdCS phenotype in relation to the deletion breakpoint in 5p14.3 (D5S28). Some clinical features and malformations are attributable to partial trisomy $5 p$ and others are common both to partial monosomy and partial trisomy $5 \mathrm{p}$ (table 1 ).

The phenotype of patient 1 is milder than patient 2, although the deletion is bigger. We therefore speculate that in patient $1,5 \mathrm{p}$ deletion and $5 \mathrm{p}$ duplication could compensate for each other with the duplicated cell line contributing a double dosage of the critical region in $5 \mathrm{p} 15.2{ }^{5}$ while the cat-like cry $^{4}$ and the speech delay regions $s^{6}$ are present in single dose (fig $1 \mathrm{~B}$ ). This compensation is not possible in patient 2 , where the region between $5 \mathrm{p} 14.3$ and the telomere is deleted in both cell lines (fig 2B). Overall, in both cases the CdCS phenotype prevails.

The cell line with the deletion is more prevalent compared with that with the duplication, at least in periph-

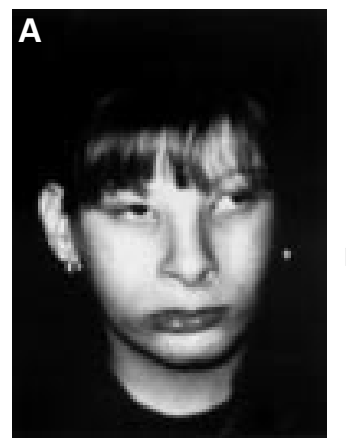

B

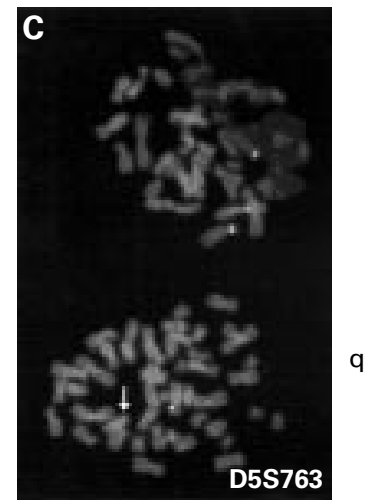

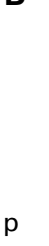

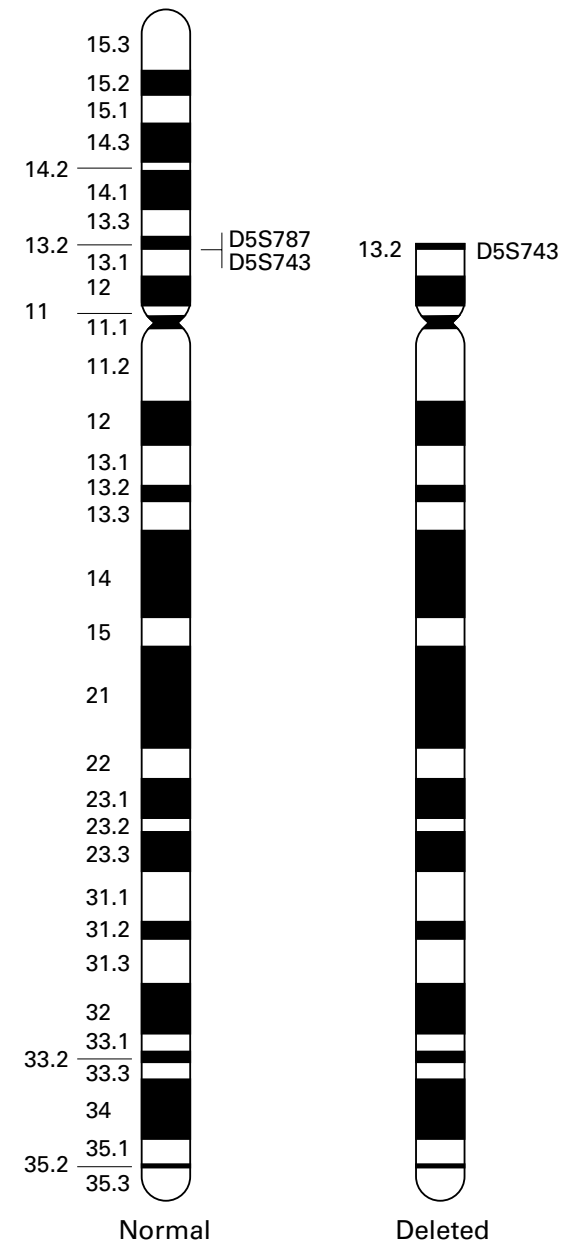

Chromosomes 5 in $78 \%$ of cells
Chromosomes 5 in $22 \%$ of cells

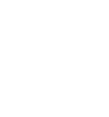

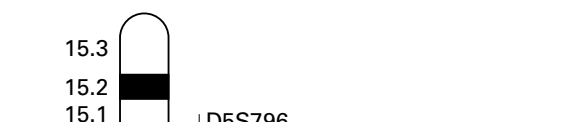

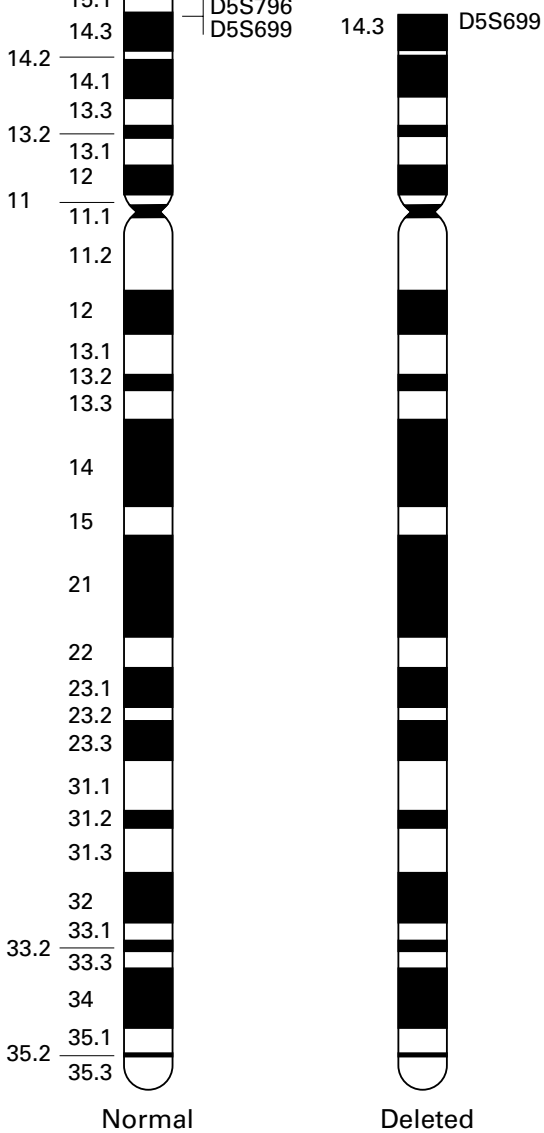

Figure 3 (A) Case 3 at 12 years. (B) Ideogram of the normal and the abnormal chromosomes 5 in both cell lines. Specific single locus probes used to define breakpoints are reported. (C) FISH performed with D5S763 lambda phage probe shows two different deletions in the two adjacent metaphases; in the upper one the probe is not deleted, while in the lower it is deleted (arrow). 
Table 1 Clinical features described in patients with monosomy $5 p^{128}$ and with trisomy $5 p^{12-20}$ compared to those observed in cases 1 and 2

\begin{tabular}{|c|c|c|c|c|}
\hline Clinical feature & $5 p$ monosomy & $5 p$ trisomy & Case 1 & Case 2 \\
\hline Low birth weight & $\square$ & & $\square$ & $\square$ \\
\hline Early death & & - & & \\
\hline Cat-like cry & ㅁ & & ㅁ & ㅁ \\
\hline Microcephaly & $\square$ & & $\square$ & 口 \\
\hline Macrodolichocephaly & & - & & \\
\hline Hydrocephalus & & - & & \\
\hline Round face & ㅁ & & & \\
\hline Broad nose bridge & $\square$ & & & $\square$ \\
\hline Downward slanting palpebral & & & & \\
\hline $\begin{array}{l}\text { fissures } \\
\text { Upward slanting palpebral } \\
\text { fissures }\end{array}$ & $\square$ & - & $\square$ & $\square$ \\
\hline Hypertelorism & $\square$ & - & $\square$ & $\square$ \\
\hline Epicanthic fold & $\square$ & - & $\square$ & $\square$ घ \\
\hline Strabismus & ㅁ & & & 口 \\
\hline Bulbous nose & & - & & - \\
\hline Low set ears & $\square$ & - & $\square$ & $\square$ (घ) \\
\hline Preauricular tags & ㅁ & & & 口 \\
\hline Narrow, high arched palate & $\square$ & & $\square$ & \\
\hline Transverse flexion creases & $\square$ & & & $\square$ \\
\hline Clinodactyly & $\square$ & - & & 口. \\
\hline Brachymetacarpals & $\square$ & & & $\square$ \\
\hline Brachymetatarsals & ㅁ & & & ㅁ \\
\hline Cerebral malformations & & - & - & \\
\hline Congenital heart defect & $\square$ & - & & \\
\hline Gut malformations & & - & & \\
\hline Kidney malformations & & - & & \\
\hline Club foot & $\square$ & - & & \\
\hline Flat arches of feet & $\square$ & & $\square$ & 口 \\
\hline Short first toes & & - & & \\
\hline Anteriorly placed anus & & - & & \\
\hline Feeding difficulty & $\square$ & & $\square$ & $\square$ \\
\hline Recurrent infections & ㅁ & - & & $\square$ \\
\hline Seizures & $\square$ & - & & 口. \\
\hline Psychomotor retardation & $\square$ & - & 口曰 & 口曰 \\
\hline
\end{tabular}

eral blood lymphocytes. This would suggest that the deletion has been favoured during development because monosomy $5 \mathrm{p}$ is less severe than trisomy $5 \mathrm{p}$, as supported by the fact that monosomy $5 p$ is far more common than trisomy $5 \mathrm{p}$.

Patient 3, where both cell lines have a deletion (fig 3B), shows a classical CdCS phenotype (fig 3A) and its severity could be because of the prevalence of the more deleted cell line.

We report a frequency of mosaicism in CdCS of 3.75\%. To the best of our knowledge, this is the largest record of cases that allows an estimation of frequency from a homogeneous pool of data. Mosaicism for structural aberrations is generally thought to be very uncommon, and the relative frequencies of the various types of structural aberrations, including deletions, have not been established. Data available on chromosomal structural rearrangements report a frequency of mosaicism varying from $0.008 \%$ in a postnatal study to $0.09 \%$ in a prenatal study. ${ }^{212}$ Hence, the frequency of mosaicism in CdCS appears to be very high if compared with other chromosomal rearrangements. Many hypotheses could explain this observation. The real frequency of mosaicism in chromosomal structural rearrangements could be understimated either because of the small number of metaphases analysed or because most studies were performed using only cytogenetic analysis and some subtle rearrangements could have been missed. For instance, in patient 2 the duplicated chromosome 5 was clearly distinguishable only by the use of molecular cyotgenetics with locus specific probes. The instability of the short arm of chromosome 5 could be attributable to the unusual richness of low or medium copy number repetitive sequences, such as LINE-1 elements, chromosome 5 specific repeats, or expressed pseudogenes, ${ }^{23-25}$ causing aberrant recombination and rearrangements within the region. There is increasing evidence that chromosome rearrangements resulting from unequal crossing overs between homologues, unequal sister chromatid exchanges, meiotic recombination within a single chromatid, and excision of intrachromatid loops may result from the presence of repeated sequences in the human genome. ${ }^{26-28}$

The absence of a normal cell line in all three cases presented here is consistent with a prezygotic origin of inverted tandem duplication. Different mechanisms have been proposed to explain the origin of such duplications. ${ }^{29-35}$ In these cases, the explanation is complicated by the presence of mosaicism and by the absence of preferential breakpoints. We could postulate that, in all cases, the first common event is the formation of a dicentric chromosome by recombination between mispaired copies of repeated and inversely oriented sequences at meiosis I; then, at anaphase I, a breakage of the resulting dicentric isochromosome would cause, respectively, the inv $\operatorname{dup}(5 p)$ in patients 1 and 2 and a $\operatorname{del}(5 p)$ in patient 3. Mosaicism could then arise mitotically at the level of a single DNA strand where loop formation and unequal crossing over between repeated sequences could cause breakage of the strand at different points and generate the deleted cell line in patients 1 and 2 and the line with a bigger deletion in patient 3.

In conclusion, these patients represent the first three cases of de novo $5 \mathrm{p}$ anomalies involving two rearranged cell lines, and provide new insights into mosaic structural rearrangements and into genotype-phenotype correlations in CdCS.

The first two authors contributed equally to this work. We thank the families for their cooperation and Mr Domenico Carratta for his skilful photographic assistance. This work was supported by an Italian Telethon Foundation grant (E.511) and by the Italian Cri du Chat Children Association (ABC). IL-2 lymphocyte cell lines of patients are stored at the Galliera Genetic Bank, supported by an Italian Telethon Foundation grant (C.42).

$$
\begin{array}{r}
\text { C PERFUMO } \\
\text { P CERRUTI MAINARDI } \\
\text { A CALI } \\
\text { P }^{\dagger} \\
\text { G COUCOURDE } \dagger \\
\text { F ZARA } \\
\text { S CAVANI } \\
\text { J OVERHAUSER } \\
\text { F DAGNA BRICARELLI } \\
\text { M PIERLUIGI }
\end{array}
$$

${ }^{\star}$ Human Genetics Laboratory, Galliera Hospital, Via A Volta 10r, 16128 Genova, Italy

tDepartment of Paediatrics and Genetics, S Andrea Hospital, Vercelli, Italy

¥Thomas fefferson University, Philadelphia, PA, USA

Correspondence to: Dr Dagna Bricarelli, dagna@galliera.it

1 Lejeune J, Lafourcade J, Berger R, Turpin R. Trois cas de délétion partielle du bras court d'un chromosome 5. C R Acad Sci 1963;257:3098-102.

Niebuhr E. The cri du chat syndrome. Epidemiology, cytogenetics and clinical features. Hum Genet 1978;44:227-75

3 Overhauser J, Huang X, Gersh M, Wilson W, McMahon J, Bengtsson U, Rojas K, Meyer M, Wasmuth JJ. Molecular and phenotypic mapping of the short arm of chromosome 5: sublocalization of the critical region for cri-du-chat syndrome. Hum Mol Genet 1994;3:247-52.

4 Gersh M, Goodart SA, Pasztor LM, Harris DJ, Weiss L, Overhauser J. Evidence for a distinct region causing a cat-like cry in patients with $5 \mathrm{p}$ deletions. Am F Hum Genet 1995;56:1404-10.

5 Goodart SA, Simmons AD, Grady D, Rojas K, Moyzis RK, Lovett M, Overhauser J. A yeast artificial chromosome contig of the critical region for cridu-chat syndrome. Genomics 1994;24:63-8.

6 Church DM, Bengtsson U, Nielsen KV, Wasmuth JJ, Niebhur E. Molecular definition of deletions of different segments of distal $5 p$ that results in distinct phenotypic features. Am ₹ Hum Genet 1995;56:1162-72.

7 Romano C, Ragusa RM, Scillato F, Greco D, Amato G, Barletta C. Phenotypic and phoniatric findings in mosaic cri du chat syndrome. Am $\mathcal{F}$ Med Genet 1991;39:391-5.

8 Cerruti Mainardi P. La sindrome del cri-du chat in età adulta. In: Andria G, Dagna Bricarelli F, Del Porto G, De Marchi M, Federico A, ed. Patologia genetica ad esordio tardivo. Bologna: Monduzzi, 1987:113-28.

9 Frankenburg WK, Dodds JB. The Denver Developmental Screening Tests. f Pediatr 1967;71:181-91.

10 Carlock LR, Wasmuth JJ. Molecular approach to analyzing the human $5 \mathrm{p}$ deletion syndrome, cri du chat. Som Cell Mol Genet 1985;11:267-77.

11 Dib C, Fauré S, Fizames C, Samson D, Drouot N, Vignal A, Millasseau P, Marc S, Hazan J, Seboun E, Lathrop M, Gyapay G, Morissette J, Weissenbach J. A comprehensive genetic map of the human genome based on 5,264 microsatellites. Nature 1996;380:152-4.

12 Lejeune J, Lafourcade J, Berger R, Vialatte J, Boeswillwald M, Seringe P, Turpin R. Ségrégation familiale d'une translocation 5-13 déterminant une monosomie et une trisomie partielle du bras court du chromosome 5 . Maladie du cri du chat et sa réciproque. C R Acad Sci 1964;258:5767-70. 
13 Opitz JM, Patau K. A partial trisomy $5 \mathrm{p}$ syndrome. Birth Defects 1975;11:191-200

14 Dallapiccola B, Calabro A, Forabosco A, Preto G. Trisomy 5p. Acta Med Auxol 1976;8:63-73.

15 Cordero JF, Miller WA, Liberfarb RM, Atkins L, Holmes LB. Trisomy 5p: a variable phenotype. Pediatr Res 1977;11:525.

16 Di Liberti JH, McKean R, Webb MJ, Williams G. Trisomy 5p: delineation of clinical features. Birth Defects 1977; 13(3C):185-94.

17 Rodewald A.Trisomy 5p syndrome. $\mathcal{F}$ Med Genet 1979;16:406-7.

18 Carnevale A, Hernandez M, Limòn-Toledo I, Frias S, Castillo J, del Castillo V. A clinical syndrome associated with dup(5p). Am f Med Genet 1982;13: 277-83.

19 Kleczkowska A, Fryns JP, Moerman PH, Vandenberghe K, Van der Berghe $\mathrm{H}$. Trisomy of the short arm of chromosome 5: autopsy data in a malformed newborn with inv dup (5)(p13.1-p15.3). Clin Genet 1987;32: 49-56.

20 Khodr GS, Cadena G, Le KL, Kagan-Hallet J. Duplication (5p13-pter): prenatal diagnosis and review of the literature. Am $\mathcal{f}$ Med Genet prenatal diagnc

21 Kleczkowska A, Fryns JP, Van der Berghe H. On the variable effect of mosaic normal/balanced chromosomal rearrangements in man. $\mathcal{F}$ Med

22 Hsu LYF, Yu MT, Richkind KE, Van Dike DL, Crandall BF, Saxe DF, Khodr GS, Mennuti M, Stetten G, Miller WA, Priest JH. Incidence and significance of chromosome mosaicism involving an autosomal structural abnormality diagnosed prenatally through amniocentesis: a collaborative study. Prenat Diagn 1996;16:1-28.

23 Sargent CA, Chalmers IJ, Leversha M, Affara NA. A rearrangement on chromosome 5 of an expressed human beta-glucuronidase pseudogene. Mamm Genome 1994;5:791-6.

24 Simmons AD, Goodart SA, Gallardo TD, Overhauser J. Five novel genes from cri-du-chat critical region isolated by direct selection. Hum Mol Genet $1995 ; 4: 295-302$

25 Thompson TG, DiDonato CJ, Simard LR, Ingraham SE, Burghes AH, Crawford TO, Rochette JR, Mendell JR, Wasmuth JJ. A novel cDNA detects homozygous microdeletions in greater than $50 \%$ of type I spinal muscular atrophy patients. Nat Genet 1995;9:56-62

26 Henry I, Puech A, Riesewijk A, Ahnine L, Mannens M, Beldjord C, Bitun P, Tournade MF, Landrieu P, Junien C. Somatic mosaicism for partial paternal isodisomy in Wiedemann-Beckwith syndrome: a postfertilization event. Eur 7 Hum Genet 1993;1:19-29.

27 Robinson WP, Dutly F, Nicholls RD, Bernasconi F, Penaherrera M, Michaelis RC, Abeliovich D, Schinzel A. The mechanism involved in formation of deletion and duplications of $15 \mathrm{q} 11 \rightarrow 13$. I Med Genet 1998;35:130-6.

28 Lopes J, Ravise N, Vandenberghe A, Palau F, Ionasescu V, Mayer M., Levy N, Wood N, Tachi N, Bouche P, Latour P, Ruberg M., Brice A, LeGuern E. Fine mapping of de novo CMT1A and HNPP rearrangements within CMT1A-REPs evidences two distinct sex-dependent mechanisms and candidate sequences involved in recombination. Hum Mol Genet 1998;7: $141-8$.

29 Weleber RG, Verma RS, Kimberling WJ, Fieger HG, Lubs HA. Duplication-deficiency of the short arm of chromosome 8 following artificial insemination. Ann Genet 1976;19:241-7.

30 Dill FJ, Scherzter M, Sandercock J, Tischler B, Wood S. Inverted tandem duplication generates a duplication deficiency of chromosome $8 \mathrm{p}$. Clin Genet 1987;32:109-13

31 Mitchell JJ, Vekemans M, Luscombe S, Hayden M, Weber B, Richter A, Sparkes R, Kojis T, Watters G, Der Kaloustian VM. U-type exchange in a paracentric inversion as a possible mechanism of origin of an inverted tandem duplication of chromosome 8. Am ₹ Med Genet 1994;49:384-7.

32 Guo WJ, Callif-Daley F, Zapata MC, Miller ME. Clinical and cytogenetic findings in seven cases of inverted duplication of $8 \mathrm{p}$ with evidence of a telomeric deletion using fluorescence in situ hybridization. Am $\mathcal{7}$ Med Genet meric deletion

33 Hoo JJ, Chao M, Szego K, Rauer M, Echiverri SC, Harris C. Four new cases of inverted terminal duplication: a modified hypothesis of mechanism of origin. Am f Med Genet 1995;58:299-304.

34 Floridia G, Piantanida M, Minelli A, Dellavecchia C, Bonaglia C, Rossi E, Gimelli G, Croci G, Franchi F, Gilgenkrantz S, Grammatico P, Dalpra' L, Wood S, Danesino C, Zuffardi O. The same molecular mechanism at maternal meiosis I produces mono- and dicentric $8 \mathrm{p}$ duplications. Am $\mathcal{f}$ Hum Genet 1996;58:785-96

35 Jenderny J, Poetch M, Hoelzenbein M, Friedrich U, Jauch A. Detection of a concomitant distal deletion in an inverted duplication of chromosome 3. Is there an overall mechanism for the origin of such duplications/deficiencies? Eur f Hum Genet 1998;6:439-44.

\section{Abnormal sex differentiation and multiple congenital abnormalities in a subject harbouring an apparently balanced $(6 ; 8)$ translocation}

EDITOR-In XY subjects, the testes are influenced by the activity of the sex determining region $\mathrm{Y}(S R Y)$ gene and its abnormal function usually results in various degrees of sex reversal. ${ }^{1}$ However, as suggested by several authors, ${ }^{2-5}$ abnormal sexual development may also be caused by errors in genes located on either the $\mathrm{X}$ chromosome (the dosage sensitive sex reversal locus (DSS) at Xp21.3) or autosomes. A few reports also describe abnormal sex development in male patients presenting with $6 \mathrm{q}$ chromosome rearrangements, ${ }^{67}$ but a more precise localisation at this level of a gene involved in sex determination has not been done.

The present report describes a 46,XY subject of Algerian origin, presenting with complete gonadal failure, abnormal external genitalia, and multiple congenital abnormalities. At birth, bilateral undescended testes, glandular hypospadias, and hypoplastic penis were noted. However, owing to sociocultural conditions, no investigations were performed until the age of 34 years, when he was assessed for infertility and learning disability. His phenotype included several dysmorphic features: squint, full lips, broad nasal root, large and low set ears, mildly short neck, gynaecomastia, widely spaced nipples, dorsal and lumbar scoliosis, and gynaecoid morphology. The external genitalia were hypoplastic and no gonads were found in the scrotum. However, the patient presented with post-androgen therapy virilisation, including sparse pubic and facial hair. $X$ ray examination of the skeleton showed L5-S1 vertebral fusion and bilateral lysis of the vertebral isthmus, increased lumbar vertebral canal, and bilateral 4-5 brachymetacarpus. Ophthalmological examination showed considerable reduction in visual acuity (6/10 on the right side and $3 / 10$ on the left side), amblyopia, divergent strabismus, and visual field loss with right central scotoma. Abdominal ultrasound examination failed to identify any structure that might be interpreted as a gonad. Endocrinological investigation showed complete absence of testicular function: plasma testosterone was $0.57 \mathrm{ng} / \mathrm{ml}$ (normal 3.4-9 ng/ml) with no response to HCG stimulation, plasma FSH was $67.5 \mathrm{mIU} / \mathrm{ml}$ (normal 1-5 mIU/ml) and plasma LH was 19 $\mathrm{mIU} / \mathrm{ml}$ (normal $0.8-4 \mathrm{mIU} / \mathrm{ml}$ ). After administration of

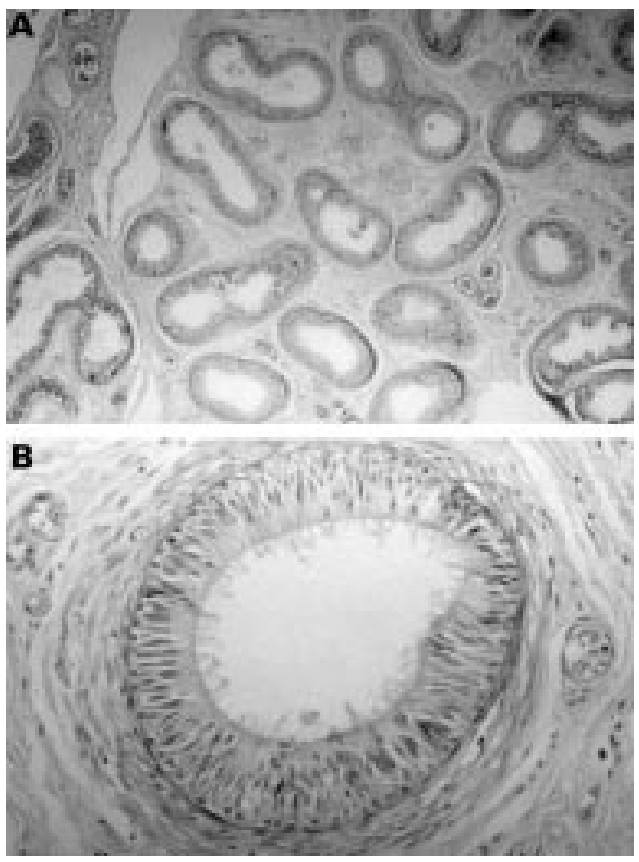

Figure 1 Histological section through the left inguinal structure showing anarchic epididymal tissue surrounded by a small amount of fibrous cells. Microscopic magnification $\times 4(A)$ and $\times 40(B)$. 
A

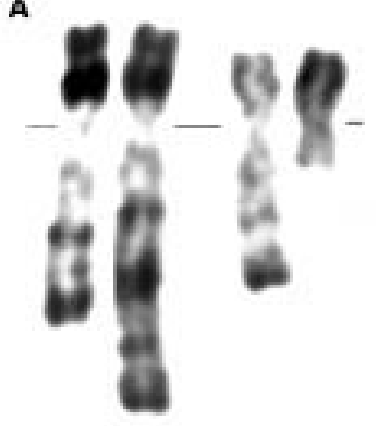

B
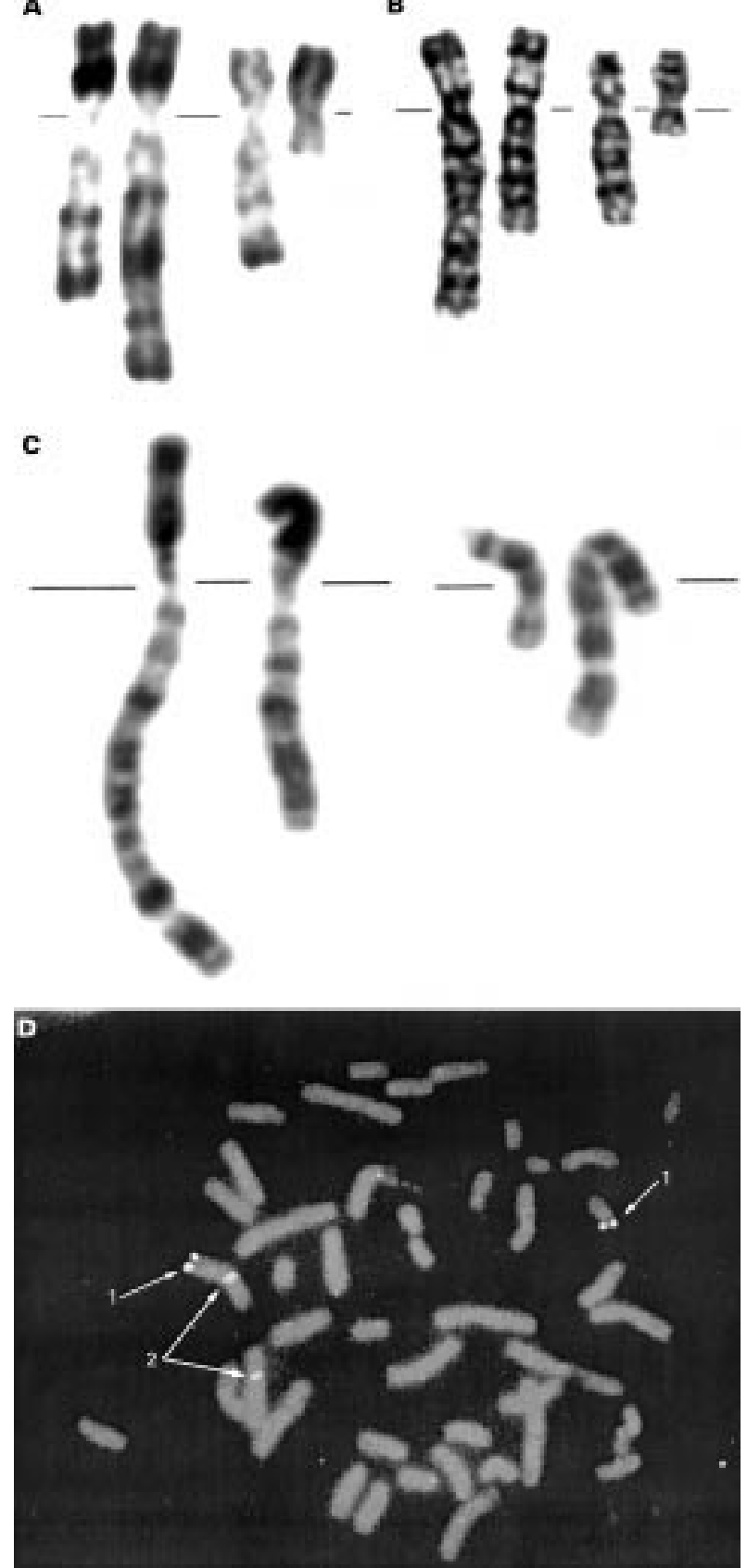

Figure 2 Balanced translocation 6;8 (A) RHG banding, (B) GTG banding, and $(C)$ high resolution banding. (D) FISH using the probe specific for the chromosomal band $6 q 27$ (arrows 1) showed that the breakpoint on the chromosome 6 is proximal to the TATA binding factor (hTBP, TFIID) gene. Arrows 2=alpha satellite chromosome 6 (ONCOR).

LHRH $\left(0.1 \mathrm{mg} / \mathrm{m}^{2}\right) \mathrm{FSH}$ rose to $194 \mathrm{mIU} / \mathrm{ml}$ and $\mathrm{LH}$ to $63.1 \mathrm{mIU} / \mathrm{ml}$. The other plasma hormonal levels, including oestradiol, prolactin, cortisol, ACTH, TSH, DHT, 17-OHprogesterone, and $\mathrm{D}-4$-androstenedione, were within the normal range. Calcium binding protein and alkaline phosphatase were also normal.

Laparoscopy was performed and a gonad-like structure was identified and removed from the left inguinal canal. However, no such structure was found on the right side. The patient had a post-appendectomy scar in the right lower abdominal quadrant, suggesting that the gonad might have been removed during the surgical procedure. Histology of the left inguinal structure (fig 1) showed hypoplastic deferent and spermatic cords together with a thin albuginea and a structurally anarchic epididymis-like tube surrounded by a small amount of fibrous cells. The structure did not contain any specific differentiated or undifferentiated testicular tissue.

Cytogenetic analysis using RHG, GTG, GTBG, and RTBG banding showed a homogeneous 46,XY,t(6;8)(q27;q13.2) chromosomal complement (fig $2 \mathrm{~A}, \mathrm{~B}$, and $\mathrm{C})$. No microdeletion or microduplication could be identified at either breakpoint level. A count of 20 QFQ banded metaphases showed a normally fluorescent Y chromosome. The parents, of Algerian origin, were not available for investigation. Fluorescence in situ hybridisation (FISH) performed using chromosome 6 and 8 paints (ONCOR) confirmed the balanced translocation (data not shown). To position the distal breakpoint at 6q27 more closely, a FISH technique was performed, using a TATA binding factor gene specific probe (ONCOR) that gave a signal close to the breakpoint on the derivative chromosome 8 (fig 2D).

Southern blot and SSCP analysis of the SRY gene in the subject were found to be identical to that of a normal male and hybridisation with the DXS319 probe, which maps to the distal portion of the DSS locus at $\mathrm{Xp} 21.3$, indicated that he carried a single copy of this region (data not shown). Therefore, abnormalities of either of these loci could be excluded as a cause of the patient's phenotype.

To date, a few reports have described abnormal sex development in 46,XY males with partial deletion of terminal 6q. In 1975, Milosevic and Kalicanin ${ }^{8}$ reported a 46,XY subject presenting with growth and mental retardation, microcephaly, dysmorphism including hypertelorism, a broad nasal root, malformed ears, micrognathia, multicystic kidney, bone abnormalities, and bilateral cryptorchidism. The patient had a de novo chromosomal rearrangement resulting in 6q25-6qter deletion. The same cytogenetic abnormality with a similar phenotype was reported by Baroshesky et $a l .{ }^{9}$ Ito et $a l^{10}$ described a male child presenting with an 6q21-q27 deletion, mental retardation, and several congenital abnormalities including bilateral cryptorchidism and thymus atrophy. Two other reports described similar patients. ${ }^{11}{ }^{12}$ Most of these cases also presented with abnormalities of the kidney and Turner-like phenotype (short stature, cervical cystic hygroma, short neck, and widely spaced nipples). Interestingly, deletions of the long arm of chromosome 6 proximal to band $6 \mathrm{q} 25$ do not seem to result in either kidney, genital, or Turner-like anomalies. In our patient, gonadal failure was diagnosed by ultrasound and endocrinological studies, which also excluded pituitary gonadotrophin deficiency, anomalies of the androgen receptor, or a block in testosterone synthesis. In 1987, Fonatsch et $a l^{13}$ assigned the TCP1 locus to band $6 q 25-q 27$. This gene is the human homologue of the mouse $T c p-1$ locus, which is part of the mouse t complex and codes for a protein abundantly expressed in testicular germ cells. Another testis expressed gene, TCP10, which is genetically linked to the oestrogen receptor locus, has been assigned to the same region. ${ }^{14}$ Experimental knock-out mice for the $T c p-1$ and $T c p-10$ loci show abnormal testis development and are sterile. In our patient, the $6 \mathrm{q}$ breakpoint was shown to be located at $6 \mathrm{q} 27$, proximal to the TATA binding factor gene. The human homologue $(T)$ of the mouse $T$ (Brachyury) gene has also been located in this region. ${ }^{15}$ In vertebrates, the protein product of the $T$ gene is a transcription factor crucial for the formation of the normal mesoderm. T mutant Brachyury mice die in mid gestation with severe defects in posterior mesoderm tissues. Heterozygous mice are viable but have posterior axial malformations. $\mathrm{T}$ protein has been shown to be associated with the mouse $t$ haplotype, a variant form of the $t$ complex characterised by transmission ratio distortion, male sterility, and recombination suppression. In humans, the $\mathrm{T}$ protein is involved in susceptibility to spina bifida, a multifactorial 
neural tube defect. Morrison et $a l^{16}$ showed that the human $T$ gene maps to $6 \mathrm{q} 27$ and lies between the two other genes of the T complex, TCP1 and TCP10.

The present report suggests that male sex determination and differentiation is a complex process, involving several autosomal loci, and at least one of them is possibly located at $6 \mathrm{q} 27$.

$$
\begin{array}{r}
\text { A ION }^{\star} \dagger \\
\text { H COPIN } \\
\text { M BARNOUX } \\
\text { C AJZENBERG\$ } \\
\text { A LESOURD } \\
\text { O CUSSENOT }{ }^{\star \star} \\
\text { J LUBETZKI }
\end{array}
$$

*Génétique Contitutionnelle et Moléculaire, Service d'Histologie,

Embryologie, Cytogénétique, et Anatomie Pathologique, Hôpital

Saint-Vincent de Paul, 82 Av Denfert Rochereau, Paris 75014, France

tDepartment of Medical Genetics, St George's Hospital Medical School,

London, UK

$\ddagger$ Laboratoire de Cytogénétique, Hôpital Lariboisière, Paris, France

SService de Médecine Interne, Hôpital Lariboisière, Paris, France

- Service d'Anatomie et de Cytologie Pathologiques, Hôpital St Louis,

Paris, France

**Service d'Urologie, Hôpital Saint Louis, Paris, France

Correspondence to: Dr Telvi, telvi-1@filnet.fr or Dr Ion, aion@sghms.ac.uk

1 Sinclair AH, Berta P, Palmer MS, Hawkins JR, Griffiths BL, Smith MJ, Foster JW, Frischauf AM, Lovell-Badge R, Goodfellow PN. A gene from the human sex-determining region encodes a protein with homology to a conserved DNA-binding motif. Nature 1990;346:240-4.

2 Foster JW, Dominguez-Steglich MA, Guioli S, Kwok C, Weller PA, Stevanovic M, Weissenbach J, Mansour S, Young ID, Goodfellow PN, Brook JD, Schafer AJ. Campomelic dysplasia and autosomal sex reversal caused by mutations in an SRY-related gene. Nature 1994;372:525-30.
3 Wilkie AOM, Campbell FM, Daubeney P, Grant DB, Daniels RJ, Mullarkey M, Affara NA, Fitchett M, Huson SM. Complete and partial XY sex M, Affara NA, Fitchett M, Huson SM. Complete and partial XY sex reversal associated with terminal deletion of 10q:

4 Jotterand M, Juillard E. A new case of trisomy for the distal part of $13 \mathrm{q}$ due to maternal translocation, $\mathrm{t}(9 ; 13)(\mathrm{p} 21 ; \mathrm{q} 21)$. Hum Genet 1976;33:213-22.

5 Bennett CP, Docherty Z, Robb SA, Ramani P, Hawkins JR, Grant D. Deletion $9 \mathrm{p}$ and sex reversal. $\mathcal{F}$ Med Genet 1993;30:518-20.

6 Oliveira-Duarte MH, Martelli-Soares LR, Sarquis-Cintra T, Machado ML, Lison MP. Distal monosomy of the long arm of chromosome 6 $(6 \mathrm{q} 25 \rightarrow 6 \mathrm{qter})$ inherited by maternal translocation $\mathrm{t}(6 \mathrm{q} ; 17 \mathrm{q})$. Ann Genet 1990;33:56-9.

7 Valat C, Galliano D, Mettey R, Toutain A, Moraine C. Monosomy 6q: report on four new cases. Clin Genet 1992;41:159-66.

8 Milosevic J, Kalicanin P. Long arm deletion of chromosome no 6 in a mentally retarded boy with multiple physical malformations. $\mathcal{f}$ Ment Defic Res tally retarded boy

9 Baroshesky L, Lewis MB, Pashayan HM. Developmental abnormalities associated with long arm deletion of chromosome No 6. Clin Genet 1978; 13:68-71.

10 Ito $\mathrm{H}$, Yamasaki T, Okamoto O, Tahara E. Infantile hemangioendothelioma of the liver in patient with interstitial deletion of chromosome 6q: report of an autopsy case. Am F Med Genet 1989:34:325.

11 McLeod DR, Fowlows SB, Robertson A, Samcoe D, Burgess I, Hoo JJ. Chromosome $6 \mathrm{q}$ deletions: a report of two additional cases and a review of the literature. Am f Med Genet 1990;35:79-84.

12 Sukumar S, Wang S, Hoang K, Vanchiere CM, England K, Fick R, Pagon B, Reddy KS. Subtle overlapping deletions in the terminal region of chromosome 6q24.2-q26: three cases studied using FISH. Am f Med Genet 1999; 87:17-22.

13 Fonatsch C, Grald G, Ragoussis J, Ziegler A. Assignment of the TCP1 locus to the long arm of human chromosome 6 by in situ hybridisation. Cytogenet Cell Genet 1987;45:109-12.

14 Zuppan PJ, Hall JM, Ponglikitmongkol M, Spieman R, King MC. Polymorphism at the estrogen receptor (ESR) locus and linkage relationship on the phism at the estrogen receptor (ESR) locus and linka

15 Bibbins KB, Tsai JY, Schimenti J, Sarvetnick N, Zoghbi HY, Goodfellow P, Silver LM. Human homologs of two testes-expressed loci on mouse chromosome 17 map to opposite arms of chromosome 6. Genomics 1989;5:139-43

16 Morrison K, Papapetrou C, Attwood J, Hol F, Lynch SA, Samath A, Hamel B, Burn J, Sowden J, Stott D, Mariman E, Edwards YH. Genetic mapping of the human homologue ( $\mathrm{T}$ ) of mouse $\mathrm{T}$ (Brachyury) and a search for allele association between human T and spina bifida. Hum Mol Genet 1996; 5:669-74.

f Med Genet 2000;37:974-976

\section{Distal trisomy $2 \mathrm{p}$ and arachnodactyly}

EDITOR-We report two sibs with an unbalanced translocation of chromosomes 2 and 10 resulting in distal $2 p$ trisomy. We feel that this sib pair could help to delineate the common features that may result from duplication of this specific region, in particular to show that arachnodactyly is a key feature. We suggest that the combination of arachnodactyly with developmental delay should prompt investigation of this region within the differential diagnosis.

This sib pair was first seen in 1995 aged 8 years (male) and 11 years (female). They were referred with a combination of speech and language delay, poor coordination, and concordant dysmorphic features.

The male sib (fig 1) was born at 38 weeks' gestation weighing $3200 \mathrm{~g}$ ( 25 th centile). He was noted to have gross motor delay with hypotonia and walked at 22 months. Speech development was severely delayed necessitating Makaton from the age of 2 years. He attended a school for moderate learning difficulties and required intensive speech therapy. His motor development is still delayed and at the age of 11 , he cannot ride a bicycle, catch a ball, or fasten shoe laces. He continues to require considerable supplemental educational input and speech therapy.

His height has followed the 90th centile with weight between the 25 th and 50 th centile and head circumference on the 50th. There is no limb or body segment disproportion. Joint flexibility is normal. $\mathrm{He}$ has arachnodactyly (palm length $10.5 \mathrm{~cm}$ (75th centile), middle finger length $8.0 \mathrm{~cm}$ (97th centile), middle finger to total hand ratio $43 \%$ ) with fifth finger clinodactyly and prominent finger pads. His feet (fig 2) are narrow with metatarsus varus, medial deviation of the second toe, and a wide sandal gap.
His face is long and triangular with semilunar palpebral fissures (length $2.8 \mathrm{~cm}$ ). There is a bulbous tip to the nose with a high bridge. The palate is high and arched.

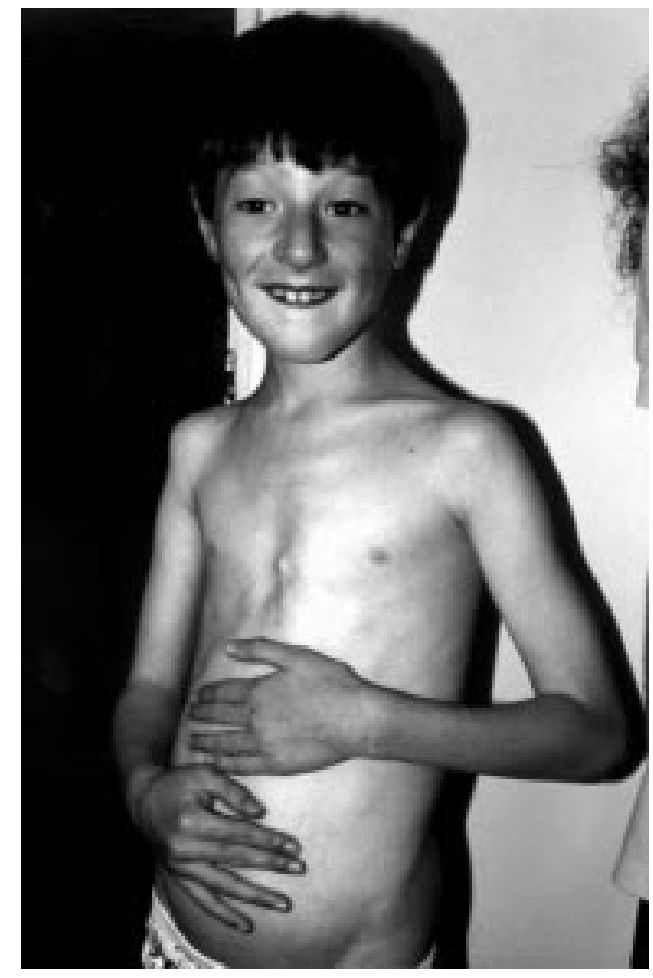

Figure 1 Male sib aged 8 years showing facial dysmorphism and arachnodactyly. 


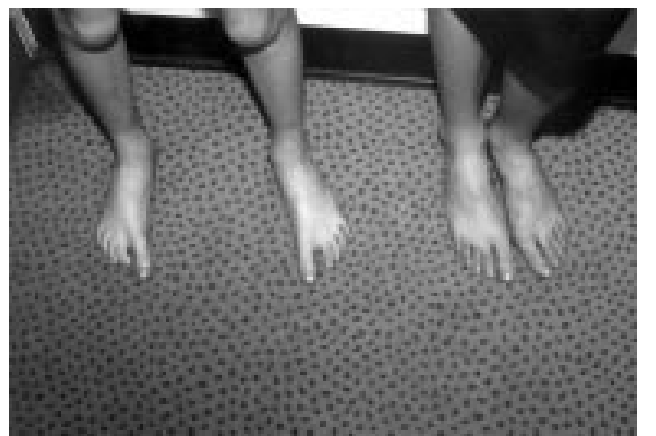

Figure 2 Feet of male child on left aged 8 years, female on right aged 11 years. Their foot abnormalities became more pronounced with increasing age.

Ophthalmological examination showed unilateral myopia only. Hearing is normal. Echocardiography is normal.

His sister (fig 3) was born at 38 weeks' gestation weighing $2940 \mathrm{~g}$ (50th centile). She had a splint applied for congenital dislocation of the left hip. Her motor skills were at the extreme of the normal range but she was noted to be clumsy. She was unable to ride a bicycle until 8 years old. Speech and language development was delayed requiring speech therapy. She is educated in a mainstream school with extra help. Her height follows the 95th centile, head circumference on the 50th, and her weight is on the 25 th. Upper to lower segment ratio is 0.85 , arm span is less than height, and joint flexibility is normal. Her face is elongated, the nose is bulbous with a broad bridge, and the palate is high and arched. Her palpebral fissures are of normal length $(3.1 / 2.9 \mathrm{~cm})$. She has arachnodactyly with finger length on the 97 th centile $(8.6 \mathrm{~cm})$, palm length 75 th centile $(10.5 \mathrm{~cm})$, and middle finger to total hand ratio $45 \%$. Her feet (fig 2) are narrow with an exaggerated arch and there is partial $2 / 3$ syndactyly on the right and overriding $1 \mathrm{st} / 2 \mathrm{nd}$ and 4 th $/ 5$ th toes on the left. Ophthalmological examination, echocardiography, and audiology are normal.

There is one older male sib who is developmentally normal. His height (aged 17) is $194 \mathrm{~cm}$ (>97th centile). In contrast to his sibs, he is of stocky build. Middle finger length is $9.6 \mathrm{~cm}$ and palm $11.9 \mathrm{~cm}$. Middle finger to whole hand ratio is $44 \%$. His karyotype is unknown. Three other pregnancies ended in early miscarriage at $12-14$ weeks.

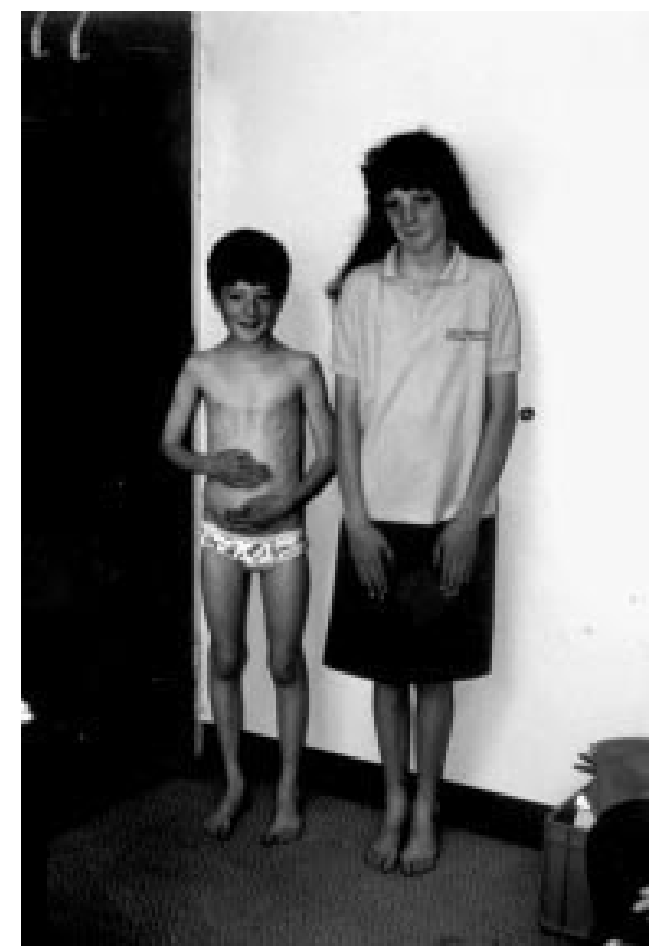

Figure 3 Both children displaying concordant dysmorphic features.

Maternal height is $169 \mathrm{~cm}$ (75th centile), middle finger length $7.2 \mathrm{~cm}$, and palm length $10.5 \mathrm{~cm}$, and the father's height is $180 \mathrm{~cm}$ (75th centile), middle finger length 8.8 $\mathrm{cm}$, and palm length $12.3 \mathrm{~cm}$. They are unrelated.

Cytogenetic studies using $\mathrm{G}$ banding showed an unbalanced translocation $46, \mathrm{XY}$ or $46, \mathrm{XX},-10,+\operatorname{der}(10) \mathrm{t}(2 ; 10)$ (p25.1;q26.3)mat resulting in distal $2 \mathrm{p}$ trisomy $(2 \mathrm{p}+)$. Fluorescence in situ hybridisation studies were not performed as the same translocation in balanced form was identified in their mother and maternal grandmother. They are phenotypically normal. Previous descriptions of $2 \mathrm{p}+$ have included skeletal abnormalities, facial dysmorphism, severe developmental delay, and cardiac and genital abnormalities. These features have been reported with break-

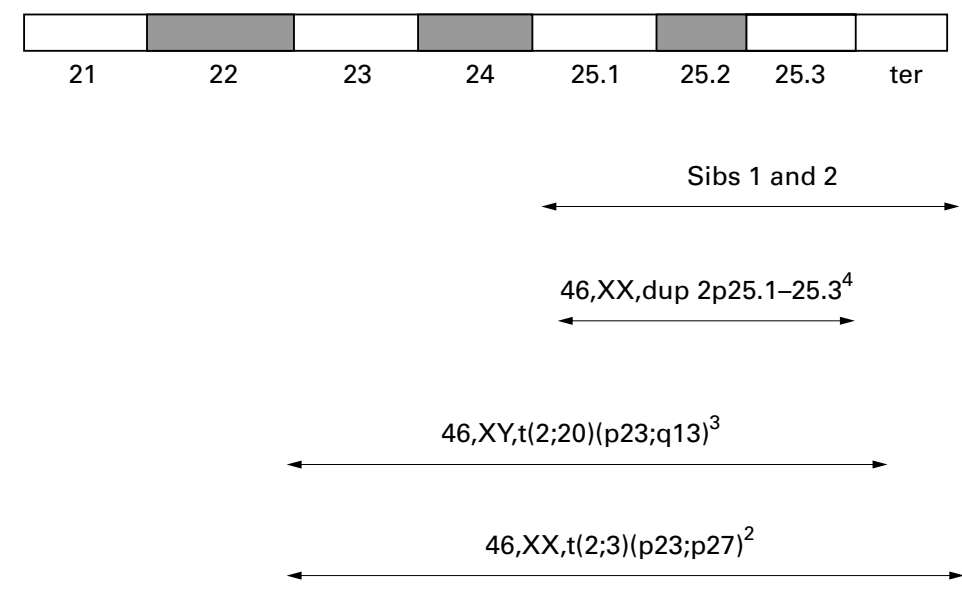

$46, X Y, \operatorname{der}(15)$, rep $(2,15)(\mathrm{p} 21 ; \mathrm{q} 26)$ pat $^{1}$

Figure 4 Diagrammatic representation of distal $2 p$ and regions involved in previously described duplications. 
Table 1 Comparison of features

\begin{tabular}{llll}
\hline Feature & Female & Male & Others \\
\hline Arachnodactyly & + & + & + \\
Foot abnormalities & + & + & + \\
Congenital dislocation of the hip & + & - & + \\
Vertebral abnormalities & - & - & + \\
Scoliosis & - & - & + \\
Pectus excavatum & - & + & + \\
Developmental delay & Mild & Moderate & Severe \\
IUGR & - & - & + \\
Postnatal growth delay & - & - & + \\
Triangular face & + & + & + \\
Bulbous nose & + & + & + \\
High arched palate & + & + & + \\
Bossed forehead & - & $+/$ & + \\
Micrognathia & - & - & + \\
Hypertelorism & - & - & + \\
Strabismus & - & - & + \\
Myopia & - & + & + \\
Genital abnormalities & - & - & + \\
Cardiac abnormalities & - & - & + \\
Fits & - & - & + \\
\hline
\end{tabular}

points at $2 \mathrm{p} 21,{ }^{1} 2 \mathrm{p} 22,{ }^{2}$ and $2 \mathrm{p} 23,{ }^{3}$ usually in combination with partial monosomy involving one of various other chromosomes. However, with the exception of the report from Wakita et $a l,{ }^{4}$ the breakpoint in this case differs from other published cases in that a much shorter duplicated segment is produced (fig 4). The reciprocal chromosome in the translocation also varies. In the case described by Wakita $\mathrm{et} \mathrm{al}^{4}{ }^{4}$ trisomy $2 \mathrm{p}$ resulted from an isolated duplication $2 \mathrm{p}$ and not a translocation. In this case the 10qter deletion is very small (on $\mathrm{G}$ banding) and probably does not contribute to the phenotype, although modification of clinical expression by this deletion cannot be excluded.

In these two sibs, the translocation is inherited maternally. In other cases reported, paternal ${ }^{1}$ and maternal $^{2}$ transmission as well as de novo ${ }^{4}$ duplications have been described with features consistent with distal trisomy $2 p$, making the role of imprinting less likely.

To our knowledge correlation of phenotype to duplicated segment length has not been possible. As this sib pair display some phenotypic differences from other cases described, they may contribute to the understanding of this correlation. The main phenotypic differences are summarised in table 1 . In particular, these sibs have neither cardiac nor genital abnormalities and their development is mildly to moderately delayed. They do not have growth failure but have a marfanoid habitus. Arachnodactyly is a feature of Marfan syndrome which is associated with mutations in fibrillin genes mapped to chromosomes 5 and 15. ${ }^{5}$ However, the marfanoid habitus with mental retardation has also been described in an X linked disorder. ${ }^{6}$ Marfanoid skeletal and cardiovascular phenotypes have also been reported which are not linked to known fibrillin genes. ${ }^{7}$ The children presented here do not fulfil the criteria required for a diagnosis of Marfan syndrome. ${ }^{5}$

A combination of retardation (particularly speech and language) with arachnodactyly can also occur in $22 \mathrm{q} 11$ microdeletion syndrome, but these children have none of the associated features. ${ }^{8}$

The presence of arachnodactyly coupled with the evident arachnodactyly in the short duplication reported by Wakita $e t a l^{4}$ leads us to conclude that this a key feature of duplications in this region. The influence of the reciprocal chromosome involved in the translocation must be considered. In other cases described,,$^{1-39}$ the reciprocal chromosome varies yet arachnodactyly is a constant feature. In this case, the 10qter deletion is unlikely to contribute much to the phenotype (although cannot be excluded) and the case reported by Wakita et $a l^{4}$ was an isolated duplication without a translocation, so the features described can be assumed to result from duplication of this region alone.

The common features evident in these children combined with the notable absence of others described in distal trisomy $2 \mathrm{p}$ syndrome aid the phenotype/genotype correlation in this region. We would be interested in other reports of duplications which would help this process.

These sibs also show the importance of investigating this region in children who present with arachnodactyly and developmental delay of unknown origin; very small duplications may produce few additional features.

D J STALKER
S VIGNESWAREN†
P M SHARPLES $\ddagger$
P W LUUT*

*Department of Clinical Genetics, Institute of Child Health, Royal Hospital for Sick Children, St Michael's Hill, Bristol BS2 8BF, UK

†Department of Cytogenetics, Southmead General Hospital, Westbury-on-Trym, Bristol BS10 5NB, UK

$\ddagger$ Department of Paediatric Neurology, Royal Hospital for Sick Children, St Michael's Hill, Bristol BS2 8BF, UK

Correspondence to: Dr Stalker, Post Office Cottage, Compton Road, Hilmarton, Calne, Wilts SN11 8SG, UK, drdeb@pocottage.prestel.co.uk

1 Armendares S, Salamanca-Gomez F. Partial trisomy (2p21-pter) in two siblings of a family with a 2p-:15q+ translocation. Clin Genet 1978;13:17-24.

2 Cassidy SB, Heller RM, Chazen EM, Engel E. The chromosome 2 distal short arm trisomy syndrome. F Pediatr 1977;91:934-8.

3 Rosenfeld W, Verma RS, Jhaveri R, Dosik H, Evans H. Partial duplication for the short arm of chromosome 2: the 2p23-pter syndrome. Ann Genet 1985;25:28-31.

4 Wakita Y, Narahara K, Takahashi Y, Kikkawa K, Kimura S, Oda M, Kimoto H. Duplication of 2p25: confirmation of the assignment of soluble acid $\mathrm{H}$. Duplication of $2 \mathrm{p} 25$ : confirmation of the assignment of so
phosphatase $\left(\mathrm{ACP}_{1}\right)$ locus to $2 \mathrm{p} 25$. Hum Genet 1985;71:259-60.

5 Pyeritz RE. Marfan syndrome. In: Rimoin DL, Connor JM, Pyeritz RE, eds. Principles and practice of medical genetics. 3rd ed. Edinburgh: Churchill Livingstone, 1996:1060.

6 Fryns JP, Buttiens M. X-linked mental retardation with marfanoid habitus. Am F Med Genet 1987;28:267-74.

7 Boileau C, Babron MC, Jondeau G, Alexandre JA, Sakaj L, Bonaiti-Pellie C, Bourdarias JP, Junien C. Marfan-like cardiovascular and skeletal phenotype not linked to known fibrillin genes. Am $\mathcal{F}$ Hum Genet Suppl 1992;51:A183.

8 Ryan AK, Goodship JA, Wilson DI, Philip N, Levy A, Seidel H, Schuffenhauer S, Oechsler H, Belohradsky B, Prieur M, Aurias A, Raymond FL, Clayton-Smith J, Hatchwell E, McKeown C, Beemer FA, Dallapiccila B, Novelli G, Hurst JA, Ignatius J, Green AJ, Winter RM, Brueton L, Brondum-Nielsen K, Stewart F, Van Essen T, Patton M, Paterson J, Scambler PJ. Spectrum of clinical features associated with interstitial chroScambler PJ. Spectrum of clinical features associated with interstitial chro1997;34:798-804.

9 Stoll C, Messer J, Vors J. Translocation t $(2 ; 14)$ equilibree chez une mere et trisomie partielle d'une partie du bras court d'un chromosome 2 chez deux de ses enfants. Ann Genet 1974;17:193-6. 